\title{
Plumbagin suppresses epithelial to mesenchymal transition and stemness via inhibiting Nrf2- mediated signaling pathway in human tongue squamous cell carcinoma cells
}

\author{
This article was published in the following Dove Press journal: \\ Drug Design, Development and Therapy \\ 5 October 2015 \\ Number of times this article has been viewed
}

\begin{abstract}
Shu-Ting Pan, 'Yiru Qin, ${ }^{2}$ Zhi-Wei Zhou, ${ }^{2,3}$ Zhi-Xu He, ${ }^{3}$ Xueji Zhang, ${ }^{4}$ Tianxin Yang, ${ }^{5}$ Yin-Xue Yang, ${ }^{6}$ Dong Wang, ${ }^{7}$ Shu-Feng Zhou, ${ }^{2}$ Jia-Xuan Qiu'

'Department of Oral and Maxillofacial Surgery, The First Affiliated Hospital of Nanchang University, Nanchang, Jiangxi, People's Republic of China; ${ }^{2}$ Department of Pharmaceutical Sciences, College of Pharmacy, University of South Florida, Tampa, FL, USA; ${ }^{3}$ Guizhou Provincial Key Laboratory for Regenerative Medicine, Stem Cell and Tissue Engineering Research Center and Sino-US Joint Laboratory for Medical Sciences, Guiyang Medical University, Guiyang, Guizhou, People's Republic of China; ${ }^{4}$ Research Center for Bioengineering and Sensing Technology, University of Science and Technology Beijing, Beijing, People's Republic of China; ${ }^{5}$ Department of Internal Medicine, University of Utah and Salt Lake Veterans Affairs Medical Center, Salt Lake City, UT, USA; ${ }^{6}$ Department of Colorectal Surgery, General Hospital of Ningxia Medical University, Yinchuan, Ningxia, People's Republic of China; ${ }^{7}$ Cancer Center, Daping Hospital and Research Institute of Surgery, Third Military Medical University, Chongqing, People's Republic of China
\end{abstract}

Correspondence: Jia-Xuan Qiu

Department of Oral and Maxillofacial Surgery, The First Affiliated Hospital of Nanchang University, 17 Yongwai Main St, Nanchang, Jiangxi 330006, People's Republic of China Tel +86 79l 88695069

Fax +86 791 8869 2745

Email qiujiaxuan@163.com

Shu-Feng Zhou

Department of Pharmaceutical Sciences, College of Pharmacy, University of South

Florida, I290I Bruce B Downs Boulevard,

Tampa, FL 33612, USA

Tel +I 8139746276

Fax + I 8I39059885

Email szhou@health.usf.edu
Abstract: Tongue squamous cell carcinoma (TSCC) is the most common malignancy in oral and maxillofacial tumors with highly metastatic characteristics. Plumbagin (5-hydroxy-2-methyl-1, 4-naphthoquinone; PLB), a natural naphthoquinone derived from the roots of Plumbaginaceae plants, exhibits various bioactivities, including anticancer effects. However, the potential molecular targets and underlying mechanisms of PLB in the treatment of TSCC remain elusive. This study employed stable isotope labeling by amino acids in cell culture (SILAC)-based quantitative proteomic approach to investigate the molecular interactome of PLB in human TSCC cell line SCC25 and elucidate the molecular mechanisms. The proteomic data indicated that PLB inhibited cell proliferation, activated death receptor-mediated apoptotic pathway, remodeled epithelial adherens junctions pathway, and manipulated nuclear factor erythroid 2-related factor 2 (Nrf2)-mediated oxidative stress response signaling pathway in SCC25 cells with the involvement of a number of key functional proteins. Furthermore, we verified these protein targets using Western blotting assay. The verification results showed that PLB markedly induced cell cycle arrest at $\mathrm{G}_{2} / \mathrm{M}$ phase and extrinsic apoptosis, and inhibited epithelial to mesenchymal transition (EMT) and stemness in SCC25 cells. Of note, $N$-acetyl-1-cysteine (NAC) and l-glutathione (GSH) abolished the effects of PLB on cell cycle arrest, apoptosis induction, EMT inhibition, and stemness attenuation in SCC25 cells. Importantly, PLB suppressed the translocation of Nrf2 from cytosol to nucleus, resulting in an inhibition in the expression of downstream targets. Taken together, these results suggest that PLB may act as a promising anticancer compound via inhibiting Nrf2-mediated oxidative stress signaling pathway in SCC25 cells. This study provides a clue to fully identify the molecular targets and decipher the underlying mechanisms of PLB in the treatment of TSCC.

Keywords: PLB, SILAC, EMT, stemness, Nrf2, tongue squamous cell carcinoma

\section{Introduction}

Tongue squamous cell carcinoma (TSCC) is the most prevalent type of oral and maxillofacial tumor, with an estimated 14,320 new cases and 2,190 deaths in the US in $2015 .{ }^{1}$ The most important etiological factors are tobacco, excessive consumption of alcohol, and betel quid usage, which act separately or synergistically. ${ }^{2}$ It has been reported that TSCC is more commonly found in males, with a percentage of $72.0 \%$ of all TSCC cases, compared with a percentage of $28.0 \%$ in females. ${ }^{1}$ Of note, the incidence of TSCC in young white women is significantly increasing, according to the Surveillance, Epidemiology, and End Results program data from 1973 to 2010 in the US. ${ }^{3}$ Because of the mobility and masticatory function of the tongue, TSCC is inclined to spread locally, involving perioral structures, and metastasize to local 
regional lymph nodes. For this reason, TSCC always demonstrates a much more aggressive behavior than other kinds of oral and maxillofacial tumors. ${ }^{4}$ Although there has been advancement in the sequential therapies, including radiation, surgery, and chemotherapy, the patients still suffer from serious relapse and the 5-year survival rate shows no inspiring progress. ${ }^{5}$ It requires the development of novel therapeutics with improved therapeutic effect and reduced side effect for TSCC treatment.

It has been revealed that acquisition of epithelial to mesenchymal transition (EMT) and induction of cancer stem cell (CSC)-like properties are closely involved in the initiation, development, progression, metastasis, and relapse of solid tumors. ${ }^{6,7}$ Normal epithelial cells show apical-basal polarity maintained by apical tight junctions and basolateral adherens junctions. The loss of epithelial property and acquisition of mesenchymal features enables cancer cells to metastasize easily and quickly. The reverse process of mesenchymal to epithelial transition (MET) can also occur. Cancer progression is affected by the balance between EMT and MET ${ }^{8,9}$ Thus, interfering with the EMT process may help regress cancer metastasis. On the other hand, the proliferation of tumors is driven by a bulk of dedicated stem cells, the CSCs. CSCs, also known as cancer-initiating cells, are involved in cancer cell renewal and differentiation. ${ }^{10} \mathrm{CSCs}$ can display EMT characteristics such as loss of adhesion protein E-cadherin. ${ }^{11}$ It is reported that CSCs play an important role in chemotherapy resistance due to the self-renewal ability. Multiple oncogenes are involved in the maintenance of stemness and tumorigenicity of CSCs, such as Octamer-4 (Oct-4), Bmi-1, Nanog, and sex-determing region Y-box 2 (Sox-2). ${ }^{12-15}$ Hence, targeting the CSCs shows great therapeutic potential in cancer therapy. ${ }^{16}$

Plumbagin (5-hydroxy-2-methyl-1, 4-naphthoquinone; PLB) is isolated from the root of Plumbago zeylanica L, Juglans regia, Juglans cinerea, and Juglans nigra, with a variety of pharmacological activities including anti-inflammatory, antiatherosclerotic, antibacterial, antifungal, and anticancer activities in in vitro and in vivo models. ${ }^{17}$ Notably, PLB shows a potent ability in killing cancer cells with minimal side effects. ${ }^{18}$ Previous studies from our and other groups have shown that PLB regulates various cellular processes such as cell cycle, apoptosis, autophagy, and cellular redox status. ${ }^{19-21}$ PLB also induces cancer cell apoptosis and autophagy by inhibition of nuclear factor kappa B (NF- $\mathrm{KB})$ activation and phosphatidylinositide 3-kinase (PI3K)/protein kinase B (Akt)/ mTOR signaling pathway. ${ }^{21-25}$ Besides, PLB can efficiently facilitate reactive oxygen species (ROS) generation, which also contributes to the cancer cell killing effect. ${ }^{26-28}$ However, the full spectrum of the molecular targets and therapeutic effects of PLB in TSCC are not clear.

Accumulating evidence shows that stable isotope labeling by amino acids in cell culture (SILAC)-based quantitative proteomic approach has the capability of revealing the potential targets of a given compound or drug..$^{29,30}$ In this study, we aimed at elucidating the possible mechanisms for PLB's anticancer effect in the treatment of TSCC using a SILACbased quantitative proteomic approach to take a panoramic view of PLB in a TSCC cell line (SCC25). The corresponding verifications were also performed. In addition, we also carried out separate experiments to investigate the relationship between PLB-induced ROS generation and PLB-mediated cell cycle arrest, apoptosis induction, EMT inhibition, and stemness attenuation.

\section{Materials and methods Chemicals and reagents}

Dulbecco's Modified Eagle's Medium (DMEM) and Ham's F12 medium were obtained from Corning Cellgro Inc. (Herndon, VA, USA). Fetal bovine serum (FBS), PLB, dimethyl sulfoxide (DMSO), hydrocortisone, $N$-acetyl-Lcysteine (NAC, a ROS scavenger), L-glutathione (GSH, a ROS scavenger), ammonium persulfate, D-glucose, propidium iodide (PI), ribonuclease, protease and phosphatase inhibitor cocktails, radioimmunoprecipitation assay buffer (RIPA), bovine serum albumin (BSA), Tris base, sodium dodecyl sulfate (SDS), ethylenediaminetetraacetic acid, Dulbecco's phosphate-buffered saline (PBS), dithiothreitol (DTT), ${ }^{13} \mathrm{C}_{6}$ L-lysine, L-lysine, ${ }^{13} \mathrm{C}_{6}{ }^{15} \mathrm{~N}_{4}$-L-arginine, and L-arginine were purchased from Sigma-Aldrich (St Louis, MO, USA). FASPTM protein digestion kit was bought from Protein Discovery Inc. (Knoxville, TN, USA). The Annexin V:PE apoptosis detection kit was purchased from BD Pharmingen Biosciences (San Jose, CA, USA). Ionic Detergent Compatibility Reagent (IDCR) kit, nuclear and cytoplasmic extraction kit, Pierce bicinchoninic acid (BCA) protein assay kit, skimmed milk, and Western blotting substrate were bought from Thermo Fisher Scientific (Waltham, MA, USA). The polyvinylidene difluoride (PVDF) membrane was purchased from Bio-Rad (Hercules, CA, USA). Primary antibodies against human CDK1/cdc2, Cyclin B1, cdc25, Fas (TNFRSF6)-associated via death domain (FADD), TNF1 receptor-associated death domain (TRADD), TRAIL-R2 (DR5), cleaved caspase-3 (CC3), E-cadherin, $\mathrm{N}$-cadherin, Snail, Slug, zinc finger E-box-binding homeobox 1 (TCF8/ZEB1), vimentin, $\beta$-Catenin, zona occludens protein 1 (ZO-1), claudin-1, Oct-4, Bmi-1, Nanog, Sox-2, and 
glutathione $S$-transferase (GST) were purchased from Cell Signaling Technology Inc. (Beverly, MA, USA). Primary antibodies against nuclear factor erythroid 2-related factor 2 (Nrf2), NAD(P)H quinone oxidoreductase 1 (NQO1), and heat shock protein 90 (HSP90) were purchased from Santa Cruz Biotechnology Inc. (Santa Cruz, CA, USA). The antibodies against human $\beta$-actin and Histone $\mathrm{H} 3$ were obtained from Santa Cruz Biotechnology Inc.

\section{Cell line and cell culture}

The TSCC cell line SCC25 was obtained from the American Type Culture Collection (Manassas, VA, USA) and cultured in a 1:1 mixture of DMEM and Ham's F12 medium containing $1.2 \mathrm{~g} / \mathrm{L}$ sodium bicarbonate, $2.5 \mathrm{mM}$ L-glutamine, $15 \mathrm{mM}$ HEPES, and $0.5 \mathrm{mM}$ sodium pyruvate and was supplemented with $400 \mathrm{ng} / \mathrm{mL}$ hydrocortisone and $10 \%$ heat-inactivated FBS. The cells were maintained at $37^{\circ} \mathrm{C}$ in a $5 \% \mathrm{CO}_{2} / 95 \%$ air humidified incubator. PLB was dissolved in DMSO with a stock concentration of $100 \mathrm{mM}$ and was freshly diluted to the desired concentrations with the culture medium. The final concentration of DMSO was at $0.05 \%$ (v/v, volume per volume). The control cells received only the vehicle. No ethics approval was required for the use of this cell line this paper.

\section{SILAC quantitative proteomics}

Quantitative proteomic experiments were performed using SILAC as described previously. ${ }^{31-33}$ Briefly, SCC25 cells were cultured in the medium with or without stable isotope-labeled amino acids ( ${ }^{13} \mathrm{C}_{6}$ L-lysine and ${ }^{13} \mathrm{C}_{6}{ }^{15} \mathrm{~N}_{4}$ L-arginine). SCC25 cells were passaged for five times by changing medium or splitting cells. Then, cells with stable isotope-labeled amino acids were treated with $5 \mu \mathrm{M}$ PLB for 24 hours. Following that, the cell samples were harvested and lysed with hot lysis buffer (100 mM Tris base, 4\% SDS, and $100 \mathrm{mM} \mathrm{DTT}$ ). The proteins were denatured at $95^{\circ} \mathrm{C}$ for 5 minutes and sonicated at 20\% amplitude (AMPL) for 3 seconds with 6 pulses. Later, the samples were centrifuged at $15,000 \times g$ for 20 minutes and the supernatant was collected in clean tubes. The protein concentration was determined using the IDCR kits. Then, equal amounts of heavy and light protein sample were combined to reach a total volume of $30-60 \mu \mathrm{L}$ containing 300-600 $\mu \mathrm{g}$ proteins. The combined protein sample was digested using FASP ${ }^{\mathrm{TM}}$ protein digestion kit. After proteins were digested, the resultant sample was acidified to $\mathrm{pH}$ of 3 and desalted using a $\mathrm{C}_{18}$ solid-phase extraction column. The samples were then concentrated using vacuum concentrator at $45^{\circ} \mathrm{C}$ for 120 minutes and the peptide mixtures $(5 \mu \mathrm{L})$ were subject to the hybrid linear ion trap-Orbitrap (LTQ Orbitrap
XL, Thermo Scientific Inc.). Liquid chromatography-tandem mass spectrometry (LC-MS/MS) was performed using a $10 \mathrm{~cm}$ long $75 \mu \mathrm{m}$ (inner diameter) reversed-phase column packed with $5 \mu \mathrm{m}$ diameter $\mathrm{C}_{18}$ material with $300 \AA$ pore size (New Objective, Woburn, MA, USA), with a gradient mobile phase of $2 \%-40 \%$ acetonitrile in $0.1 \%$ formic acid at $200 \mu \mathrm{L} /$ minute for 125 minutes. The Orbitrap full MS scanning was performed at a mass $(\mathrm{m} / \mathrm{z})$ resolving power of 60,000 , with positive polarity in profile mode $\left(\mathrm{M}+\mathrm{H}^{+}\right)$. Peptide SILAC ratio was calculated using MaxQuant version 1.2.0.13. The SILAC ratio was determined by averaging all peptide SILAC ratios from peptides identified of the same protein. The protein IDs were identified using Scaffold 4.3.2 from Proteome Software Inc. (Portland, OR, USA) and the pathway was analyzed using Ingenuity Pathway Analysis (IPA) from QIAGEN (Redwood City, CA, USA).

\section{Cell cycle distribution analysis}

The effect of PLB on cell cycle distribution of SCC25 cells was determined by flow cytometry using PI as the DNA stain as described previously. ${ }^{20}$ Briefly, SCC25 cells were treated with PLB at concentrations of $0.1,1$, and $5 \mu \mathrm{M}$ for 24 hours. In separate experiments, SCC25 cells were treated with $5 \mu \mathrm{M}$ PLB for 6, 24, and 48 hours. In addition, the effect of ROS scavengers (GSH and NAC) ${ }^{34}$ on PLB-induced $\mathrm{G}_{2} / \mathrm{M}$ arrest was also examined. Cells were trypsinized and resuspended in $1 \mathrm{~mL}$ serum-free medium. Subsequently, the cells were fixed with $3 \mathrm{~mL} 70 \%$ ethanol at $-20^{\circ} \mathrm{C}$ overnight. The cells were stained using $50 \mu \mathrm{g} / \mathrm{mL}$ PI. A total number of $1 \times 10^{4}$ cells was subject to cell cycle analysis using a flow cytometer (Becton Dickinson Immunocytometry Systems, San Jose, CA, USA). Finally, the raw data were analyzed by ModFitLT software (version 3.2.1) (Verity Software House, Topsham, MA, USA).

\section{Quantification of cellular apoptosis}

We used Annexin V:PE apoptosis detection kit to measure apoptotic cells after the cells were treated with $0.1,1$, and $5 \mu \mathrm{M}$ PLB for 24 hours. In separate experiments, SCC25 cells were treated with $5 \mu \mathrm{M}$ PLB for 6,24 , and 48 hours. In addition, the effect of GSH and NAC on PLB-induced apoptosis was also examined. Briefly, cells were trypsinized and washed twice with cold PBS, and then resuspended in $1 \times$ binding buffer with $5 \mu \mathrm{L}$ of PE Annexin $\mathrm{V}$ and $5 \mu \mathrm{L}$ of 7 -amino-actinomycin $\mathrm{D}$ at a concentration of $1 \times 10^{5} / \mathrm{mL}$ cells in a total volume of $100 \mu \mathrm{L}$. The cells were gently mixed and incubated in the dark for 15 minutes at room temperature. Following that, a quota of $1 \times$ binding buffer $(400 \mu \mathrm{L})$ was added to each test tube and the number of apoptotic cells 
was quantified by flow cytometry (BD LSR II Analyzer) within 1 hour.

\section{Western blotting assay}

The levels of various cellular proteins were determined using Western blotting assays. The SCC25 cells were incubated with PLB at $0.1,1$, and $5 \mu \mathrm{M}$ for 24 hours. In separate experiments, SCC25 cells were treated with $5 \mu \mathrm{M}$ PLB for 6, 24, and 48 hours. After PLB treatment, cells were washed twice with precold PBS and lysed with the RIPA buffer containing the protease inhibitor and phosphatase inhibitor cocktails. In addition, we extracted the nuclear proteins according to the instruction given in the nuclear and cytoplasmic extraction kit. Protein concentrations were measured using the Pierce BCA protein assay kit. Equal amounts of protein samples at $20 \mu \mathrm{g}$ were electrophoresed on $7 \%-12 \%$ sodium dodecyl sulfate-polyacrylamide gel electrophoresis (SDS-PAGE) minigel after thermal denaturation for 5 minutes at $95^{\circ} \mathrm{C}$. Proteins were transferred onto immobilon PVDF membrane at $80 \mathrm{~V}$ for 3 hours at $4^{\circ} \mathrm{C}$. Subsequently, membranes were blocked with 5\% BSA and probed with indicated primary antibody overnight at $4{ }^{\circ} \mathrm{C}$ and then blotted with respective secondary antibody. Visualization was performed using the
Bio-Rad system. Cytosolic protein level was normalized to the matching densitometric value of $\beta$-actin, and nuclear protein level was normalized to the matching densitometric value of Histone H3.

\section{Statistical analysis}

Data are presented as the mean \pm standard deviation (SD). Multiple comparisons were evaluated by one-way analysis of variance (ANOVA), followed by Tukey's multiple comparison. A value of $P<0.05$ was considered statistically significant. All the assays were performed in triplicate.

\section{Results}

\section{Summary of proteomic response to PLB treatment in SCC25 cells}

We first performed SILAC-based proteomics to evaluate the potential molecular targets of PLB in SCC25 cells. PLB increased the expression level of 143 protein molecules, but decreased the expression level of 255 protein molecules in SCC25 cells (Tables 1 and 2). Subsequently, these proteins were subject to IPA. The results showed that 101 signaling pathways were potentially regulated by PLB in SCC25 cells (Table 3 and Figure 1). The top ten targeted signaling

Table I Proteins upregulated by PLB in SCC25 cells

\begin{tabular}{|c|c|c|c|c|c|}
\hline Fold change & ID & Symbol & Entrez gene name & Location & Type(s) \\
\hline 16.699 & Q9Y4LI & HYOUI & Hypoxia upregulated I & Cytoplasm & Other \\
\hline 6.339 & Q86UP2 & KTNI & Kinectin I (kinesin receptor) & Plasma membrane & $\begin{array}{l}\text { Transmembrane } \\
\text { receptor }\end{array}$ \\
\hline 5.171 & P07996 & THBSI & Thrombospondin I & Extracellular space & Other \\
\hline 4.993 & Q9H3K6 & BOLA2/BC & BolA family member 2 & Cytoplasm & Other \\
\hline 4.304 & Q9NY33 & DPP3 & Dipeptidyl-peptidase 3 & Cytoplasm & Peptidase \\
\hline 3.861 & PI 2277 & CKB & Creatine kinase, brain & Cytoplasm & Kinase \\
\hline 3.794 & PI4866 & HNRNPL & Heterogeneous nuclear ribonucleoprotein $\mathrm{L}$ & Nucleus & Other \\
\hline 3.14 & HOY4RI & IMPDH2 & IMP (inosine 5'-monophosphate) dehydrogenase 2 & Cytoplasm & Enzyme \\
\hline 3.022 & Q9NZB2 & FAMI20A & Family with sequence similarity I20A & Cytoplasm & Other \\
\hline 2.667 & Q9P2E9 & RRBPI & Ribosome binding protein I & Cytoplasm & Other \\
\hline 2.61 & Q9BQE3 & TUBAIC & Tubulin, alpha Ic & Cytoplasm & Other \\
\hline 2.289 & P62।36 & PPPICA & Protein phosphatase I, catalytic subunit, alpha isozyme & Cytoplasm & Phosphatase \\
\hline 2.164 & P23284 & PPIB & Peptidylprolyl isomerase B (cyclophilin B) & Cytoplasm & Enzyme \\
\hline 2.142 & $\mathrm{PI} 4923$ & JUP & Junction plakoglobin & Plasma membrane & Other \\
\hline 2.136 & P38646 & HSPA9 & Heat shock 70 kDa protein 9 (mortalin) & Cytoplasm & Other \\
\hline 2.052 & C9JZR2 & CTNNDI & Catenin (cadherin-associated protein), delta I & Nucleus & Other \\
\hline 1.978 & O43852 & CALU & Calumenin & Cytoplasm & Other \\
\hline 1.871 & Q01082 & SPTBNI & Spectrin, beta, non-erythrocytic I & Plasma membrane & Other \\
\hline 1.864 & P50454 & SERPINHI & $\begin{array}{l}\text { Serpin peptidase inhibitor, clade } \mathrm{H} \text { (heat shock } \\
\text { protein } 47 \text { ), member I, (collagen binding protein I) }\end{array}$ & Extracellular space & Other \\
\hline 1.753 & QI375I & LAMB3 & Laminin, beta 3 & Extracellular space & Transporter \\
\hline 1.742 & Q13158 & FADD & Fas (TNFRSF6)-associated via death domain & Cytoplasm & Other \\
\hline 1.732 & Q9UHXI & PUF60 & Poly-U binding splicing factor $60 \mathrm{kDa}$ & Nucleus & Other \\
\hline 1.718 & P32320 & CDA & Cytidine deaminase & Nucleus & Enzyme \\
\hline 1.695 & P05556 & ITGBI & $\begin{array}{l}\text { Integrin, beta I (fibronectin receptor, beta } \\
\text { polypeptide, antigen CD29 includes MDF2, MSK I2) }\end{array}$ & Plasma membrane & $\begin{array}{l}\text { Transmembrane } \\
\text { receptor }\end{array}$ \\
\hline
\end{tabular}


Table I (Continued)

\begin{tabular}{|c|c|c|c|c|c|}
\hline Fold change & ID & Symbol & Entrez gene name & Location & Type(s) \\
\hline 1.682 & P04844 & RPN2 & Ribophorin II & Cytoplasm & Enzyme \\
\hline 1.615 & PI7844 & DDX5 & DEAD (Asp-Glu-Ala-Asp) box helicase 5 & Nucleus & Enzyme \\
\hline 1.612 & OI4579 & COPE & Coatomer protein complex, subunit epsilon & Cytoplasm & Transporter \\
\hline 1.581 & Q13409 & DYNCI/2 & Dynein, cytoplasmic I, intermediate chain 2 & Cytoplasm & Other \\
\hline 1.576 & Q13753 & LAMC2 & Laminin, gamma 2 & Extracellular space & Other \\
\hline 1.556 & Q96QKI & VPS35 & Vacuolar protein sorting 35 (S. cerevisiae) & Cytoplasm & Transporter \\
\hline 1.536 & P04I8I & OAT & Ornithine aminotransferase & Cytoplasm & Enzyme \\
\hline 1.535 & E7EPN9 & PRRC2C & Proline-rich coiled-coil $2 \mathrm{C}$ & Other & Other \\
\hline 1.534 & P22102 & GART & $\begin{array}{l}\text { Phosphoribosylglycinamide formyltransferase, } \\
\text { phosphoribosylglycinamide synthetase, } \\
\text { phosphoribosylaminoimidazole synthetase }\end{array}$ & Cytoplasm & Enzyme \\
\hline 1.518 & P45974 & USP5 & Ubiquitin specific peptidase 5 (isopeptidase T) & Cytoplasm & Peptidase \\
\hline 1.508 & P62263 & RPSI 4 & Ribosomal protein SI4 & Cytoplasm & Translation regulator \\
\hline 1.474 & P08779 & KRTI6 & Keratin 16 & Cytoplasm & Other \\
\hline 1.463 & P6270I & RPS4X & Ribosomal protein S4, X-linked & Cytoplasm & Other \\
\hline 1.454 & P31939 & ATIC & $\begin{array}{l}\text { 5-Aminoimidazole-4-carboxamide ribonucleotide } \\
\text { formyltransferase/IMP cyclohydrolase }\end{array}$ & Cytoplasm & Enzyme \\
\hline 1.442 & Q6NZI2 & PTRF & Polymerase I and transcript release factor & Nucleus & Transcription regulator \\
\hline 1.439 & BIAH77 & RAC2 & $\begin{array}{l}\text { Ras-related C } 3 \text { botulinum toxin substrate } 2 \\
\text { (rho family, small GTP binding protein Rac2) }\end{array}$ & Cytoplasm & Enzyme \\
\hline 1.412 & P05787 & KRT8 & Keratin 8 & Cytoplasm & Other \\
\hline 1.41 & P60228 & EIF3E & Eukaryotic translation initiation factor 3 , subunit $E$ & Cytoplasm & Other \\
\hline 1.408 & AIA4ZI & IQUB & IQ motif and ubiquitin domain containing & Cytoplasm & Other \\
\hline 1.405 & Q15459 & SF3AI & Splicing factor $3 \mathrm{a}$, subunit I, $120 \mathrm{kDa}$ & Nucleus & Other \\
\hline 1.404 & 095817 & BAG3 & BCL2-associated athanogene 3 & Cytoplasm & Other \\
\hline 1.398 & F5GWP8 & KRTI7 & Keratin 17 & Cytoplasm & Other \\
\hline 1.396 & 000303 & EIF3F & Eukaryotic translation initiation factor 3 , subunit $F$ & Cytoplasm & Translation regulator \\
\hline 1.388 & PII02I & HSPA5 & $\begin{array}{l}\text { Heat shock } 70 \mathrm{kDa} \text { protein } 5 \text { (glucose-regulated } \\
\text { protein, } 78 \mathrm{kDa} \text { ) }\end{array}$ & Cytoplasm & Enzyme \\
\hline 1.374 & Q07065 & CKAP4 & Cytoskeleton-associated protein 4 & Cytoplasm & Other \\
\hline 1.367 & P494II & TUFM & Tu translation elongation factor, mitochondrial & Cytoplasm & Translation regulator \\
\hline 1.363 & K7EK07 & $\begin{array}{l}\mathrm{H} 3 \mathrm{~F} 3 \mathrm{~A} / \\
\mathrm{H} 3 \mathrm{~F} 3 \mathrm{~B}\end{array}$ & $\mathrm{H} 3$ histone, family $3 \mathrm{~A}$ & Nucleus & Other \\
\hline 1.36 & PI5924 & DSP & Desmoplakin & Plasma membrane & Other \\
\hline 1.357 & P20700 & LMNBI & Lamin BI & Nucleus & Other \\
\hline 1.324 & $\mathrm{PI} 4625$ & HSP90BI & Heat shock protein 90 kDa beta (Grp94), member I & Cytoplasm & Other \\
\hline 1.315 & F8VY35 & NAPILI & Nucleosome assembly protein I-like I & Nucleus & Other \\
\hline 1.314 & F8VZX2 & PCBP2 & Poly $(\mathrm{rC})$ binding protein 2 & Nucleus & Other \\
\hline 1.302 & P42224 & STATI & Signal transducer and activator of transcription I, 9l kDa & Nucleus & Transcription regulator \\
\hline 1.286 & P356I3 & BSG & Basigin (Ok blood group) & Plasma membrane & Transporter \\
\hline 1.268 & Q9UQ80 & PA2G4 & Proliferation-associated $2 \mathrm{G} 4,38 \mathrm{kDa}$ & Nucleus & Transcription regulator \\
\hline 1.258 & K7EJ78 & RPSI5 & Ribosomal protein SI5 & Cytoplasm & Other \\
\hline 1.254 & F8VPF3 & PDE6H & Phosphodiesterase 6H, cGMP-specific, cone, gamma & Cytoplasm & Enzyme \\
\hline 1.252 & P32969 & RPL9 & Ribosomal protein L9 & Cytoplasm & Other \\
\hline 1.243 & P09972 & ALDOC & Aldolase C, fructose-bisphosphate & Cytoplasm & Enzyme \\
\hline 1.243 & P26038 & MSN & Moesin & Plasma membrane & Other \\
\hline 1.234 & P68366 & TUBA4A & Tubulin, alpha 4a & Cytoplasm & Other \\
\hline 1.232 & P23526 & $\mathrm{AHCY}$ & Adenosylhomocysteinase & Cytoplasm & Enzyme \\
\hline 1.224 & P31949 & SIOOAII & SI00 calcium binding protein AII & Cytoplasm & Other \\
\hline 1.22 & R4GNH3 & PSMC3 & $\begin{array}{l}\text { Proteasome (prosome, macropain) } 26 \mathrm{~S} \text { subunit, } \\
\text { ATPase, } 3\end{array}$ & Nucleus & Transcription regulator \\
\hline 1.215 & Q12906 & ILF3 & Interleukin enhancer binding factor $3,90 \mathrm{kDa}$ & Nucleus & Transcription regulator \\
\hline 1.214 & P46777 & RPL5 & Ribosomal protein L5 & Cytoplasm & Other \\
\hline 1.21 & H0YA96 & HNRNPD & $\begin{array}{l}\text { Heterogeneous nuclear ribonucleoprotein D } \\
\text { (AU-rich element RNA binding protein I, 37kDa) }\end{array}$ & Nucleus & Transcription regulator \\
\hline 1.209 & $\mathrm{P} 22314$ & UBAI & Ubiquitin-like modifier activating enzyme I & Cytoplasm & Enzyme \\
\hline 1.199 & P02786 & TFRC & Transferrin receptor & Plasma membrane & Transporter \\
\hline 1.198 & P02545 & LMNA & Lamin $A / C$ & Nucleus & Other \\
\hline
\end{tabular}


Table I (Continued)

\begin{tabular}{|c|c|c|c|c|c|}
\hline Fold change & ID & Symbol & Entrez gene name & Location & Type(s) \\
\hline 1.17 & Q082II & DHX9 & DEAH (Asp-Glu-Ala-His) box helicase 9 & Nucleus & Enzyme \\
\hline 1.163 & P3II53 & MAT2A & Methionine adenosyltransferase II, alpha & Cytoplasm & Enzyme \\
\hline 1.162 & P55072 & VCP & Valosin containing protein & Cytoplasm & Enzyme \\
\hline 1.16 & P62979 & RPS27A & Ribosomal protein S27a & Cytoplasm & Other \\
\hline 1.16 & P31947 & SFN & Stratifin & Cytoplasm & Other \\
\hline 1.159 & P2338I & WARS & Tryptophanyl-tRNA synthetase & Cytoplasm & Enzyme \\
\hline 1.154 & P46940 & IQGAPI & IQ motif containing GTPase activating protein I & Cytoplasm & Other \\
\hline 1.153 & Q13177 & PAK2 & P2I protein (Cdc42/Rac)-activated kinase 2 & Cytoplasm & Kinase \\
\hline 1.148 & Q9Y446 & PKP3 & Plakophilin 3 & Plasma membrane & Other \\
\hline 1.147 & HOYLC2 & PSMA4 & Proteasome (prosome, macropain) subunit, alpha type, 4 & Cytoplasm & Peptidase \\
\hline 1.144 & P25705 & ATP5AI & $\begin{array}{l}\text { ATP synthase, } \mathrm{H}+\text { transporting, mitochondrial FI } \\
\text { complex, alpha subunit I, cardiac muscle }\end{array}$ & Cytoplasm & Transporter \\
\hline 1.143 & Q।4697 & GANAB & Glucosidase, alpha; neutral $A B$ & Cytoplasm & Enzyme \\
\hline 1.137 & P06576 & ATP5B & $\begin{array}{l}\text { ATP synthase, } \mathrm{H}+\text { transporting, mitochondrial FI } \\
\text { complex, beta polypeptide }\end{array}$ & Cytoplasm & Transporter \\
\hline 1.136 & P07355 & ANXA2 & Annexin A2 & Plasma membrane & Other \\
\hline 1.136 & Q99460 & PSMDI & $\begin{array}{l}\text { Proteasome (prosome, macropain) } 26 \mathrm{~S} \text { subunit, } \\
\text { non-ATPase, I }\end{array}$ & Cytoplasm & Other \\
\hline 1.133 & P07858 & CTSB & Cathepsin B & Cytoplasm & Peptidase \\
\hline 1.129 & Q9UMS4 & PRPFI9 & Pre-mRNA processing factor 19 & Nucleus & Enzyme \\
\hline 1.127 & P31948 & STIPI & Stress-induced phosphoprotein I & Cytoplasm & Other \\
\hline 1.126 & P05783 & KRTI8 & Keratin 18 & Cytoplasm & Other \\
\hline 1.125 & P20618 & PSMBI & Proteasome (prosome, macropain) subunit, beta type, I & Cytoplasm & Peptidase \\
\hline 1.123 & P30I0I & PDIA3 & Protein disulfide isomerase family $\mathrm{A}$, member 3 & Cytoplasm & Peptidase \\
\hline 1.122 & P04083 & ANXAI & Annexin Al & Plasma membrane & Enzyme \\
\hline 1.115 & Q96FWI & OTUBI & OTU deubiquitinase, ubiquitin aldehyde binding I & Cytoplasm & Enzyme \\
\hline 1.115 & P55735 & $\mathrm{SECl} 3$ & SECI3 homolog (S. cerevisiae) & Cytoplasm & Transporter \\
\hline 1.111 & P09936 & UCHLI & $\begin{array}{l}\text { Ubiquitin carboxyl-terminal esterase LI } \\
\text { (ubiquitin thiolesterase) }\end{array}$ & Cytoplasm & Peptidase \\
\hline 1.108 & 060506 & SYNCRIP & $\begin{array}{l}\text { Synaptotagmin binding, cytoplasmic RNA interacting } \\
\text { protein }\end{array}$ & Nucleus & Other \\
\hline 1.104 & P02533 & KRTI4 & Keratin 14 & Cytoplasm & Other \\
\hline 1.103 & P36952 & SERPINB5 & $\begin{array}{l}\text { Serpin peptidase inhibitor, clade B (ovalbumin), } \\
\text { member } 5\end{array}$ & Extracellular space & Other \\
\hline 1.103 & O43399 & TPD52L2 & Tumor protein D52-like 2 & Cytoplasm & Other \\
\hline 1.099 & P50991 & СCT4 & Chaperonin containing TCPI, subunit 4 (delta) & Cytoplasm & Other \\
\hline 1.096 & $\mathrm{PIII42}$ & HSPA8 & Heat shock 70 kDa protein 8 & Cytoplasm & Enzyme \\
\hline 1.096 & P40926 & $\mathrm{MDH} 2$ & Malate dehydrogenase 2, NAD (mitochondrial) & Cytoplasm & Enzyme \\
\hline \multirow[t]{2}{*}{1.096} & P31946 & YWHAB & Tyrosine 3-monooxygenase/tryptophan & Cytoplasm & Transcription regulator \\
\hline & & & 5-monooxygenase activation protein, beta & & \\
\hline 1.094 & Q92597 & NDRGI & N-myc downstream regulated I & Nucleus & Kinase \\
\hline 1.086 & H7C5W9 & ATP2A2 & $\begin{array}{l}\text { ATPase, } \mathrm{Ca}^{2+} \text { transporting, cardiac muscle, slow } \\
\text { twitch } 2\end{array}$ & Cytoplasm & Transporter \\
\hline 1.086 & PI3489 & RNHI & Ribonuclease/angiogenin inhibitor I & Cytoplasm & Other \\
\hline 1.083 & P31930 & UQCRCI & Ubiquinol-cytochrome $\mathrm{c}$ reductase core protein I & Cytoplasm & Enzyme \\
\hline 1.08 & PI7655 & CAPN2 & Calpain 2, (m/ll) large subunit & Cytoplasm & Peptidase \\
\hline 1.08 & P34932 & HSPA4 & Heat shock 70 kDa protein 4 & Cytoplasm & Other \\
\hline 1.076 & P6224I & RPS8 & Ribosomal protein $\mathrm{S} 8$ & Cytoplasm & Other \\
\hline 1.071 & $\mathrm{PI} 3647$ & KRT5 & Keratin 5 & Cytoplasm & Other \\
\hline 1.07 & P02538 & KRT6A & Keratin 6A & Other & Other \\
\hline \multirow[t]{2}{*}{1.058} & P6198I & YWHAG & Tyrosine 3-monooxygenase/tryptophan & Cytoplasm & Other \\
\hline & & & 5-monooxygenase activation protein, gamma & & \\
\hline 1.057 & P04075 & ALDOA & Aldolase $A$, fructose-bisphosphate & Cytoplasm & Enzyme \\
\hline 1.053 & Q96AG4 & LRRC59 & Leucine rich repeat containing 59 & Cytoplasm & Other \\
\hline \multirow[t]{2}{*}{1.05} & P23219 & PTGSI & Prostaglandin-endoperoxide synthase I & Cytoplasm & Enzyme \\
\hline & & & (prostaglandin G/H synthase and cyclooxygenase) & & \\
\hline \multirow[t]{2}{*}{1.05} & P27348 & YWHAQ & Tyrosine 3-monooxygenase/tryptophan & Cytoplasm & Other \\
\hline & & & 5-monooxygenase activation protein, theta & & \\
\hline
\end{tabular}


Table I (Continued)

\begin{tabular}{|c|c|c|c|c|c|}
\hline Fold change & ID & Symbol & Entrez gene name & Location & Type(s) \\
\hline 1.046 & P00387 & CYB5R3 & Cytochrome b5 reductase 3 & Cytoplasm & Enzyme \\
\hline 1.046 & Q9UL46 & PSME2 & $\begin{array}{l}\text { Proteasome (prosome, macropain) activator } \\
\text { subunit } 2 \text { (PA28 beta) }\end{array}$ & Cytoplasm & Peptidase \\
\hline 1.037 & P06748 & NPMI & $\begin{array}{l}\text { Nucleophosmin (nucleolar phosphoprotein B23, } \\
\text { numatrin) }\end{array}$ & Nucleus & Transcription regulator \\
\hline 1.036 & P36578 & RPL4 & Ribosomal protein L4 & Cytoplasm & Enzyme \\
\hline 1.033 & P28066 & PSMA5 & $\begin{array}{l}\text { Proteasome (prosome, macropain) subunit, alpha } \\
\text { type, } 5\end{array}$ & Cytoplasm & Peptidase \\
\hline 1.032 & P08238 & HSP90ABI & $\begin{array}{l}\text { Heat shock protein } 90 \mathrm{kDa} \text { alpha (cytosolic), class B } \\
\text { member I }\end{array}$ & Cytoplasm & Enzyme \\
\hline 1.03 & P52907 & CAPZAI & Capping protein (actin filament) muscle Z-line, alpha I & Cytoplasm & Other \\
\hline 1.03 & $\mathrm{P} 16152$ & CARI & Carbonyl reductase I & Cytoplasm & Enzyme \\
\hline 1.028 & Q14019 & COTLI & Coactosin-like F-actin binding protein I & Cytoplasm & Other \\
\hline 1.027 & P04632 & CAPNSI & Calpain, small subunit I & Cytoplasm & Peptidase \\
\hline 1.026 & PI9I05 & MYLI2A & Myosin, light chain $12 \mathrm{~A}$, regulatory, nonsarcomeric & Cytoplasm & Other \\
\hline 1.024 & $\mathrm{PI} 28 \mid 4$ & ACTNI & Actinin, alpha I & Cytoplasm & Other \\
\hline 1.021 & P50395 & GDI2 & GDP dissociation inhibitor 2 & Cytoplasm & Other \\
\hline 1.02 & Q01518 & CAPI & CAP, adenylate cyclase-associated protein I (yeast) & Plasma membrane & Other \\
\hline 1.018 & J3КРЕЗ & GNB2LI & $\begin{array}{l}\text { Guanine nucleotide binding protein (G protein), beta } \\
\text { polypeptide } 2 \text {-like I }\end{array}$ & Cytoplasm & Enzyme \\
\hline 1.014 & Q99880 & HISTIH2BL & Histone cluster I, $\mathrm{H} 2 \mathrm{bl}$ & Nucleus & Other \\
\hline 1.012 & P27695 & APEXI & $\begin{array}{l}\text { APEX nuclease (multifunctional DNA repair } \\
\text { enzyme) I }\end{array}$ & Nucleus & Enzyme \\
\hline 1.007 & P6837I & TUBB4B & Tubulin, beta 4B class IVb & Cytoplasm & Other \\
\hline 1.006 & F5GZS6 & $\mathrm{SLC} 3 \mathrm{~A} 2$ & $\begin{array}{l}\text { Solute carrier family } 3 \text { (amino acid transporter heavy } \\
\text { chain), member } 2\end{array}$ & Plasma membrane & Transporter \\
\hline 1.004 & OI537| & EIF3D & Eukaryotic translation initiation factor 3 , subunit $D$ & Cytoplasm & Other \\
\hline 1.002 & D6RGI3 & RPS3A & Ribosomal protein S3A & Nucleus & Other \\
\hline 1.001 & MOR2L9 & RPSI9 & Ribosomal protein SI9 & Cytoplasm & Other \\
\hline
\end{tabular}

Abbreviation: PLB, plumbagin.

Table 2 Proteins downregulated by PLB in SCC25 cells

\begin{tabular}{|c|c|c|c|c|c|}
\hline $\begin{array}{l}\text { Fold } \\
\text { change }\end{array}$ & ID & Symbol & Entrez gene name & Location & Type(s) \\
\hline-3.32 & P52306 & RAPIGDSI & RAPI, GTP-GDP dissociation stimulator I & Cytoplasm & Other \\
\hline-2.964 & P29966 & MARCKS & Myristoylated alanine-rich protein kinase $\mathrm{C}$ substrate & Plasma membrane & Other \\
\hline-2.937 & P04264 & KRTI & Keratin I & Cytoplasm & Other \\
\hline-2.79 & Q15942 & ZYX & Zyxin & Plasma membrane & Other \\
\hline-2.644 & P35527 & KRT9 & Keratin 9 & Other & Other \\
\hline-2.642 & P80723 & BASPI & Brain abundant, membrane attached signal protein I & Nucleus & Transcription regulator \\
\hline-2.561 & B8ZZQ6 & PTMA & Prothymosin, alpha & Nucleus & Other \\
\hline-2.542 & P25786 & PSMAI & Proteasome (prosome, macropain) subunit, alpha type, I & Cytoplasm & Peptidase \\
\hline-2.476 & P35637 & FUS & FUS RNA binding protein & Nucleus & Transcription regulator \\
\hline-2.439 & PI6989 & YBX3 & $Y$ box binding protein 3 & Nucleus & Transcription regulator \\
\hline-2.394 & K7EL20 & EIF3G & Eukaryotic translation initiation factor 3 , subunit $\mathrm{G}$ & Cytoplasm & Other \\
\hline-2.346 & PI3726 & F3 & Coagulation factor III (thromboplastin, tissue factor) & Plasma membrane & Transmembrane receptor \\
\hline-2.3 & Q08J23 & NSUN2 & NOP2/Sun RNA methyltransferase family, member 2 & Nucleus & Enzyme \\
\hline-2.244 & P47895 & ALDHIA3 & Aldehyde dehydrogenase I family, member A3 & Cytoplasm & Enzyme \\
\hline-2.128 & P26358 & DNMTI & DNA (cytosine-5-)-methyltransferase I & Nucleus & Enzyme \\
\hline-2.111 & Q15582 & TGFBI & Transforming growth factor, beta-induced, $68 \mathrm{kDa}$ & Extracellular space & Other \\
\hline-2.081 & P30I53 & PPP2RIA & Protein phosphatase 2 , regulatory subunit $A$, alpha & Cytoplasm & Phosphatase \\
\hline-2.052 & P06744 & GPI & Glucose-6-phosphate isomerase & Extracellular space & Enzyme \\
\hline-2.018 & Q5JXT2 & NOP56 & NOP56 ribonucleoprotein & Nucleus & Other \\
\hline-2.013 & P5362I & COPA & Coatomer protein complex, subunit alpha & Cytoplasm & Transporter \\
\hline-1.946 & Q16777 & $\mathrm{HIST} 2 \mathrm{H} 2 \mathrm{AC}$ & Histone cluster 2, $\mathrm{H} 2 \mathrm{ac}$ & Nucleus & Other \\
\hline
\end{tabular}


Table 2 (Continued)

\begin{tabular}{|c|c|c|c|c|c|}
\hline $\begin{array}{l}\text { Fold } \\
\text { change }\end{array}$ & ID & Symbol & Entrez gene name & Location & Type(s) \\
\hline-1.921 & C9JNR4 & RHOA & Ras family member $\mathrm{A}$ & Cytoplasm & Enzyme \\
\hline$-1.92 \mid$ & F8VWSO & RPLPO & Ribosomal protein, large, P0 & Cytoplasm & Other \\
\hline-1.915 & P092II & GSTPI & Glutathione S-transferase pi I & Cytoplasm & Enzyme \\
\hline-1.88 & Q06830 & PRDXI & Peroxiredoxin I & Cytoplasm & Enzyme \\
\hline-1.87 & PII498 & $\mathrm{PC}$ & Pyruvate carboxylase & Cytoplasm & Enzyme \\
\hline-1.86 & P33176 & KIF5B & Kinesin family member $5 B$ & Cytoplasm & Other \\
\hline-1.858 & I7HJJ0 & SLC25A6 & $\begin{array}{l}\text { Solute carrier family } 25 \text { (mitochondrial carrier; } \\
\text { adenine nucleotide translocator), member } 6\end{array}$ & Cytoplasm & Transporter \\
\hline-1.856 & P52566 & ARHGDIB & Rho GDP dissociation inhibitor (GDI) beta & Cytoplasm & Other \\
\hline-1.844 & P67809 & YBXI & Y box binding protein I & Nucleus & Transcription regulator \\
\hline-1.764 & Q9UKY7 & CDV3 & CDV3 homolog (mouse) & Cytoplasm & Other \\
\hline-1.764 & B7Z972 & PCMTI & Protein-L-isoaspartate (D-aspartate) O-methyltransferase & Cytoplasm & Enzyme \\
\hline-1.737 & E9PBSI & PAICS & $\begin{array}{l}\text { Phosphoribosylaminoimidazole carboxylase, phosphoribo- } \\
\text { sylaminoimidazole succinocarboxamide synthetase }\end{array}$ & Cytoplasm & Enzyme \\
\hline-1.727 & $\mathrm{PI} 3010$ & $\mathrm{XRCC5}$ & $\begin{array}{l}\text { X-ray repair complementing defective repair in Chinese } \\
\text { hamster cells } 5 \text { (double-strand-break rejoining) }\end{array}$ & Nucleus & Enzyme \\
\hline-1.723 & P26368 & U2AF2 & U2 small nuclear RNA auxiliary factor 2 & Nucleus & Other \\
\hline-1.722 & P28074 & PSMB5 & Proteasome (prosome, macropain) subunit, beta type, 5 & Cytoplasm & Peptidase \\
\hline-1.715 & PI5374 & UCHL3 & $\begin{array}{l}\text { Ubiquitin carboxyl-terminal esterase L3 (ubiquitin } \\
\text { thiolesterase) }\end{array}$ & Cytoplasm & Peptidase \\
\hline-1.709 & P68104 & EEFIAI & Eukaryotic translation elongation factor I alpha I & Cytoplasm & Translation regulator \\
\hline-1.698 & J3KTF8 & ARHGDIA & Rho GDP dissociation inhibitor (GDI) alpha & Cytoplasm & Other \\
\hline-1.694 & 075367 & H2AFY & $\mathrm{H} 2 \mathrm{~A}$ histone family, member $\mathrm{Y}$ & Nucleus & Other \\
\hline-1.663 & P63010 & $\mathrm{AP} 2 \mathrm{BI}$ & Adaptor-related protein complex 2 , beta I subunit & Plasma membrane & Transporter \\
\hline-1.655 & B4DUR8 & ССТ3 & Chaperonin containing TCPI, subunit 3 (gamma) & Cytoplasm & Other \\
\hline-1.646 & PI3667 & PDIA4 & Protein disulfide isomerase family A, member 4 & Cytoplasm & Enzyme \\
\hline-1.638 & P23229 & ITGA6 & Integrin, alpha 6 & Plasma membrane & Transmembrane receptor \\
\hline-1.632 & F8VZ29 & UBE2N & Ubiquitin-conjugating enzyme E2N & Cytoplasm & Enzyme \\
\hline$-1.63 \mid$ & Q9UHI5 & SLC7A8 & $\begin{array}{l}\text { Solute carrier family } 7 \text { (amino acid transporter light chain, } \\
\text { L system), member } 8\end{array}$ & Plasma membrane & Transporter \\
\hline-1.629 & F8W726 & UBAP2L & Ubiquitin associated protein 2-like & Other & Other \\
\hline-1.617 & Q9HB7I & CACYBP & Calcyclin binding protein & Nucleus & Other \\
\hline-1.614 & Q12905 & ILF2 & Interleukin enhancer binding factor 2 & Nucleus & Transcription regulator \\
\hline-1.599 & 043390 & HNRNPR & Heterogeneous nuclear ribonucleoprotein $\mathrm{R}$ & Nucleus & Other \\
\hline-1.599 & E9PK47 & PYGL & Phosphorylase, glycogen, liver & Cytoplasm & Enzyme \\
\hline-1.579 & Q6NYC8 & PPPIRI8 & Protein phosphatase I, regulatory subunit I8 & Other & Other \\
\hline-1.574 & O60884 & DNAJA2 & DNAJ (Hsp40) homolog, subfamily A, member 2 & Nucleus & Enzyme \\
\hline-1.566 & E9PDF6 & MYOIB & Myosin IB & Cytoplasm & Other \\
\hline-1.565 & Q02878 & RPL6 & Ribosomal protein L6 & Cytoplasm & Other \\
\hline-1.562 & P05386 & RPLPI & Ribosomal protein, large, PI & Cytoplasm & Other \\
\hline-1.56 & E9PLD0 & RABIB & RABIB, member RAS oncogene family & Cytoplasm & Other \\
\hline-1.556 & Q14247 & CTTN & Cortactin & Plasma membrane & Other \\
\hline-1.554 & P42704 & LRPPRC & Leucine-rich pentatricopeptide repeat containing & Cytoplasm & Other \\
\hline-1.549 & Q9H4M9 & EHDI & EH-domain containing I & Cytoplasm & Other \\
\hline-1.498 & P30084 & ECHSI & Enoyl CoA hydratase, short chain, I, mitochondrial & Cytoplasm & Enzyme \\
\hline-1.498 & P499I5 & GMPS & Guanine monphosphate synthase & Nucleus & Enzyme \\
\hline-1.496 & Q86VP6 & CANDI & Cullin-associated and neddylation-dissociated I & Cytoplasm & Transcription regulator \\
\hline-1.49 & P49588 & AARS & Alanyl-tRNA synthetase & Cytoplasm & Enzyme \\
\hline-1.482 & $\mathrm{P} 62314$ & SNRPDI & Small nuclear ribonucleoprotein DI polypeptide 16 kDa & Nucleus & Other \\
\hline-1.474 & P20290 & BTF3 & Basic transcription factor 3 & Nucleus & Transcription regulator \\
\hline-1.473 & Q9ULV4 & COROIC & Coronin, actin binding protein, IC & Cytoplasm & Other \\
\hline-1.468 & P5I858 & HDGF & Hepatoma-derived growth factor & Extracellular space & Growth factor \\
\hline-1.468 & G3VIAI & RPL8 & Ribosomal protein L8 & Other & Other \\
\hline-1.466 & Q9UHD8 & SEPT9 & Septin 9 & Cytoplasm & Enzyme \\
\hline
\end{tabular}


Table 2 (Continued)

\begin{tabular}{|c|c|c|c|c|c|}
\hline $\begin{array}{l}\text { Fold } \\
\text { change }\end{array}$ & ID & Symbol & Entrez gene name & Location & Type(s) \\
\hline$-1.46 \mid$ & P55060 & CSEIL & CSEI chromosome segregation I-like (yeast) & Nucleus & Transporter \\
\hline-1.46 & P61978 & HNRNPK & Heterogeneous nuclear ribonucleoprotein $\mathrm{K}$ & Nucleus & Other \\
\hline-1.457 & P84077 & ARFI & ADP-ribosylation factor I & Cytoplasm & Enzyme \\
\hline-1.452 & P6208I & RPS7 & Ribosomal protein S7 & Cytoplasm & Other \\
\hline-1.447 & K7EJ57 & TOMM40 & $\begin{array}{l}\text { Translocase of outer mitochondrial membrane } 40 \text { homolog } \\
\text { (yeast) }\end{array}$ & Cytoplasm & lon channel \\
\hline-1.443 & Q9Y5B9 & SUPTI6H & Suppressor of Ty 16 homolog (S. cerevisiae) & Nucleus & Transcription regulator \\
\hline-1.434 & P49327 & FASN & Fatty acid synthase & Cytoplasm & Enzyme \\
\hline-1.432 & P30086 & PEBPI & Phosphatidylethanolamine binding protein I & Cytoplasm & Other \\
\hline-1.421 & C9J9K3 & RPSA & Ribosomal protein SA & Cytoplasm & Translation regulator \\
\hline-1.421 & Q12874 & SF3A3 & Splicing factor $3 a$, subunit $3,60 \mathrm{kDa}$ & Nucleus & Other \\
\hline-1.42 & P43490 & NAMPT & Nicotinamide phosphoribosyltransferase & Extracellular space & Cytokine \\
\hline-1.41 & QI4444 & CAPRINI & Cell cycle associated protein I & Plasma membrane & Other \\
\hline-1.409 & $\mathrm{PI} 3928$ & $\begin{array}{l}\text { ANXA8/ } \\
\text { ANXA8LI }\end{array}$ & Annexin A8-like I & Plasma membrane & Other \\
\hline-1.408 & Q9UK76 & $\mathrm{HNI}$ & Hematological and neurological expressed I & Nucleus & Other \\
\hline-1.404 & P00367 & GLUDI & Glutamate dehydrogenase I & Cytoplasm & Enzyme \\
\hline-1.402 & Q14764 & MVP & Major vault protein & Nucleus & Other \\
\hline$-1.39 \mid$ & Q9NTK5 & OLAI & Obg-like ATPase I & Cytoplasm & Other \\
\hline$-1.39 \mid$ & P08670 & VIM & Vimentin & Cytoplasm & Other \\
\hline-1.387 & P07I95 & LDHB & Lactate dehydrogenase $B$ & Cytoplasm & Enzyme \\
\hline-1.384 & P07384 & CAPNI & Calpain I, (mu/l) large subunit & Cytoplasm & Peptidase \\
\hline-1.378 & Q5T7C4 & HMGBI & High mobility group box I & Nucleus & Transcription regulator \\
\hline-1.374 & P55884 & ElF3B & Eukaryotic translation initiation factor 3 , subunit $B$ & Cytoplasm & Translation regulator \\
\hline-1.367 & Q15417 & CNN3 & Calponin 3, acidic & Cytoplasm & Other \\
\hline-1.367 & Q96AE4 & FUBPI & Far upstream element (FUSE) binding protein I & Nucleus & Transcription regulator \\
\hline-1.366 & F8WIN5 & NACA & Nascent polypeptide-associated complex alpha subunit & Cytoplasm & Transcription regulator \\
\hline-1.364 & Q32Q12 & NMEI-NME2 & NMEI-NME2 readthrough & Cytoplasm & Other \\
\hline$-1.36 \mid$ & P21796 & VDACI & Voltage-dependent anion channel I & Cytoplasm & lon channel \\
\hline-1.359 & P54I36 & RARS & Arginyl-tRNA synthetase & Cytoplasm & Enzyme \\
\hline-1.359 & Q9H2G2 & SLK & STE20-like kinase & Nucleus & Kinase \\
\hline-1.359 & Q12792 & TWFI & Twinfilin actin-binding protein I & Cytoplasm & Kinase \\
\hline-1.354 & Q7KZF4 & SNDI & Staphylococcal nuclease and tudor domain containing I & Nucleus & Enzyme \\
\hline-1.347 & P20042 & EIF2S2 & $\begin{array}{l}\text { Eukaryotic translation initiation factor } 2 \text {, subunit } 2 \text { beta, } \\
38 \mathrm{kDa}\end{array}$ & Cytoplasm & Translation regulator \\
\hline-1.344 & Q14204 & DYNCIHI & Dynein, cytoplasmic I, heavy chain I & Cytoplasm & Peptidase \\
\hline-1.34 & K7EIP4 & LAMA3 & Laminin, alpha 3 & Extracellular space & Other \\
\hline-1.337 & P24534 & EEFIB2 & Eukaryotic translation elongation factor I beta 2 & Cytoplasm & Translation regulator \\
\hline-1.331 & P61353 & RPL27 & Ribosomal protein L27 & Cytoplasm & Other \\
\hline-1.33 & $\mathrm{P} 4 \mid 250$ & GARS & Glycyl-tRNA synthetase & Cytoplasm & Enzyme \\
\hline-1.326 & P04080 & CSTB & Cystatin B (stefin B) & Cytoplasm & Peptidase \\
\hline-1.326 & G8JLD5 & DNMIL & Dynamin I-like & Cytoplasm & Enzyme \\
\hline-1.317 & P04792 & HSPBI & Heat shock 27 kDa protein I & Cytoplasm & Other \\
\hline-1.315 & PI2956 & $\mathrm{XRCC6}$ & $\begin{array}{l}\text { X-ray repair complementing defective repair in Chinese } \\
\text { hamster cells } 6\end{array}$ & Nucleus & Enzyme \\
\hline-1.308 & P0CW22 & RPSI7 & Ribosomal protein SI7 & Cytoplasm & Other \\
\hline-1.306 & Q13283 & G3BPI & GTPase activating protein (SH3 domain) binding protein I & Nucleus & Enzyme \\
\hline-1.306 & Q1518I & PPAI & Pyrophosphatase (inorganic) I & Cytoplasm & Enzyme \\
\hline-1.302 & $\mathrm{PI} 4618$ & PKM & Pyruvate kinase, muscle & Cytoplasm & Kinase \\
\hline-1.297 & P27797 & CALR & Calreticulin & Cytoplasm & Transcription regulator \\
\hline-1.287 & P48643 & ССT5 & Chaperonin containing TCPI, subunit 5 (epsilon) & Cytoplasm & Other \\
\hline-1.286 & P6II58 & ACTR3 & ARP3 actin-related protein 3 homolog (yeast) & Plasma membrane & Other \\
\hline-1.286 & Q0702I & CIQBP & $\begin{array}{l}\text { Complement component I, q subcomponent binding } \\
\text { protein }\end{array}$ & Cytoplasm & Transcription regulator \\
\hline
\end{tabular}


Table 2 (Continued)

\begin{tabular}{|c|c|c|c|c|c|}
\hline $\begin{array}{l}\text { Fold } \\
\text { change }\end{array}$ & ID & Symbol & Entrez gene name & Location & Type(s) \\
\hline-1.283 & P4I09I & EIF2S3 & $\begin{array}{l}\text { Eukaryotic translation initiation factor 2, subunit } 3 \text { gamma, } \\
52 \mathrm{kDa}\end{array}$ & Cytoplasm & Translation regulator \\
\hline-1.28 & P26639 & TARS & Threonyl-tRNA synthetase & Nucleus & Enzyme \\
\hline-1.279 & P43243 & MATR3 & Matrin 3 & Nucleus & Other \\
\hline-1.278 & B4DSI3 & EIF4B & Eukaryotic translation initiation factor 4B & Cytoplasm & Translation regulator \\
\hline-1.277 & P099|4 & IFITI & $\begin{array}{l}\text { Interferon-induced protein with tetratricopeptide repeats } \\
\text { I }\end{array}$ & Cytoplasm & Other \\
\hline-1.277 & QI5084 & PDIA6 & Protein disulfide isomerase family A, member 6 & Cytoplasm & Enzyme \\
\hline-1.276 & P52292 & KPNA2 & Karyopherin alpha 2 (RAG cohort I, importin alpha I) & Nucleus & Transporter \\
\hline$-1.27 \mid$ & $\mathrm{PI} 2004$ & PCNA & Proliferating cell nuclear antigen & Nucleus & Enzyme \\
\hline-1.269 & $\mathrm{PI} 3639$ & EEF2 & Eukaryotic translation elongation factor 2 & Cytoplasm & Translation regulator \\
\hline-1.267 & $\mathrm{~F} 5 \mathrm{H} 0 \mathrm{I} 8$ & RAN & RAN, member RAS oncogene family & Nucleus & Enzyme \\
\hline-1.265 & P40I2I & CAPG & Capping protein (actin filament), gelsolin-like & Nucleus & Other \\
\hline-1.264 & E7EQR4 & EZR & Ezrin & Plasma membrane & Other \\
\hline-1.264 & P43686 & PSMC4 & Proteasome (prosome, macropain) 26S subunit, ATPase, 4 & Nucleus & Peptidase \\
\hline-1.263 & P6324I & EIF5A & Eukaryotic translation initiation factor $5 \mathrm{~A}$ & Cytoplasm & Translation regulator \\
\hline$-1.26 \mid$ & $\mathrm{BIAK} 85$ & CAPZB & Capping protein (actin filament) muscle Z-line, beta & Cytoplasm & Other \\
\hline-1.254 & Q14974 & KPNBI & Karyopherin (importin) beta I & Nucleus & Transporter \\
\hline-1.253 & P07237 & P4HB & Prolyl 4-hydroxylase, beta polypeptide & Cytoplasm & Enzyme \\
\hline$-1.25 \mid$ & B4DLR8 & NQOI & NAD $(\mathrm{P}) \mathrm{H}$ dehydrogenase, quinone I & Cytoplasm & Enzyme \\
\hline$-1.25 \mid$ & O60664 & PLIN3 & Perilipin 3 & Cytoplasm & Other \\
\hline$-1.25 \mid$ & P54725 & RAD23A & RAD23 homolog A (S. cerevisiae) & Nucleus & Other \\
\hline-1.25 & PI8669 & PGAMI & Phosphoglycerate mutase I (brain) & Cytoplasm & Phosphatase \\
\hline-1.248 & P05 I4I & SLC25A5 & $\begin{array}{l}\text { Solute carrier family } 25 \text { (mitochondrial carrier; adenine } \\
\text { nucleotide translocator), member } 5\end{array}$ & Cytoplasm & Transporter \\
\hline-1.247 & P55263 & ADK & Adenosine kinase & Nucleus & Kinase \\
\hline-1.245 & P4932I & NASP & Nuclear autoantigenic sperm protein (histone-binding) & Nucleus & Other \\
\hline-1.244 & $\mathrm{P} 22626$ & HNRNPA2BI & Heterogeneous nuclear ribonucleoprotein A2/BI & Nucleus & Other \\
\hline-1.243 & P0I892 & HLA-A & Major histocompatibility complex, class I, A & Plasma membrane & Other \\
\hline-1.242 & P54727 & RAD23B & RAD23 homolog B (S. cerevisiae) & Nucleus & Other \\
\hline-1.239 & P07737 & PFNI & Profilin I & Cytoplasm & Other \\
\hline-1.237 & $\mathrm{P} 21333$ & FLNA & Filamin A, alpha & Cytoplasm & Other \\
\hline-1.236 & P06733 & ENOI & Enolase I, (alpha) & Cytoplasm & Enzyme \\
\hline-1.234 & P09382 & LGALSI & Lectin, galactoside-binding, soluble, I & Extracellular space & Other \\
\hline-1.232 & P35998 & PSMC2 & Proteasome (prosome, macropain) 26S subunit, ATPase, 2 & Nucleus & Peptidase \\
\hline-1.23 & P52272 & HNRNPM & Heterogeneous nuclear ribonucleoprotein $M$ & Nucleus & Other \\
\hline-1.229 & P06396 & GSN & Gelsolin & Extracellular space & Other \\
\hline-1.229 & Q997|4 & HSDI7BIO & Hydroxysteroid (I7-beta) dehydrogenase 10 & Cytoplasm & Enzyme \\
\hline-1.227 & P30044 & PRDX5 & Peroxiredoxin 5 & Cytoplasm & Enzyme \\
\hline-1.224 & P00491 & PNP & Purine nucleoside phosphorylase & Nucleus & Enzyme \\
\hline-1.223 & P39023 & RPL3 & Ribosomal protein L3 & Cytoplasm & Other \\
\hline$-|.22|$ & P37802 & TAGLN2 & Transgelin 2 & Cytoplasm & Other \\
\hline-1.22 & Q7L2H7 & EIF3M & Eukaryotic translation initiation factor 3 , subunit $M$ & Other & Other \\
\hline-1.22 & P62906 & RPLIOA & Ribosomal protein LIOa & Nucleus & Other \\
\hline-1.219 & P62937 & PPIA & Peptidylprolyl isomerase A (cyclophilin A) & Cytoplasm & Enzyme \\
\hline-1.215 & PII766 & ADH5 & Alcohol dehydrogenase 5 (class III), chi polypeptide & Cytoplasm & Enzyme \\
\hline-1.213 & Q09666 & AHNAK & AHNAK nucleoprotein & Nucleus & Other \\
\hline-1.207 & E7ETK0 & RPS24 & Ribosomal protein S24 & Cytoplasm & Other \\
\hline-1.205 & Q03135 & CAVI & Caveolin I, caveolae protein, 22 kDa & Plasma membrane & Transmembrane receptor \\
\hline-1.203 & P35606 & COPB2 & Coatomer protein complex, subunit beta 2 (beta prime) & Cytoplasm & Transporter \\
\hline-1.203 & P52209 & PGD & Phosphogluconate dehydrogenase & Cytoplasm & Enzyme \\
\hline-1.203 & Q13200 & PSMD2 & $\begin{array}{l}\text { Proteasome (prosome, macropain) } 26 \mathrm{~S} \text { subunit, } \\
\text { non-ATPase, } 2\end{array}$ & Cytoplasm & Other \\
\hline-1.198 & P60842 & EIF4AI & Eukaryotic translation initiation factor $4 \mathrm{AI}$ & Cytoplasm & Translation regulator \\
\hline
\end{tabular}


Table 2 (Continued)

\begin{tabular}{|c|c|c|c|c|c|}
\hline $\begin{array}{l}\text { Fold } \\
\text { change }\end{array}$ & ID & Symbol & Entrez gene name & Location & Type(s) \\
\hline-1.198 & $\mathrm{PI} 8124$ & RPL7 & Ribosomal protein L7 & Nucleus & Transcription regulator \\
\hline-1.193 & P0516I & ISGI5 & ISGI5 ubiquitin-like modifier & Extracellular space & Other \\
\hline-1.184 & A0A075B730 & EPPKI & Epiplakin I & Cytoplasm & Other \\
\hline-1.184 & Q02790 & FKBP4 & FK506 binding protein $4,59 \mathrm{kDa}$ & Nucleus & Enzyme \\
\hline-1.184 & MOROFO & RPS5 & Ribosomal protein S5 & Cytoplasm & Other \\
\hline-1.183 & P35221 & CTNNAI & Catenin (cadherin-associated protein), alpha I, $102 \mathrm{kDa}$ & Plasma membrane & Other \\
\hline-1.179 & Q01I05 & SET & SET nuclear proto-oncogene & Nucleus & Phosphatase \\
\hline-1.175 & P05387 & RPLP2 & Ribosomal protein, large, P2 & Cytoplasm & Other \\
\hline-1.174 & Q00839 & HNRNPU & $\begin{array}{l}\text { Heterogeneous nuclear ribonucleoprotein } \mathrm{U} \text { (scaffold } \\
\text { attachment factor } \mathrm{A} \text { ) }\end{array}$ & Nucleus & Transporter \\
\hline-1.173 & 015143 & ARPCIB & Actin related protein $2 / 3$ complex, subunit IB, $4 \mid \mathrm{kDa}$ & Cytoplasm & Other \\
\hline-1.173 & P23528 & CFLI & Cofilin I (non-muscle) & Nucleus & Other \\
\hline-1.173 & $\mathrm{~A} 2 \mathrm{~A} 2 \mathrm{Y} 8$ & COLI7AI & Collagen, type XVII, alpha I & Extracellular space & Other \\
\hline-1.171 & E7EQV3 & PABPCI & Poly(A) binding protein, cytoplasmic I & Cytoplasm & Translation regulator \\
\hline-1.171 & F8W7C6 & RPLIO & Ribosomal protein LIO & Cytoplasm & Other \\
\hline-1.158 & Q14980 & NUMAI & Nuclear mitotic apparatus protein I & Nucleus & Other \\
\hline-1.157 & P27824 & CANX & Calnexin & Cytoplasm & Other \\
\hline-1.155 & Q14134 & TRIM29 & Tripartite motif containing 29 & Cytoplasm & Transcription regulator \\
\hline-1.154 & E9PCY7 & HNRNPHI & Heterogeneous nuclear ribonucleoprotein $\mathrm{HI}(\mathrm{H})$ & Nucleus & Other \\
\hline-1.153 & 000299 & $\mathrm{CLICI}$ & Chloride intracellular channel I & Nucleus & lon channel \\
\hline-1.145 & Q13813 & SPTANI & Spectrin, alpha, nonerythrocytic I & Plasma membrane & Other \\
\hline-1.144 & P07900 & HSP90AAI & $\begin{array}{l}\text { Heat shock protein } 90 \mathrm{kDa} \text { alpha (cytosolic), class A } \\
\text { member I }\end{array}$ & Cytoplasm & Enzyme \\
\hline-1.143 & P68363 & TUBAIB & Tubulin, alpha Ib & Cytoplasm & Other \\
\hline-1.14 & Q5JP53 & TUBB & Tubulin, beta class I & Cytoplasm & Other \\
\hline-1.137 & $\mathrm{P} 60174$ & TPII & Triosephosphate isomerase I & Cytoplasm & Enzyme \\
\hline-1.136 & P27482 & CALML3 & Calmodulin-like 3 & Cytoplasm & Other \\
\hline-1.135 & PI9338 & $\mathrm{NCL}$ & Nucleolin & Nucleus & Other \\
\hline-1.124 & PI8206 & $\mathrm{VCL}$ & Vinculin & Plasma membrane & Enzyme \\
\hline-1.117 & PI0809 & HSPDI & Heat shock $60 \mathrm{kDa}$ protein I (chaperonin) & Cytoplasm & Enzyme \\
\hline-1.117 & Q92598 & $\mathrm{HSPHI}$ & Heat shock $105 \mathrm{kDa} / \mathrm{I} 10 \mathrm{kDa}$ protein I & Cytoplasm & Other \\
\hline-1.114 & K7ELL7 & PRKCSH & Protein kinase $\mathrm{C}$ substrate $80 \mathrm{~K}-\mathrm{H}$ & Cytoplasm & Enzyme \\
\hline-1.112 & P05।98 & EIF2SI & Eukaryotic translation initiation factor 2, subunit I alpha, $35 \mathrm{kDa}$ & Cytoplasm & Translation regulator \\
\hline-1.111 & P30050 & RPLI2 & Ribosomal protein LI2 & Nucleus & Other \\
\hline-1.108 & F8W617 & HNRNPAI & Heterogeneous nuclear ribonucleoprotein AI & Nucleus & Other \\
\hline-1.108 & P00338 & LDHA & Lactate dehydrogenase $\mathrm{A}$ & Cytoplasm & Enzyme \\
\hline-1.106 & Q16658 & FSCNI & Fascin actin-bundling protein I & Cytoplasm & Other \\
\hline-1.103 & P7837I & ССТ2 & Chaperonin containing TCPI, subunit 2 (beta) & Cytoplasm & Kinase \\
\hline-1.102 & $\mathrm{P} 68133$ & ACTAI & Actin, alpha I, skeletal muscle & Cytoplasm & Other \\
\hline-1.095 & P29728 & OAS2 & 2'-5'-oligoadenylate synthetase $2,69 / 71 \mathrm{kDa}$ & Cytoplasm & Enzyme \\
\hline-1.092 & $\mathrm{PI} 3797$ & PLS3 & Plastin 3 & Cytoplasm & Other \\
\hline-1.09 & D6RFM5 & SDHA & $\begin{array}{l}\text { Succinate dehydrogenase complex, subunit A, flavoprotein } \\
\left(F_{p}\right)\end{array}$ & Cytoplasm & Enzyme \\
\hline-1.082 & B4E022 & TKT & Transketolase & Cytoplasm & Enzyme \\
\hline-1.081 & 095433 & AHSAI & $\begin{array}{l}\text { AHAI, activator of heat shock } 90 \mathrm{kDa} \text { protein ATPase } \\
\text { homologue I (yeast) }\end{array}$ & Cytoplasm & Other \\
\hline-1.077 & E7EX73 & EIF4GI & Eukaryotic translation initiation factor 4 gamma, I & Cytoplasm & Translation regulator \\
\hline-1.076 & P04406 & GAPDH & Glyceraldehyde-3-phosphate dehydrogenase & Cytoplasm & Enzyme \\
\hline-1.076 & P26599 & PTBPI & Polypyrimidine tract binding protein I & Nucleus & Enzyme \\
\hline-1.076 & $P 11216$ & PYGB & Phosphorylase, glycogen; brain & Cytoplasm & Enzyme \\
\hline-1.072 & Q13838 & $\mathrm{DD} \times 39 \mathrm{~B}$ & DEAD (Asp-Glu-Ala-Asp) box polypeptide 39B & Nucleus & Enzyme \\
\hline-1.072 & Q99733 & NAPIL4 & Nucleosome assembly protein I-like 4 & Cytoplasm & Other \\
\hline-1.068 & P29692 & EEFID & $\begin{array}{l}\text { Eukaryotic translation elongation factor I delta (guanine } \\
\text { nucleotide exchange protein) }\end{array}$ & Cytoplasm & Translation regulator \\
\hline
\end{tabular}


Table 2 (Continued)

\begin{tabular}{|c|c|c|c|c|c|}
\hline $\begin{array}{l}\text { Fold } \\
\text { change }\end{array}$ & ID & Symbol & Entrez gene name & Location & Type(s) \\
\hline-1.067 & 000151 & PDLIMI & PDZ and LIM domain I & Cytoplasm & Transcription regulator \\
\hline-1.065 & 075369 & FLNB & Filamin B, beta & Cytoplasm & Other \\
\hline-1.063 & P62191 & PSMCI & Proteasome (prosome, macropain) 26S subunit, ATPase, I & Nucleus & Peptidase \\
\hline-1.059 & P00558 & PGKI & Phosphoglycerate kinase I & Cytoplasm & Kinase \\
\hline-1.055 & P50990 & ССТ8 & Chaperonin containing TCPI, subunit 8 (theta) & Cytoplasm & Enzyme \\
\hline-1.052 & F5H7V9 & TNC & Tenascin C & Extracellular space & Other \\
\hline-1.049 & Q99613 & EIF3C & Eukaryotic translation initiation factor 3 , subunit $\mathrm{C}$ & Other & Translation regulator \\
\hline-1.048 & P45880 & VDAC2 & Voltage-dependent anion channel 2 & Cytoplasm & lon channel \\
\hline-1.043 & P2664l & EEFIG & Eukaryotic translation elongation factor I gamma & Cytoplasm & Translation regulator \\
\hline-1.043 & P0044I & SODI & Superoxide dismutase I, soluble & Cytoplasm & Enzyme \\
\hline-1.039 & E9PFD7 & EGFR & Epidermal growth factor receptor & Plasma membrane & Kinase \\
\hline-1.039 & Q9NQC3 & RTN4 & Reticulon 4 & Cytoplasm & Other \\
\hline-1.037 & Q9NUQ9 & FAM49B & Family with sequence similarity 49 , member $B$ & Extracellular space & Other \\
\hline-1.037 & P08729 & KRT7 & Keratin 7 & Cytoplasm & Other \\
\hline-1.037 & P25398 & RPSI 2 & Ribosomal protein SI2 & Cytoplasm & Other \\
\hline-1.034 & Q13347 & EIF3I & Eukaryotic translation initiation factor 3 , subunit I & Cytoplasm & Translation regulator \\
\hline-1.034 & F8VQEI & TRMTI & tRNA methyltransferase I homolog (S. cerevisiae) & Extracellular space & Enzyme \\
\hline$-1.03 \mid$ & P6326I & ACTGI & Actin, gamma I & Cytoplasm & Other \\
\hline-1.027 & O43707 & ACTN4 & Actinin, alpha 4 & Cytoplasm & Other \\
\hline-1.027 & PI3796 & LCPI & Lymphocyte cytosolic protein I (L-plastin) & Cytoplasm & Other \\
\hline-1.027 & E7EUYO & PRKDC & Protein kinase, DNA-activated, catalytic polypeptide & Nucleus & Kinase \\
\hline-1.025 & Q8NC5I & SERBPI & SERPINEI mRNA binding protein I & Cytoplasm & Other \\
\hline-1.025 & Q13263 & TRIM28 & Tripartite motif containing 28 & Nucleus & Transcription regulator \\
\hline-1.023 & Q00610 & CLTC & Clathrin, heavy chain $(\mathrm{Hc})$ & Plasma membrane & Other \\
\hline-1.022 & P40227 & CCT6A & Chaperonin containing TCPI, subunit 6A (zeta I) & Cytoplasm & Other \\
\hline$-1.02 \mid$ & P63104 & YWHAZ & $\begin{array}{l}\text { Tyrosine 3-monooxygenase/tryptophan 5-monooxygenase } \\
\text { activation protein, zeta }\end{array}$ & Cytoplasm & Enzyme \\
\hline-1.02 & P5II49 & RAB7A & RAB7A, member RAS oncogene family & Cytoplasm & Enzyme \\
\hline-1.018 & P25787 & PSMA2 & Proteasome (prosome, macropain) subunit, alpha type, 2 & Cytoplasm & Peptidase \\
\hline-1.016 & P35268 & RPL22 & Ribosomal protein L22 & Nucleus & Other \\
\hline-1.012 & Q04828 & $\begin{array}{l}\text { AKRICI/ } \\
\text { AKRIC2 }\end{array}$ & Aldo-keto reductase family I, member C2 & Cytoplasm & Enzyme \\
\hline-1.01 & P08758 & ANXA5 & Annexin A5 & Plasma membrane & Other \\
\hline$-1.0 \mid$ & Q5VU59 & TPM3 & Tropomyosin 3 & Cytoplasm & Other \\
\hline-1.009 & Q15233 & NONO & Non-POU domain containing, octamer-binding & Nucleus & Other \\
\hline-1.009 & P62258 & YWHAE & $\begin{array}{l}\text { Tyrosine 3-monooxygenase/tryptophan 5-monooxygenase } \\
\text { activation protein, epsilon }\end{array}$ & Cytoplasm & Other \\
\hline-1.008 & P35579 & MYH9 & Myosin, heavy chain 9 , nonmuscle & Cytoplasm & Enzyme \\
\hline-1.005 & $\mathrm{PI} 6144$ & ITGB4 & Integrin, beta 4 & Plasma membrane & Transmembrane receptor \\
\hline-1.001 & Q15149 & PLEC & Plectin & Cytoplasm & Other \\
\hline
\end{tabular}

Abbreviation: PLB, plumbagin.

pathways were EIF2 signaling pathway, regulation of eIF4 and p70S6K signaling, remodeling of epithelial adherens junctions pathway, mTOR signaling pathway, protein ubiquitination pathway, Nrf2-mediated oxidative stress response signaling pathway, epithelial adherens junction signaling pathway, caveolar-mediated endocytosis signaling pathway, RhoA signaling pathway, and oxidative phosphorylation pathway (Table 3). Notably, a number of molecules were involved in cell survival, cell proliferation, redox homeostasis, cell metabolism, cell migration, and cell death, such as p53, CDK1/cdc2, FADD, Nrf2, MAPK, mTOR, p70S6K, E-cadherin, and vimentin.

\section{PLB regulates cell cycle regulators of SCC25 cells}

The cell cycle arresting effect of PLB is considered as a critical contributor to its anticancer activities. We treated SCC25 cells with $5 \mu \mathrm{M}$ PLB for 24 hours, and then, cell samples were subject to quantitative proteomic analysis. The results showed that PLB regulated cell cycle at $G_{2} / M$ 


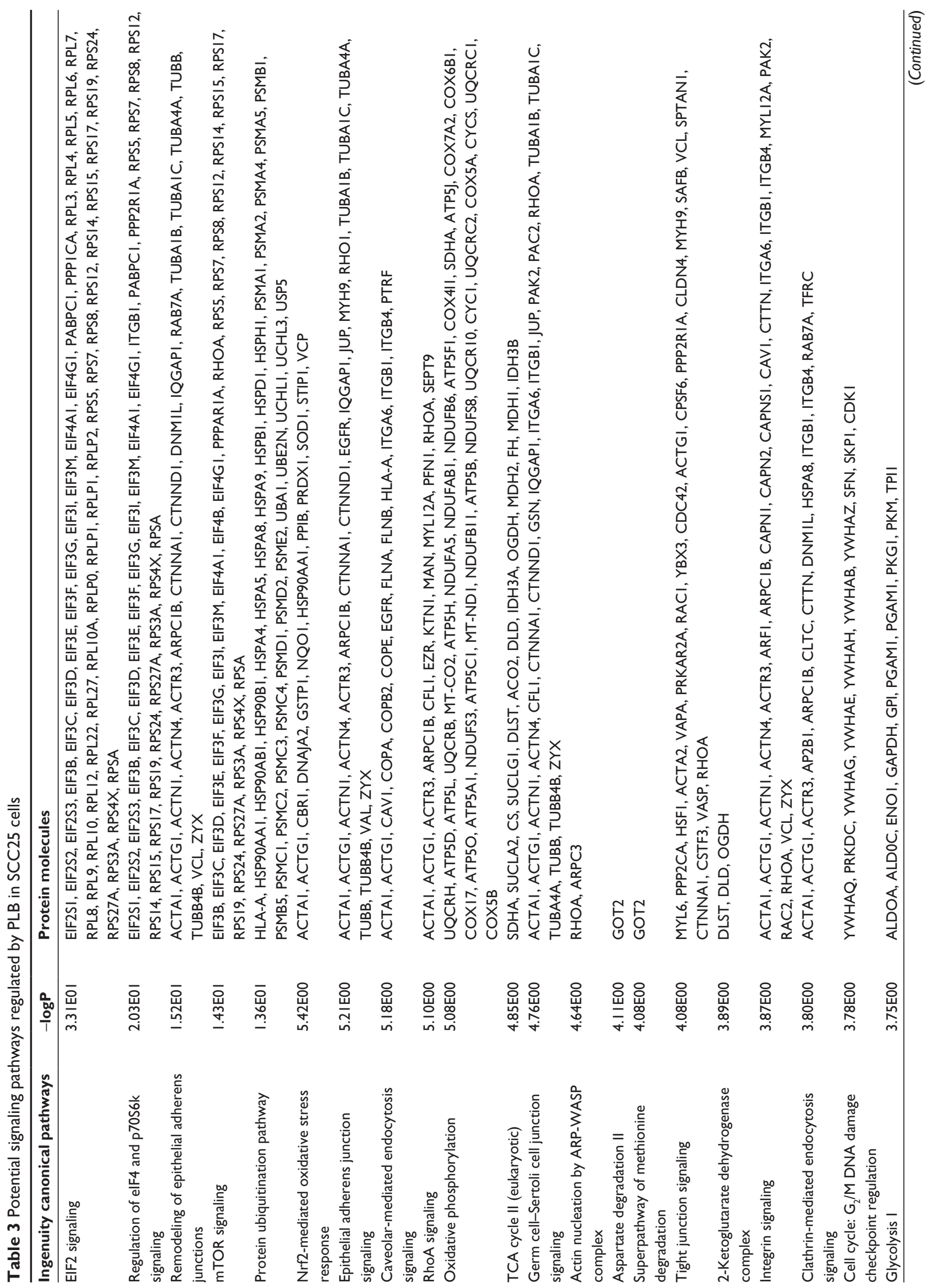




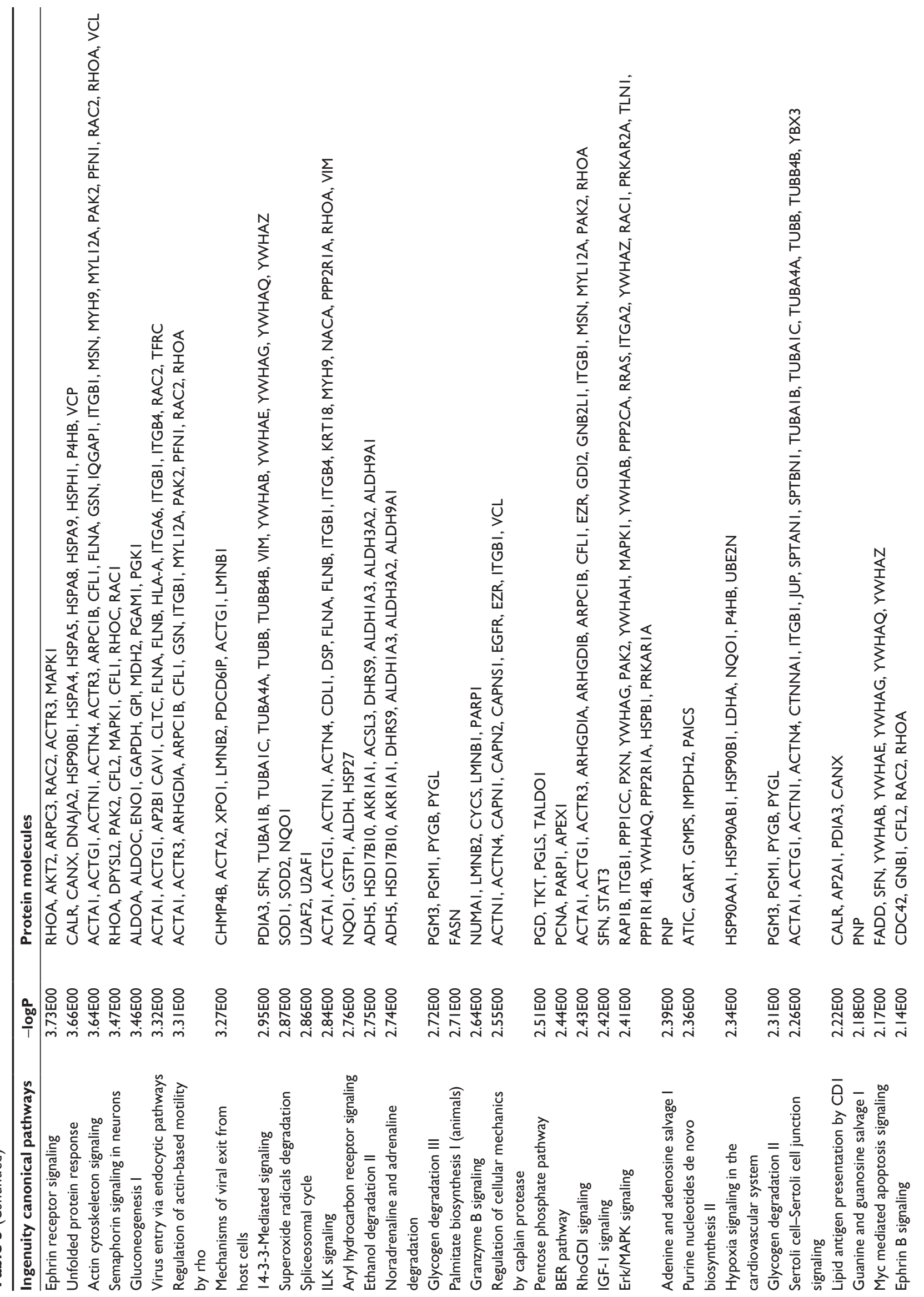




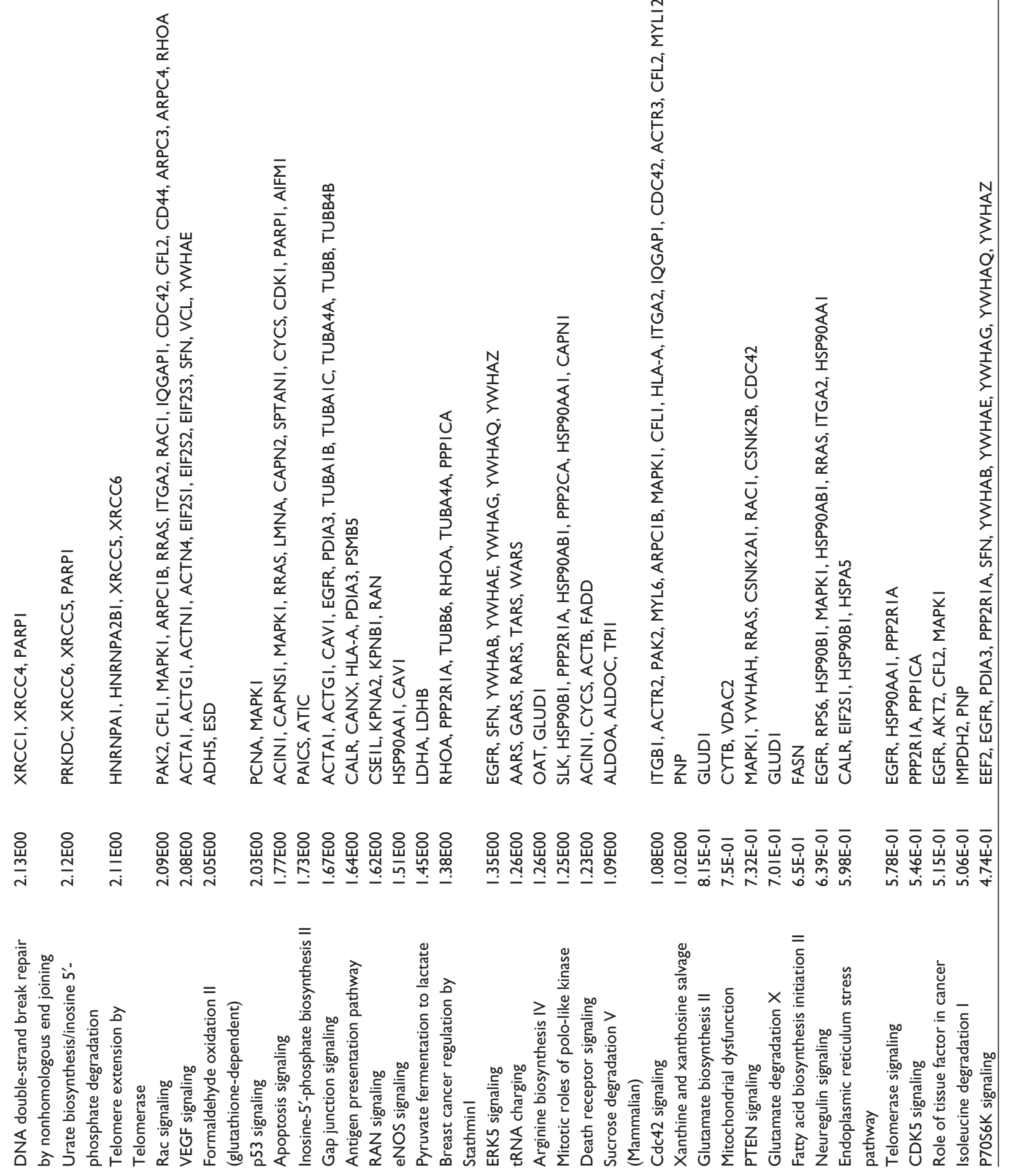




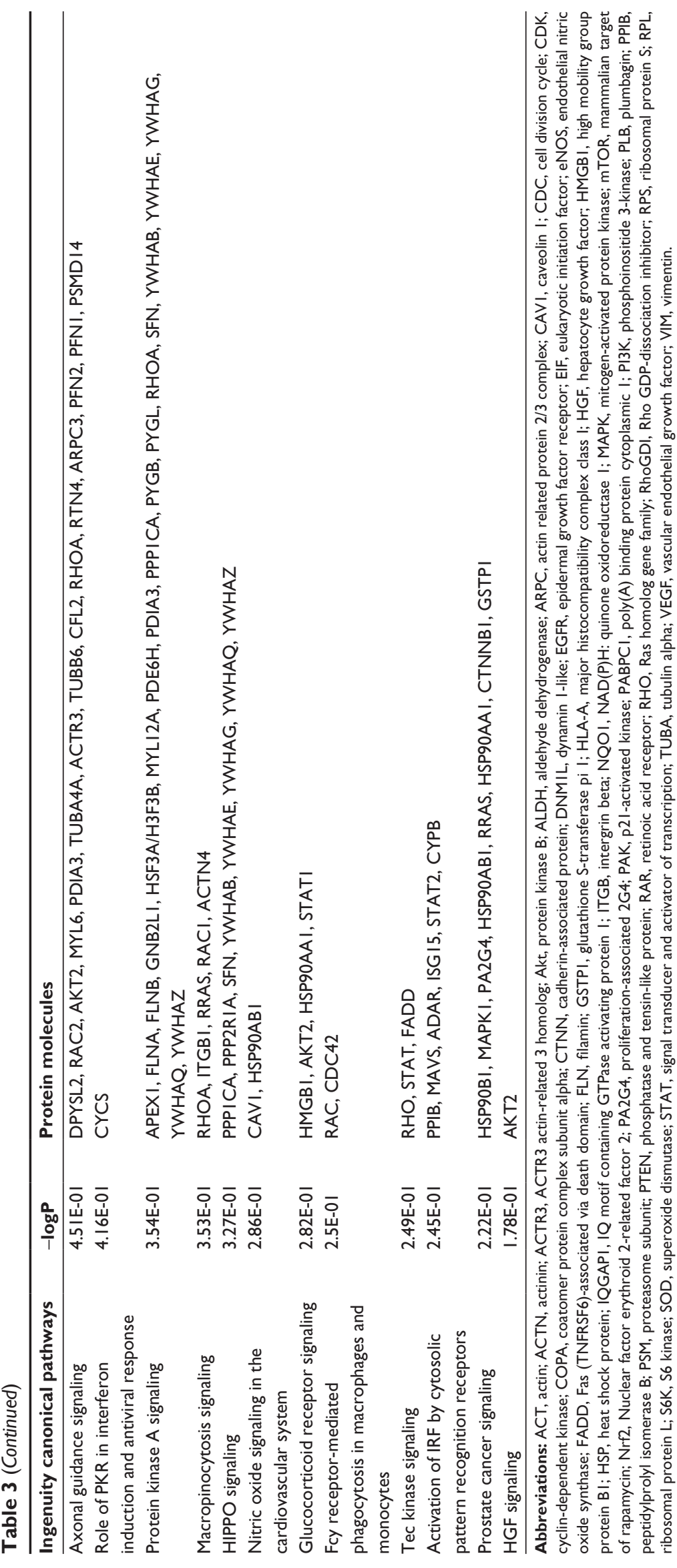




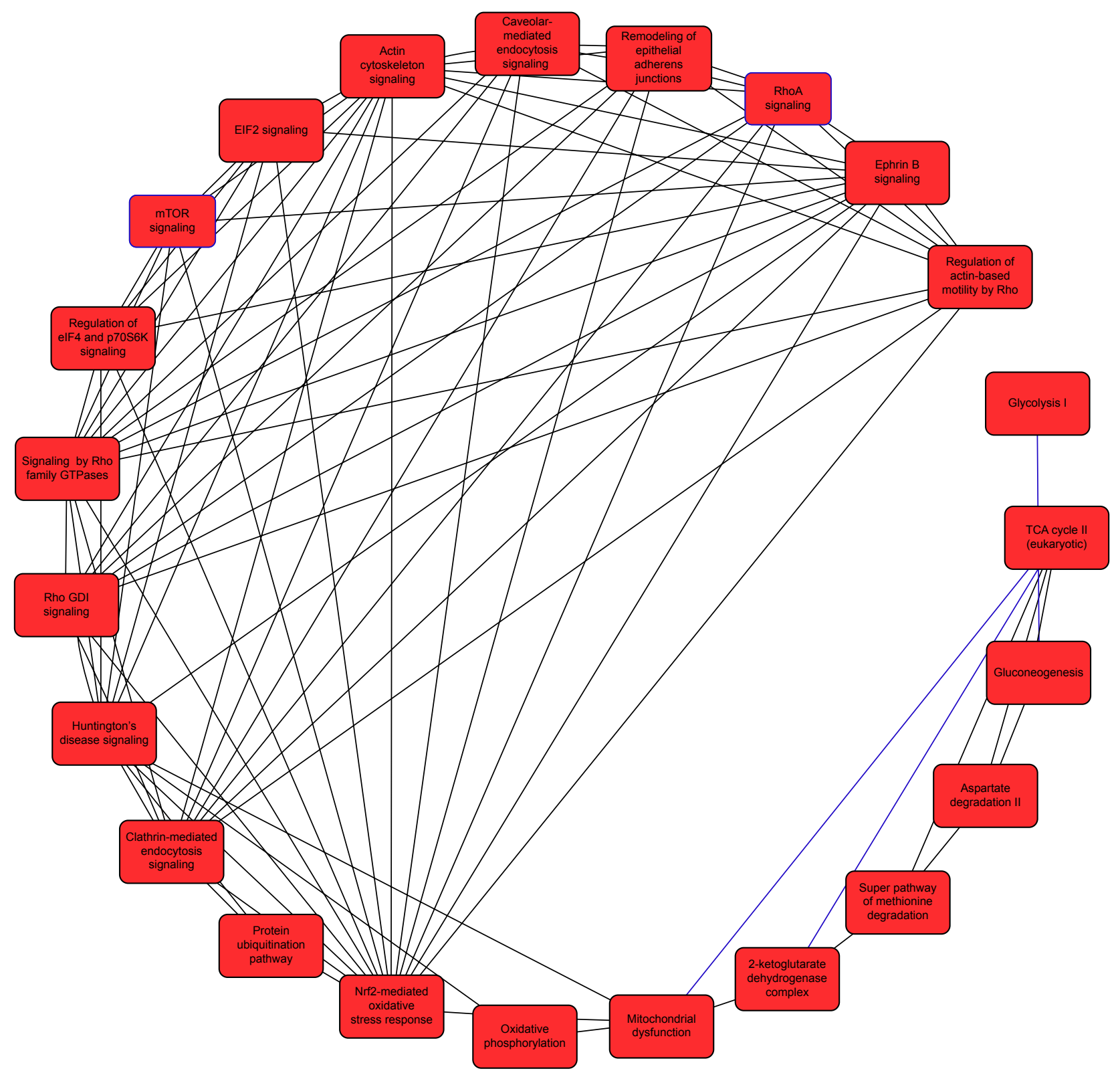

Figure I Proteomic analysis reveals a network of signaling pathways regulated by PLB in SCC25 cells.

Notes: A network of signaling pathways was analyzed by IPA according to the 398 molecules and 101 related pathways that were regulated by PLB in SCC25 cells.

Abbreviations: IPA, Ingenuity Pathway Analysis; PLB, plumbagin.

DNA damage checkpoint in SCC25 cells with the involvement of multiple functional proteins (Table 3). These included YWHAQ, PRKDC, YWHAG, YWHAE, YWHAH, YWHAB, YWHAZ, SFN, SKP1, and CDK1 at $\mathrm{G}_{2} / \mathrm{M}$ checkpoint (Figure 2).

\section{PLB regulates apoptosis in SCC25 cells}

Apoptosis is the type I programmed cell death pathway and has been considered as a promising target for the treatment of cancer either via intrinsic (mitochondrial-mediated) or extrinsic (death receptor-mediated) apoptosis pathways. As listed in Table 3, PLB regulated apoptotic signaling pathway and death receptor signaling pathway involving a number of functional proteins. These included ACIN1, CAPNS1, MAPK1, RRAS, LMNA, CAPN2, SPTAN1, CYCS, CDK1, PARP1, AIFM1, FADD, and ACTB. Moreover, the IPA results showed that $\mathrm{mTOR}$ signaling pathway played a central role in the regulation of cell metabolism, growth, proliferation, and survival through the integration of both intracellular and extracellular signals (Table 3 ). We subsequently investigated extrinsic apoptosis mediated by FADD in SCC25 cells with the treatment of PLB. 


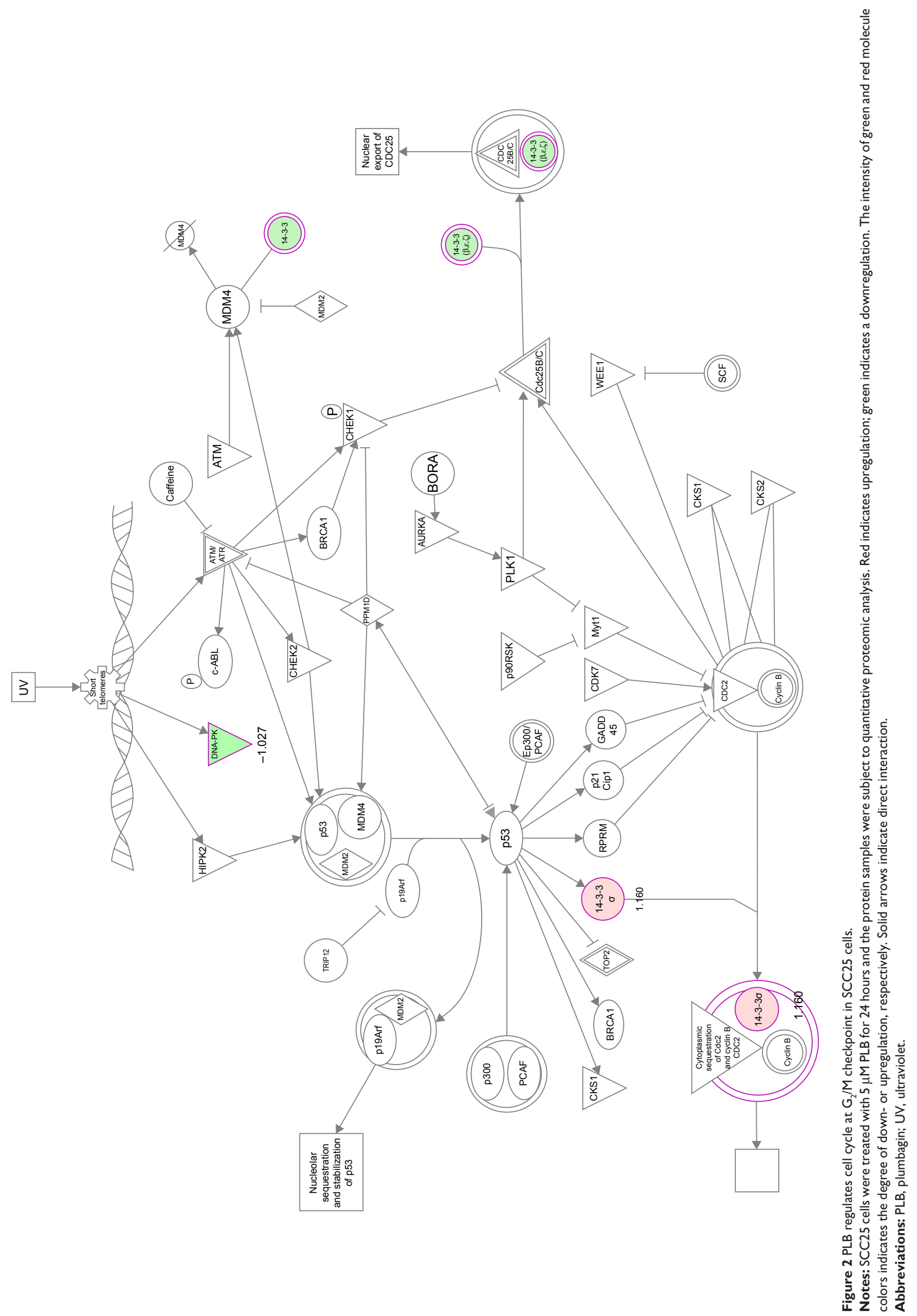

\section{$\frac{0}{\overline{3}}$
$\frac{\mathrm{d}}{0}$
$\frac{\mathrm{E}}{\mathrm{g}}$}




\section{PLB regulates EMT pathways in SCC25 cells}

EMT has a close association with cell migration, invasion, and stemness. Suppressing the progress of EMT is thought to be clinically helpful for cancer therapy. We analyzed the effect of PLB on EMT-related proteins and signaling pathways using SILAC-based proteomic approach. The proteomic data showed that PLB regulated epithelial adherens junction signaling pathway in SCC25 cells involving a number of functional proteins, including ACTA1, ACTG1, ACTN1, ACTN4, ACTR3, ARPC1B, CTNNA1, CTNND1, DNM1L, EGFR, IQGAP1, JUP, MYH9, RAB7A, RHO1, TUBA1B, TUBA1C, TUBA4A, TUBB, TUBB4B, VAL, VCL, and ZYX.

\section{PLB regulates redox homeostasis involving Nrf2-mediated signaling pathways in SCC25 cells}

Induction of ROS generation plays a critical role in the cytokine production, contributing to the cancer cell killing effect of PLB. However, the regulatory effect of PLB on ROS generation-related molecules and signaling pathways has not been fully understood. In this study, we observed that PLB regulated several critical signaling pathways related to ROS generation and redox homeostasis in SCC25 cells. Our quantitative proteomic study showed that PLB treatment regulated Nrf2-mediated oxidative stress response and oxidative phosphorylation in SCC25 cells (Table 2). A number of functional proteins were found to be involved in these pathways, including ACTA1, ACTG1, CBR, DNAJA2, GSTP1, NQO1, HSP90AA1, PPIB, SOD1, STIP1, and VCP (Table 2). Of note, Nrf2-mediated signaling pathways have critical roles in the maintenance of intracellular redox homeostasis in response to various stimuli via regulating antioxidant responsive elements. The quantitative proteomic data suggest that modulation of the expression of functional proteins involved in Nrf2-mediated signaling pathways may contribute to the anticancer effect of PLB in the treatment of TSCC. The results showed that PLB can efficiently induce ROS generation and that this can be abolished by NAC and GSH. Hence, we subsequently studied the relationship of ROS-generation-inducing effect of PLB with other cellular biological functions, including cell cycle arrest, cell apoptosis, and EMT.

\section{Verification of molecular targets of PLB in SCC25 cells by Western blotting assay}

Our aforementioned quantitative proteomic studies have predicted and shown that PLB can modulate a number of signaling pathways and functional proteins related to cell proliferation, cell migration, cell death, and cell survival. On the basis of our previous experimental and present proteomic data in SCC25 cells, we further examined the effect of PLB with a focus on cell cycle, apoptosis, EMT, and redox homeostasis and its related signaling pathways to delineate the underlying mechanisms.

\section{PLB induces $G_{2} / M$ arrest in SCC25 cells via downregulation of cyclin $\mathrm{BI}, \mathrm{CDKI}$ cdc2, and cdc25}

First, we examined the effect of PLB on cell cycle distribution of SCC25 cells using a flow cytometer. PLB markedly induced $\mathrm{a}_{2} / \mathrm{M}$ phase arrest $(P<0.05,0.01$, or 0.001 ; Figure 3). Compared with the control cells $(2.4 \%)$, the percentage of SCC25 cells in $\mathrm{G}_{2} / \mathrm{M}$ phase was increased in a concentration-dependent manner after PLB treatment (Figure $3 \mathrm{~A}$ and $\mathrm{B}$ ). The percentage of cells in $\mathrm{G}_{2} / \mathrm{M}$ phase was $5.8 \%, 9.1 \%$, and $13.1 \%$ when treated with PLB at 0.1 , 1 , and $5 \mu \mathrm{M}$, respectively. On the other hand, PLB significantly decreased the percentage of SCC25 cells in $\mathrm{G}_{1}$ phase when treated with $5 \mu \mathrm{M}$ in comparison to the control cells $(P<0.001 ;$ Figure 3B). In a separate experiment, the effect of $5 \mu \mathrm{M}$ PLB on cell cycle distribution was examined in SCC 25 cells over 48 hours (Figure $3 \mathrm{C}$ and D). Compared to the control cells, the percentage of SCC25 cells in the $\mathrm{G}_{2} / \mathrm{M}$ phase was increased from $2.7 \%$ at basal level to $8.1 \%, 9.4 \%$, and $11.1 \%$ after 6-, 24-, and 48-hour treatment with $5 \mu \mathrm{M}$ PLB, respectively $(P<0.001$; Figure $3 \mathrm{D})$, whereas $5 \mu \mathrm{M}$ PLB treatment decreased the percentage of SCC 25 cells in $\mathrm{G}_{1}$ phase from $48.8 \%$ at basal level to $41.3 \%$ after 48 hours of treatment $(P<0.05$; Figure 3D).

To explore the mechanisms for PLB-induced cell cycle arrest in SCC25 cells, the expression level of key regulators responsible for $\mathrm{G}_{2} / \mathrm{M}$ checkpoint was examined using Western blotting assay. CDK1/cdc2, cyclin B1, and cdc25 are important regulators for $\mathrm{G}_{2}$ to $M$ phase transition and thus their expression level was determined in $\mathrm{SCC} 25$ cells. The expression level of cdc2 was marked suppressed in SCC25 cells after treatment with PLB at concentrations of $0.1,1$, and $5 \mu \mathrm{M}$ for 24 hours $(P<0.001$; Figure 4A and C). Compared with the control cells, the expression level of cyclin B1 was decreased by $18.3 \%, 46.0 \%$, and $62.3 \%$ when SCC 25 cells were treated with $0.1,1$, and $5 \mu \mathrm{M}$ PLB for 24 hours, respectively $(P<0.01$ or 0.001 ; Figure $4 \mathrm{~A}$ and $\mathrm{C}$ ). There was a $10.7 \%, 14.0 \%$, and $35.3 \%$ reduction in the expression level of cdc25 in $\mathrm{SCC} 25$ cells when treated with PLB at $0.1,1$, and $5 \mu \mathrm{M}$ for 24 hours, respectively $(P<0.05,0.01$, or 0.001 ; Figure $4 \mathrm{~A}$ and $\mathrm{C})$. 

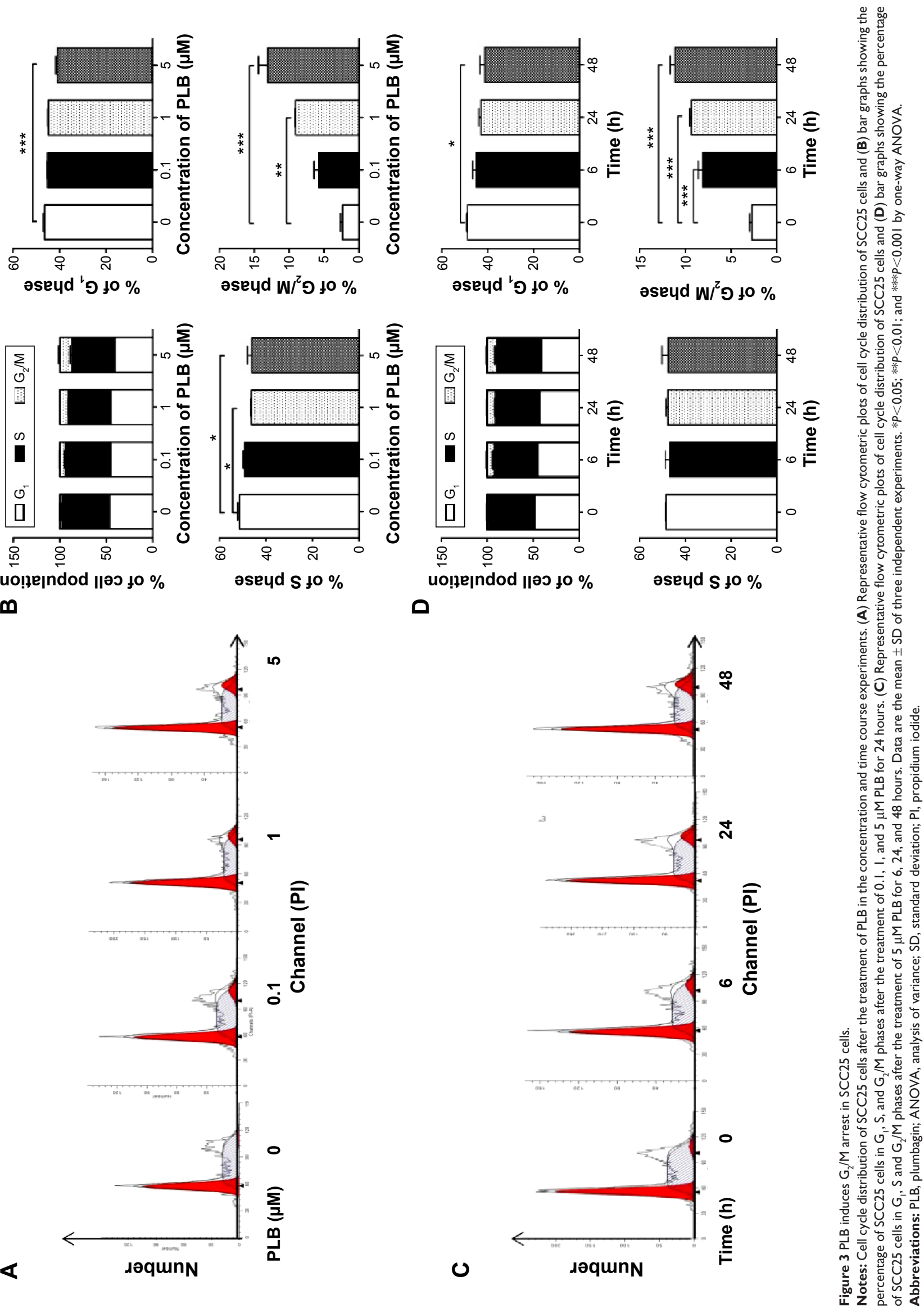

$\boldsymbol{m}$
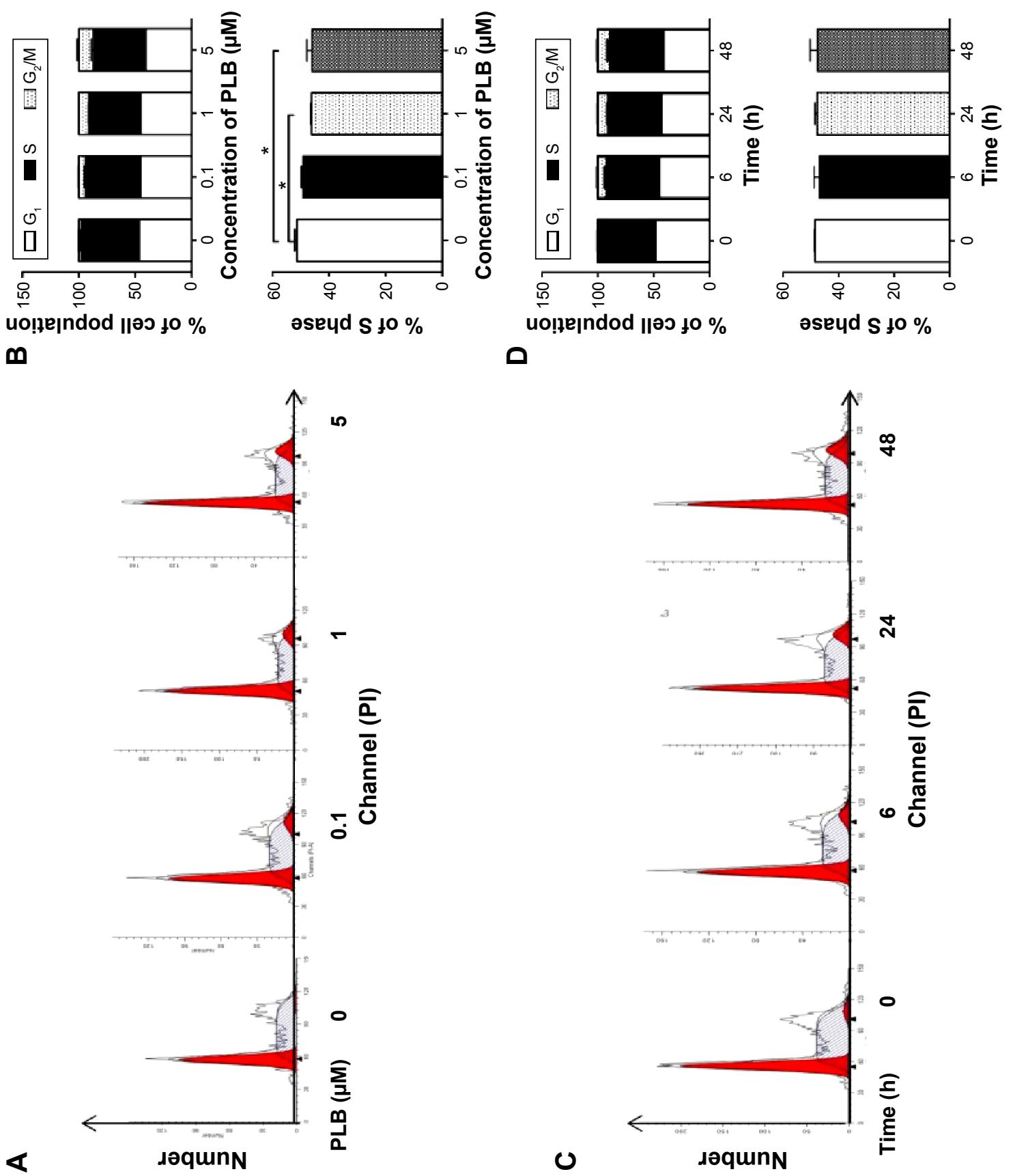

.


Next, we conducted separate experiment over 48 hours. In comparison to the control cells, the expression level of cdc2 was decreased by $18.3 \%$ and $19.0 \%$ when SCC 25 cells were treated with $5 \mu \mathrm{M}$ PLB for 24 and 48 hours, respectively $(P<0.001$; Figure 4B and D); there was a $34.3 \%$ and $49.3 \%$ reduction in the expression level of cyclin B1 when SCC25 cells were incubated with $5 \mu \mathrm{M}$ PLB for 24 and 28 hours, respectively $(P<0.001$; Figure 4B and D); and the expression level of cdc25 was also markedly suppressed $(P<0.01$ or 0.001 ; Figure $4 \mathrm{~B}$ and $\mathrm{D})$. These results demonstrate that PLB downregulates cyclin B1, CDK1/cdc2, and cdc25 in $\mathrm{SCC} 25$ cells. Importantly, these results have confirmed the regulatory effect of PLB on cell proliferation-related signaling pathways, which was predicted by our proteomic studies.

\section{PLB induces apoptosis via FADD- mediated extrinsic signaling pathway}

Apoptosis is a typical type of programmed cell death that plays an important role in PLB-induced cancer cell death. Previously, we observed that PLB significantly induced intrinsic apoptosis in $\mathrm{SCC} 25$ cells in a concentration- and time-dependent manner. ${ }^{20}$ On the basis of the results hinted at by the proteomic results
A

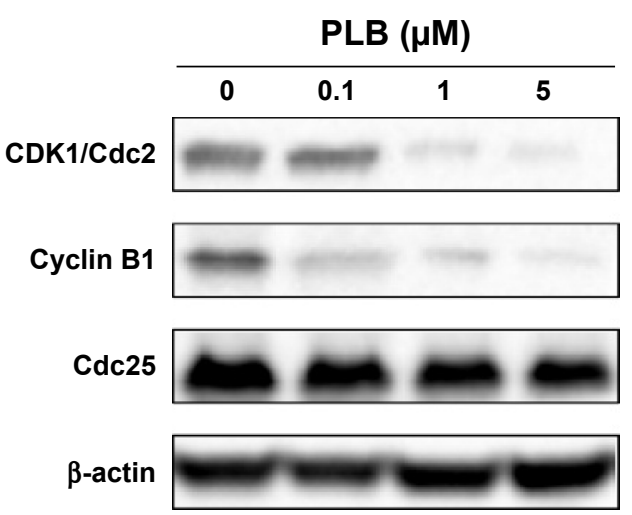

B

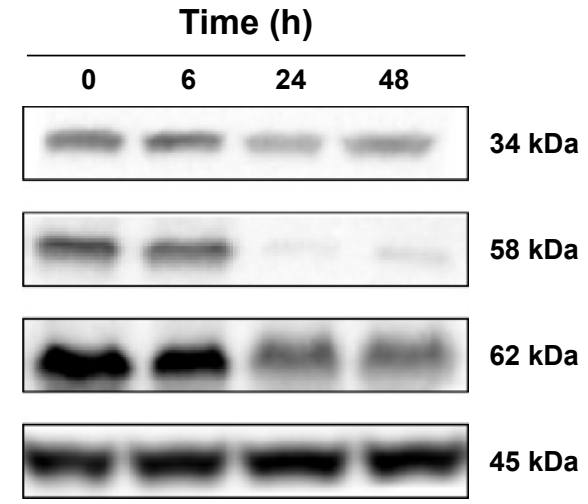

C

PLB $(\mu \mathrm{M})$
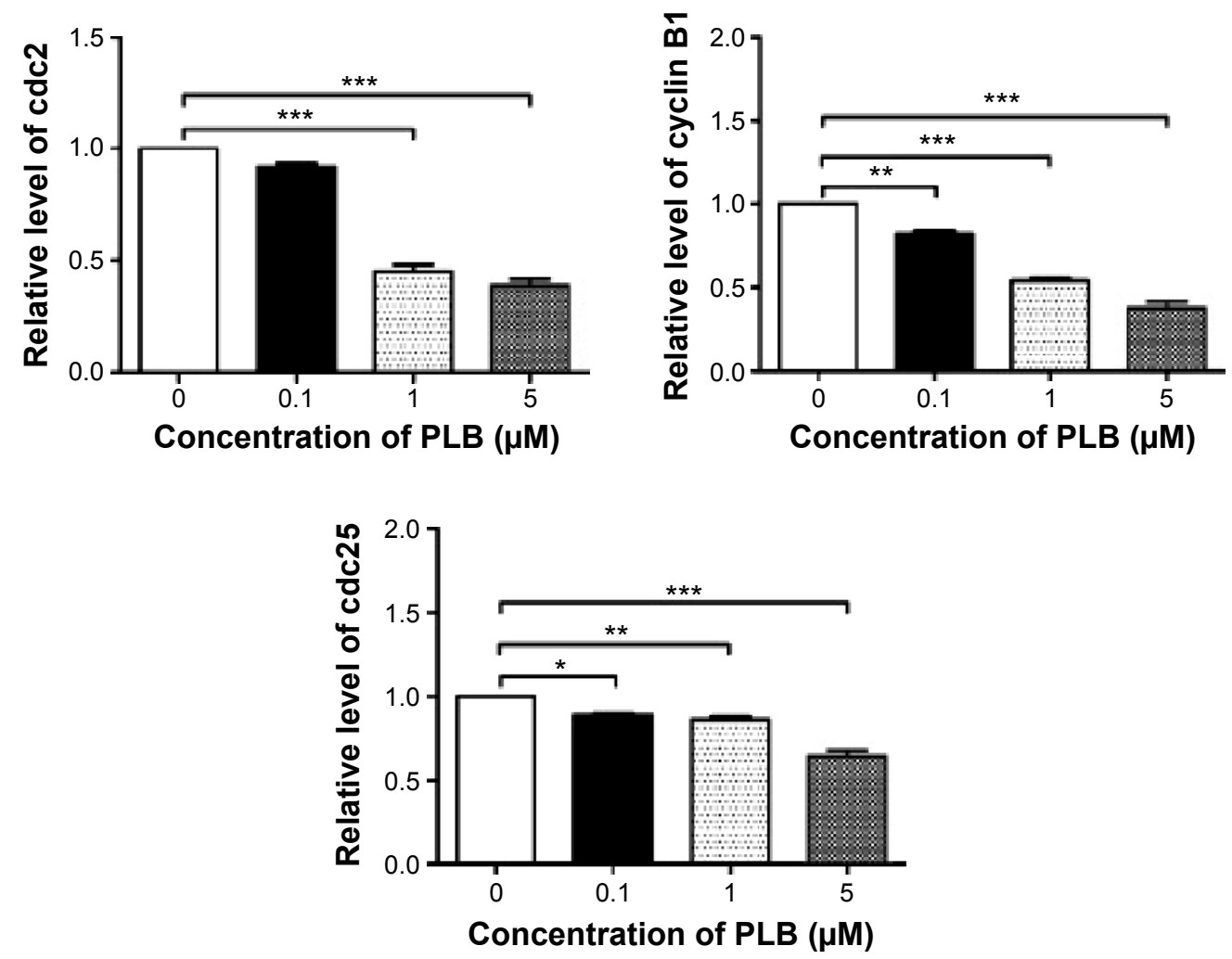

Figure 4 (Continued) 
D

Time (h)
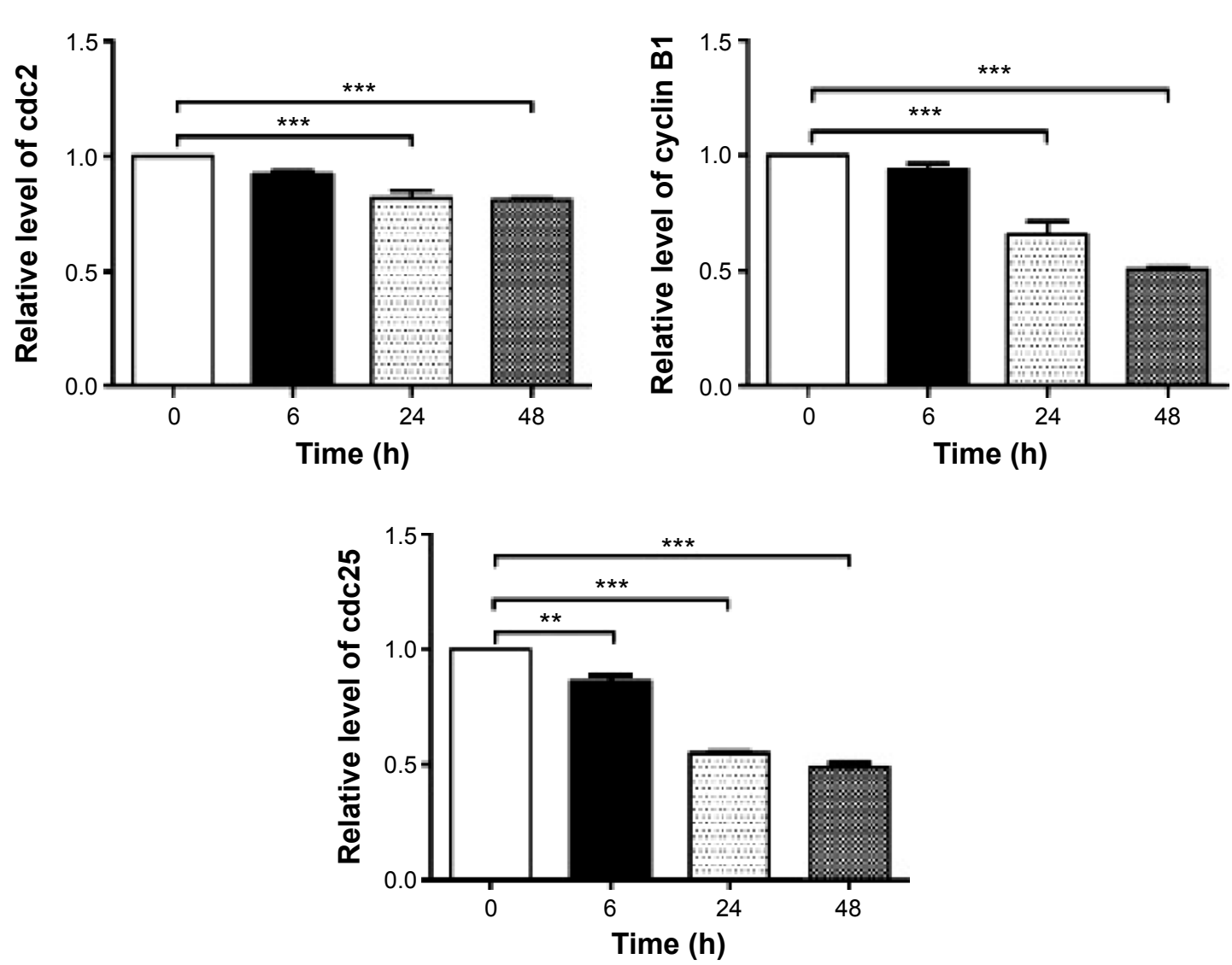

Figure 4 PLB regulates the expression of CDKI/cdc2, cyclin BI, and cdc25 in SCC25 cells.

Notes: SCC25 cells were treated with PLB in the concentration and time course experiments and the protein samples were subject to Western blotting assay. (A) Representative blots of CDKI/cdc2, cyclin BI, and cdc25 in SCC25 cells after the treatment of 0.1 , I, and $5 \mu \mathrm{M}$ PLB for 24 hours, and (B) representative blots of CDKI/cdc2, cyclin BI, and cdc25 in SCC25 cells after the treatment of $5 \mu$ M PLB for 6, 24, and 48 hours. (C) Bar graphs showing the relative levels of CDKI/cdc2, cyclin BI, and cdc25 in SCC25 cells after the treatment of $0.1, \mathrm{I}$, and $5 \mu \mathrm{M}$ PLB for 24 hours, and (D) bar graphs showing the relative level of CDKI/cdc2, cyclin BI, and cdc25 in SCC25 cells after the treatment of $5 \mu \mathrm{M}$ PLB for 6,24 , and 48 hours. Data are the mean \pm SD of three independent experiments. $* P<0.05$; $* * P<0.01$; and $* * * P<0.00$ I by one-way $A N O V A$.

Abbreviations: PLB, plumbagin; ANOVA, analysis of variance; SD, standard deviation.

(Figure 5), we further tested the apoptosis inducing effect of PLB with a focus on FADD-mediated signaling pathway. First, we employed flow cytometry to analyze the apoptosis-inducing effect of PLB in SCC25 cells. Subsequently, the modulation effect of PLB on the expression of FADD, TRADD, DR5, and cleaved caspase 3 in SCC25 cells was measured with a consideration to fully understand the apoptosis-inducing effect of PLB via FADD-mediated extrinsic signaling pathway. Cells were treated with PLB at concentrations of $0.1,1$, and $5 \mu \mathrm{M}$ for 24 hours. The apoptosis level was increased from $3.0 \%$ to $6.1 \%, 8.2 \%$, and $20.3 \%$ when SCC25 cells were treated with $0.1,1$, and $5 \mu \mathrm{M}$ for 24 hours, respectively $(P<0.05,0.01$, or 0.001 ; Figure $6 \mathrm{~A}$ and $\mathrm{B}$ ). Next, we conducted the time course experiment, and the results showed that the apoptosis level was increased from $3.5 \%$ at basal level to $11.4 \%, 21.2 \%$, and $35.7 \%$ when SCC25 cells were treated with $5 \mu \mathrm{M}$ PLB for 6 , 24 , and 48 hours, respectively ( $P<0.001$; Figure 6C and D).
Furthermore, There was a 1.3- and 1.6-fold increase in the expression level of FADD after SCC25 cells were treated with 1 and $5 \mu \mathrm{M}$ PLB for 24 hours, respectively $(P<0.01$ or 0.001 ; Figure 7A and C). The expression level of TRADD and DR5 was also increased when cells were treated with PLB $(P<0.01$ or 0.001 ; Figure 7A and C). The cleavage of caspase 3 is the determinant process in both intrinsic and extrinsic apoptosis. We found that PLB markedly increased the level of cleaved caspase 3 to 1.2- and 1.3-fold when SCC25 cells were treated with 1 and $5 \mu \mathrm{M}$ for 24 hours, respectively $(P<0.01$ or 0.001 ; Figure $7 \mathrm{~A}$ and $\mathrm{C}$ ). In a separate experiment, we examined the apoptosis-inducing effect of PLB over 48 hours. The expression level of FADD was increased 1.5-, 1.5-, and 1.6-fold when SCC25 cells were treated with $5 \mu \mathrm{M}$ for 6,24 , and 48 hours, respectively $(P<0.001$; Figure 7B and D). The expression level of DR5 was also markedly increased in comparison with the control cells $(P<0.05$ or 0.001 ; Figure 7B and D). Meanwhile, 


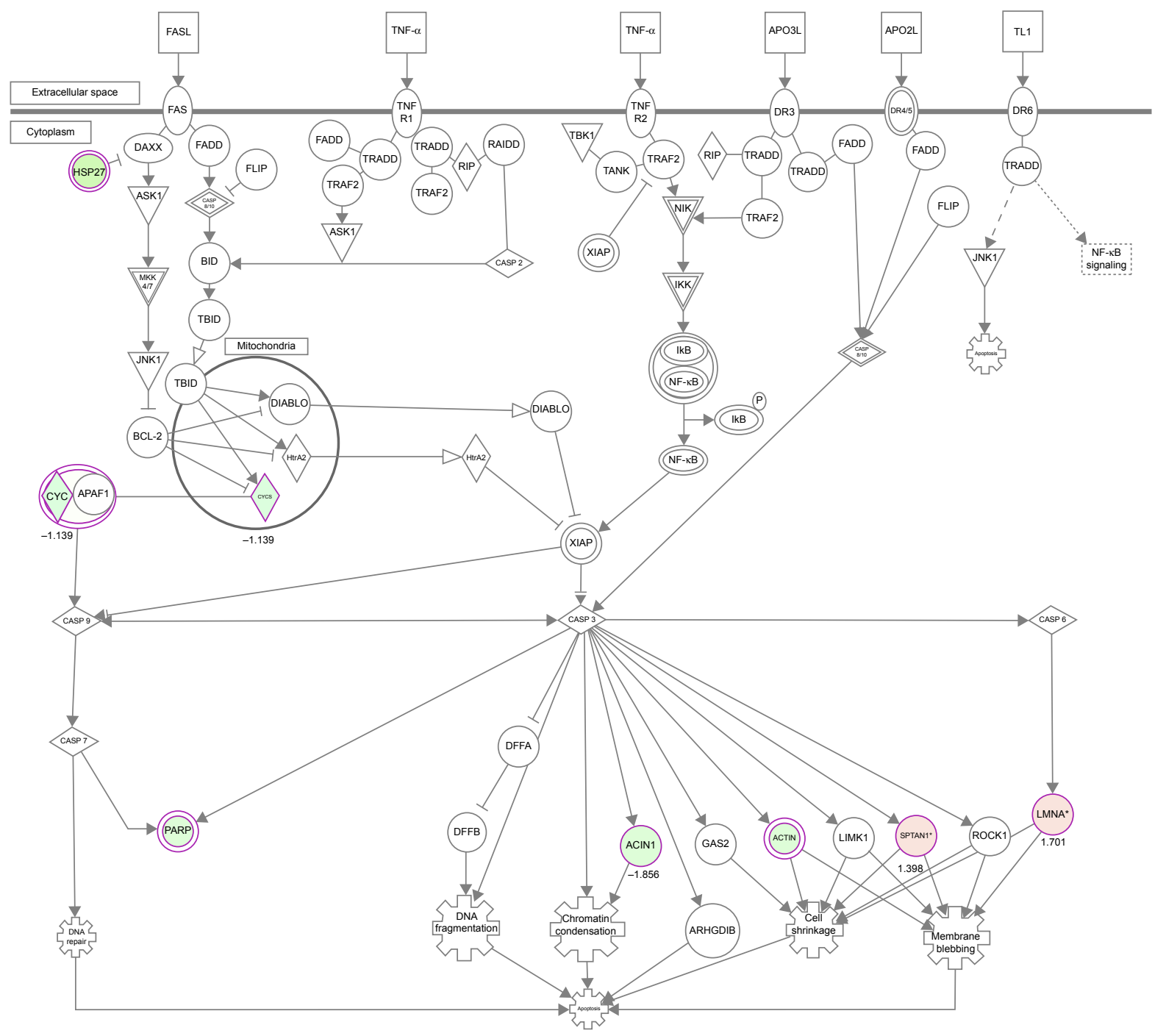

Figure 5 PLB regulates death receptor signaling in SCC25 cells.

Notes: SCC25 cells were treated with $5 \mu$ M PLB for 24 hours and the protein samples were subject to quantitative proteomic analysis. Red indicates upregulation; green indicates downregulation. The intensity of green and red molecule colors indicates the degree of down- or upregulation, respectively. Solid arrows indicate direct interaction and dashed arrows indicate indirect interaction. The arrow with white head indicates translocation. The arrow with gray head indicates activation, causation, expression, localization, membership, modification, molecular cleavage, phosphorylation, protein-DNA interactions, protein-RNA interactions, regulation of binding, transcription. Abbreviation: PLB, plumbagin.

there was a 1.1-, 1.3-, and 1-2 fold rise in the expression level of cleaved caspase 3 , when SCC25 cells were treated with $5 \mu \mathrm{M}$ PLB for 6, 24, and 48 hours, respectively $(P<0.01$ or 0.001 ; Figure 7B and D). The expression level of TRADD was also remarkably increased when SCC25 cells were treated with $5 \mu \mathrm{M}$ PLB for 48 hours. These results clearly show that PLB induces apoptosis by involving the FADD-mediated extrinsic pathway in SCC25 cells, and these data are in agreement with our proteomic findings.

\section{PLB inhibits EMT and stemness in SCC25 cells}

EMT is a critical process involved in the invasion, metastasis, and stemness of cancer. ${ }^{35}$ EMT depends on a reduction in expression of cell adhesion molecules. Tight junctions function as complete barriers between epithelium and endothelium and contribute to the maintenance of cell polarity. Claudin and occludin proteins are integral structural and functional components of tight junctions. ${ }^{36,37} \mathrm{ZO}-1,2$, and 3 are peripheral membrane adaptor proteins that link junctional transmembrane proteins to the actin cytoskeleton. ${ }^{38-40}$ Cadherins are a superfamily of transmembrane glycoproteins, which include $\mathrm{N}-, \mathrm{P}-, \mathrm{R}-, \mathrm{B}-$, and E-cadherins. ${ }^{41}$ E-cadherin is considered an active suppressor of invasion in many epithelial cancers. ${ }^{42}$ Cancer cells often have upregulated $\mathrm{N}$-cadherin in addition to loss of E-cadherin. ${ }^{43}$ Furthermore, the cytoplasmic domain of classical cadherins interacts with $\beta$-catenin, $\gamma$-catenin, and p120 catenin. ${ }^{44,45}$ It is reported that snail can interact with 


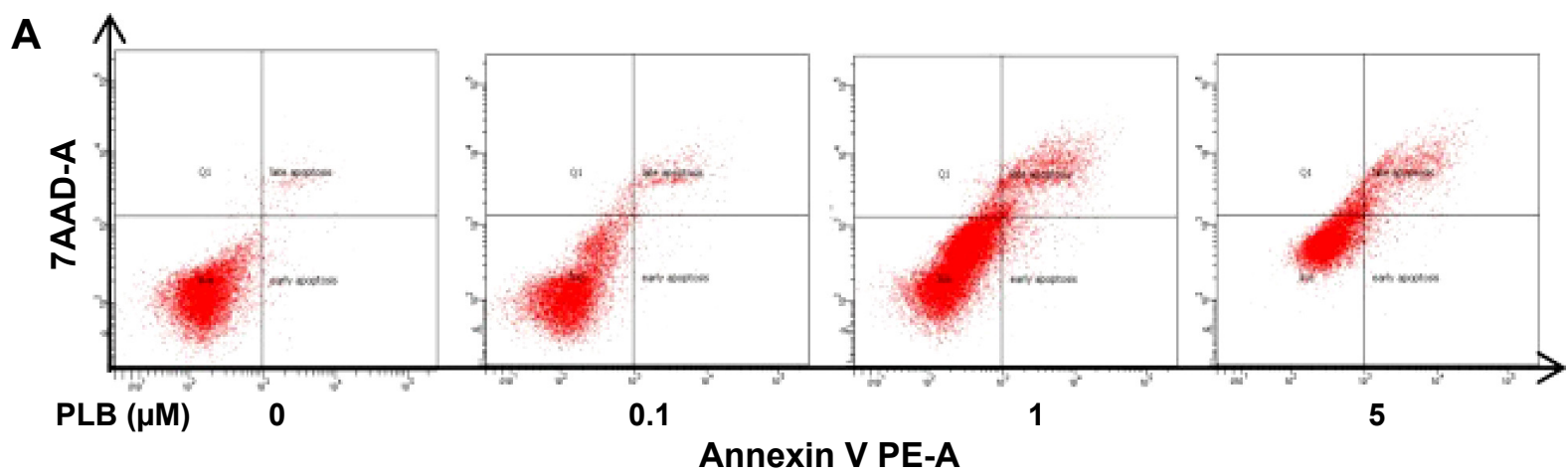

B
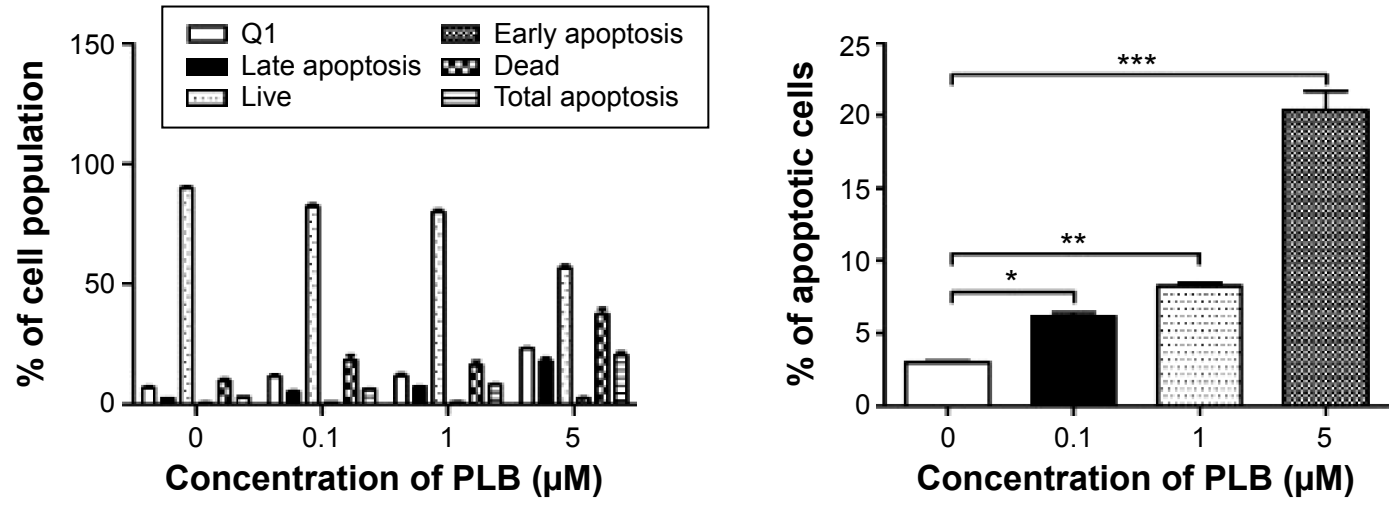

C

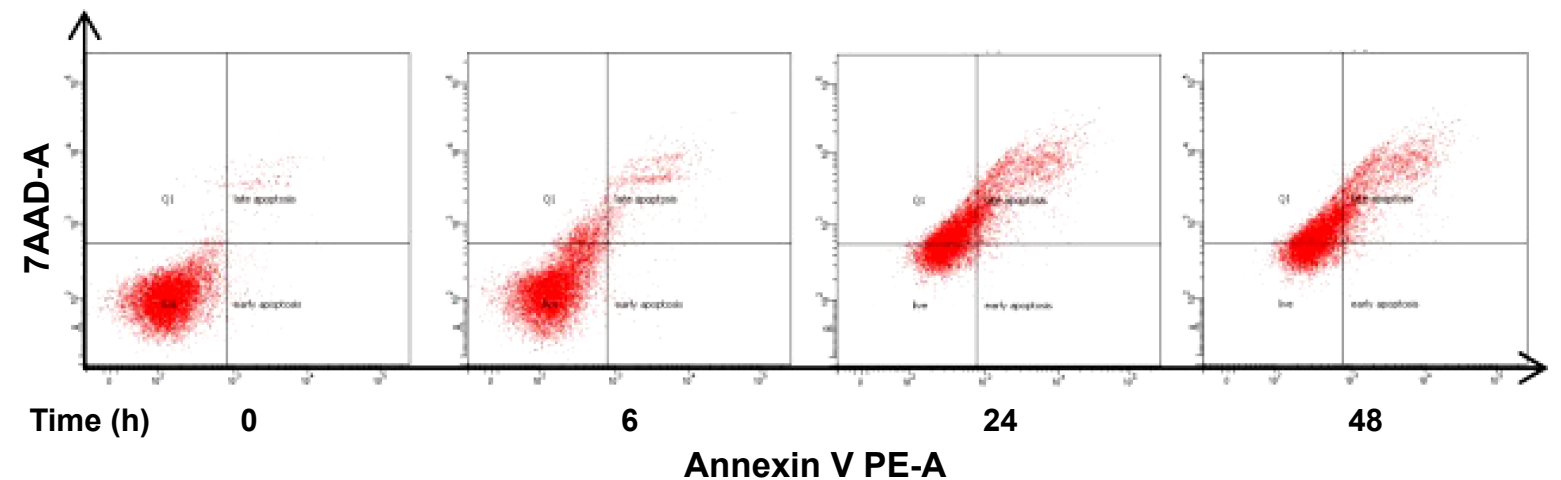

D
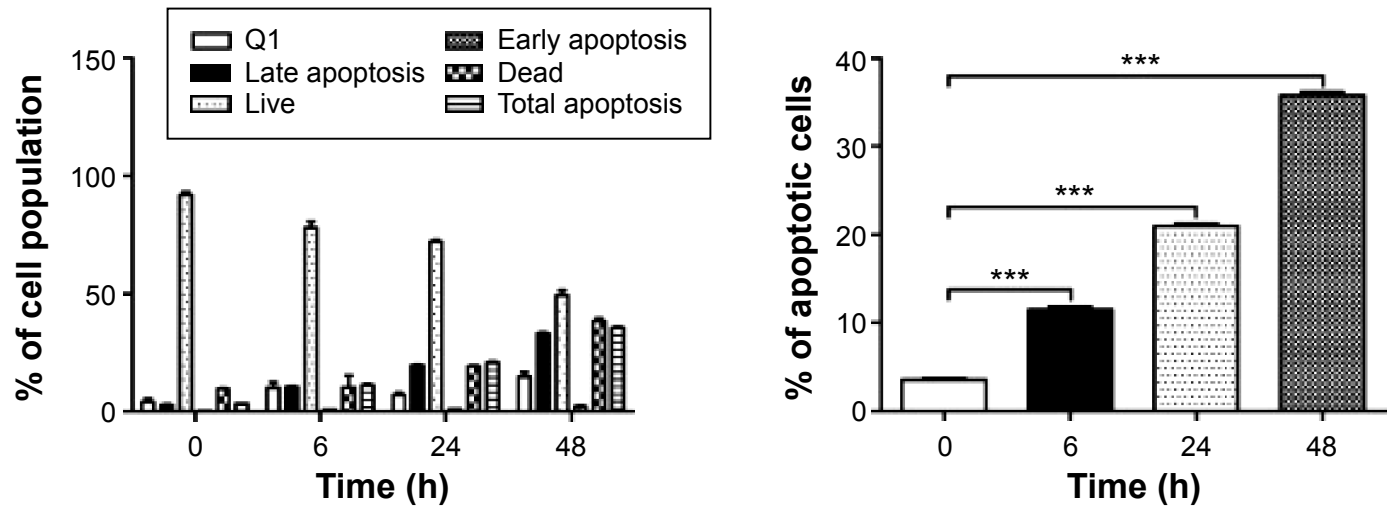

Figure 6 PLB induces apoptosis in SCC25 cells.

Notes: Apoptosis induction effect of PLB in SCC25 cells was examined. (A) Representative flow cytometric plots of apoptosis in SCC25 cells and (B) bar graphs showing the percentage of total apoptosis in SCC25 cells after the treatment of 0.1 , I, and $5 \mu$ M PLB for 24 hours. (C) Representative flow cytometric plots of apoptosis in SCC25 cells and (D) bar graphs showing the total apoptosis in SCC25 cells after the treatment of $5 \mu$ M PLB for 6,24 , and 48 hours. Data are the mean \pm SD of three independent experiments. $* P<0.05 ; * * P<0.01$; and $* * * P<0.001$ by one-way ANOVA.

Abbreviations: PLB, plumbagin; ANOVA, analysis of variance; SD, standard deviation. 
$\beta$-catenin via Wnt signaling pathway. ${ }^{46}$ Herein, on the basis of the proteomic results (Figure 8), we verified the effect of PLB treatment on EMT-associated markers in SCC25 cells using Western blotting assay. Incubation of SCC25 cells with PLB resulted in a concentration- and time-dependent increase in the expression level of E-cadherin and a decrease in the expression level of N-cadherin (Figure 9A-D). There was a 1.2- and 1.8-fold increase in the expression of E-cadherin when treated with 1 and $5 \mu \mathrm{M}$ PLB for 24 hours, respectively, whereas $5 \mu \mathrm{M}$ PLB suppressed expression level of $\mathrm{N}$-cadherin $23 \%(P<0.05$ or 0.001 ; Figure $9 \mathrm{~A}$ and $\mathrm{C})$. When SCC25 cells were treated with $5 \mu \mathrm{M}$ PLB over 48 hours, the expression level of E-cadherin was increased 1.2-, 1.4-, and 1.8-fold after the treatment of $5 \mu \mathrm{M}$ PLB for 6, 24, and 48 hours, respectively $(P<0.01$ or 0.001 ; Figure 9B and D). The expression level of $\mathrm{N}$-cadherin was decreased by $23.3 \%$ and $45.0 \%$ when SCC 25 cells were treated with $5 \mu \mathrm{M}$ PLB for 24 and 48 hours, respectively $(P<0.05$ or 0.001 ; Figure $9 \mathrm{~B}$ and $\mathrm{D})$.
A

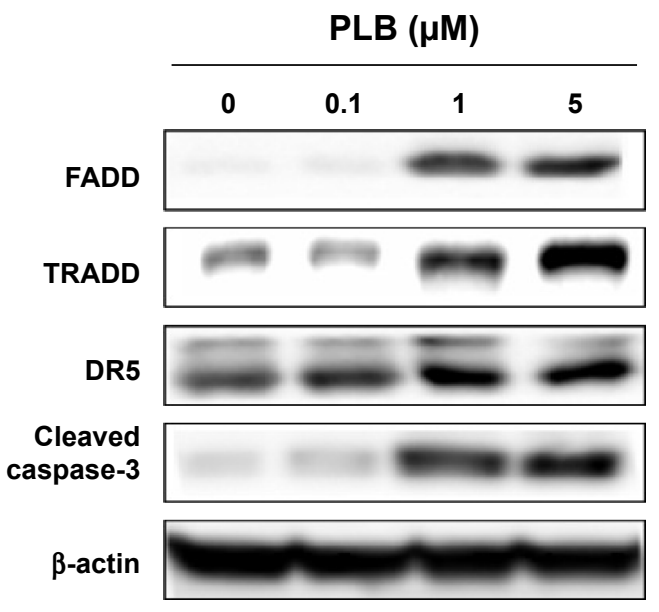

B

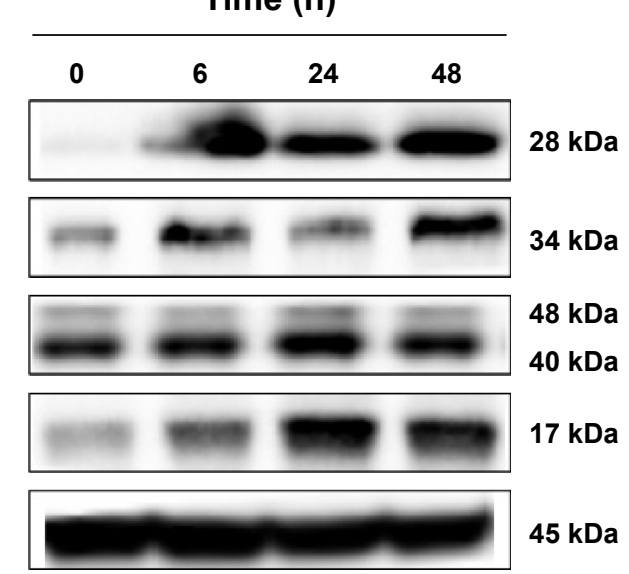

C
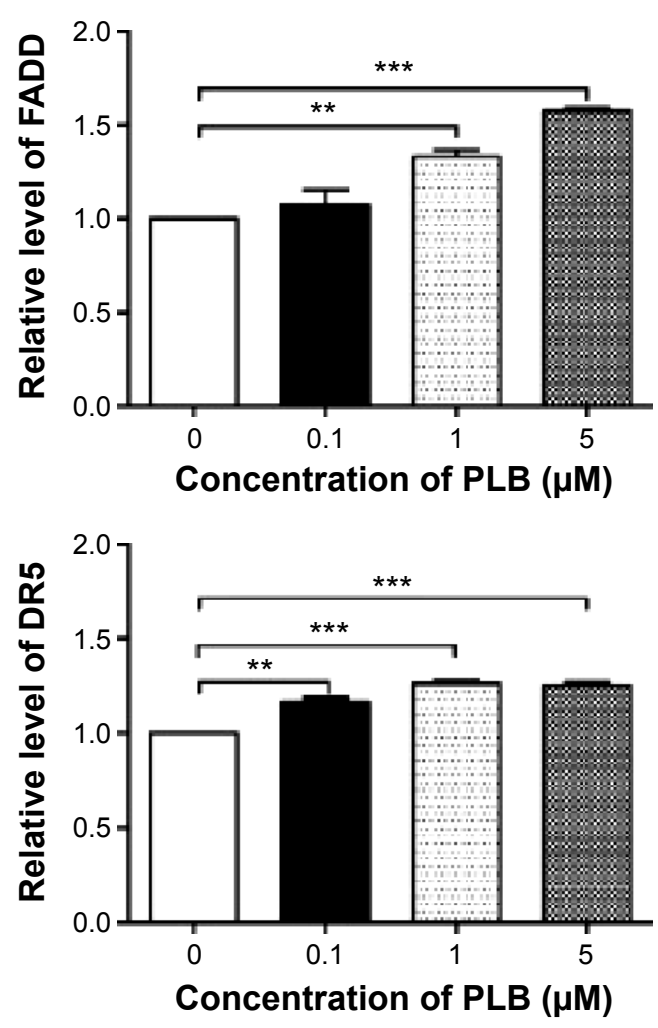

PLB $(\mu \mathrm{M})$
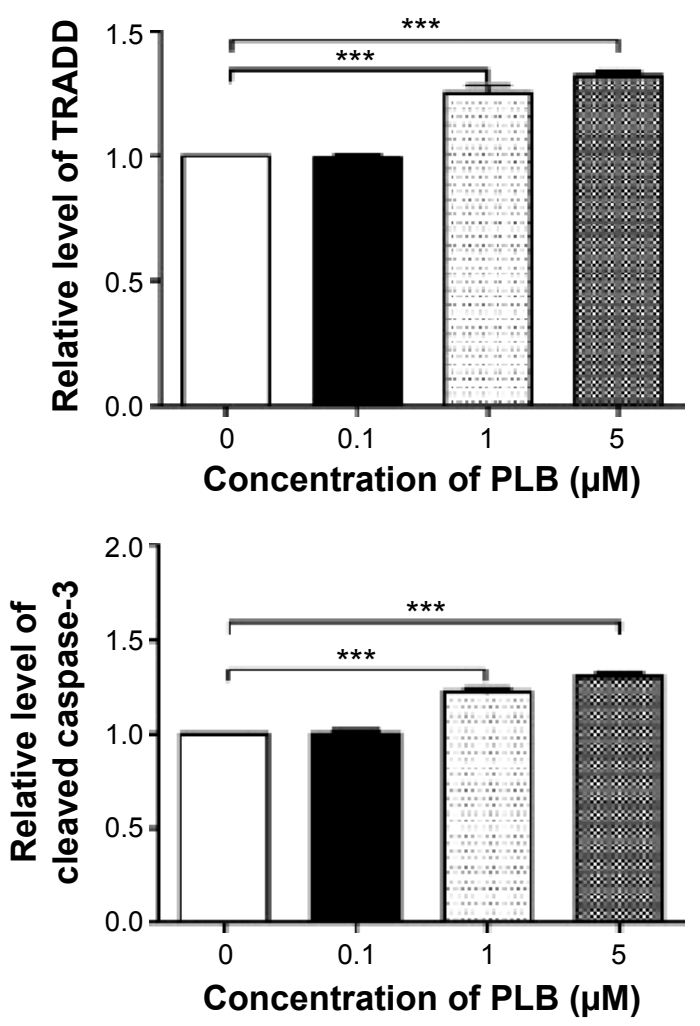

Figure 7 (Continued) 


\section{D}

Time (h)
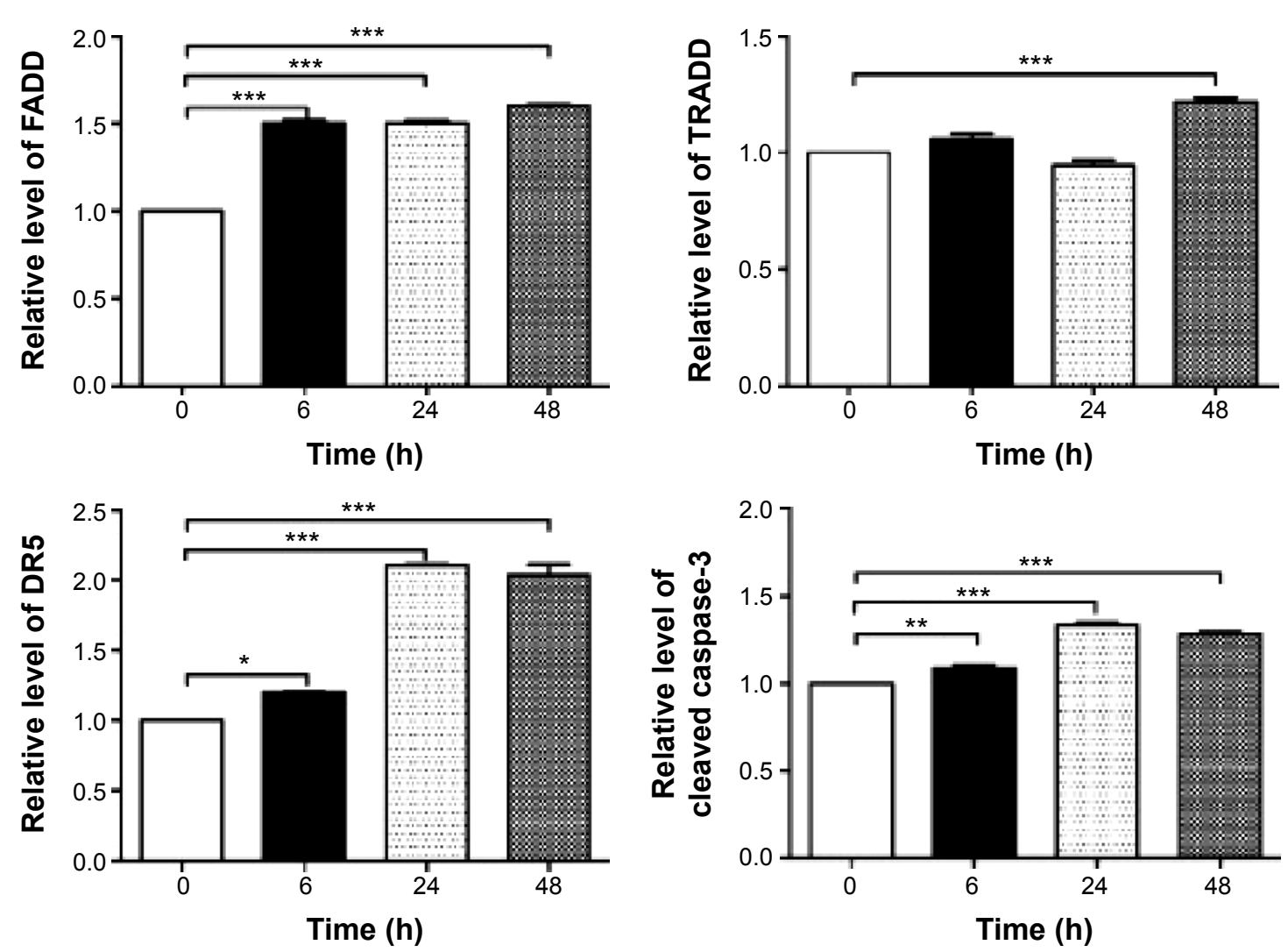

Figure 7 PLB regulates the expression of FADD, TRADD, and DR5 in SCC25 cells.

Notes: SCC25 cells were treated with PLB in the concentration and time course experiments and protein samples were subject to Western blotting assay. (A) Representative blots of FADD, TRADD, and DR5 in SCC25 cells after the treatment of 0.1 , I, and $5 \mu$ M PLB for 24 hours, and (B) representative blots of FADD, TRADD, and DR5 in SCC25 cells after the treatment of $5 \mu$ M PLB for 6, 24, and 48 hours. (C) Bar graphs showing the relative level of FADD, TRADD, and DR5 in SCC25 cells after the treatment of $0 . \mathrm{I}, \mathrm{I}$, and $5 \mu \mathrm{M}$ PLB for 24 hours, and (D) bar graphs showing the relative level of FADD, TRADD, and DR5 in SCC25 cells after the treatment of $5 \mu$ M PLB for 6,24 , and 48 hours. Data are the mean $\pm S D$ of three independent experiments. $* P<0.05$; $* * P<0.01$; and $* * * P<0.001$ by one-way ANOVA.

Abbreviations: PLB, plumbagin; ANOVA, analysis of variance; SD, standard deviation; FADD, Fas (TNFRSF6)-associated via death domain; TRADD, TNFI receptorassociated death domain.

In order to further examine the effect of PLB on EMT in SCC25 cells, we measured the expression level of several key regulators of E-cadherin. Snail and slug (both zinc finger transcriptional factors) together with TCF8/ZEB1 are suppressors of E-cadherin in EMT. PLB significantly reduced the expression level of snail and slug in SCC25 (Figure 9A and C). When SCC25 cells were treated with $5 \mu \mathrm{M}$ PLB for 24 hours, the expression level of snail and slug was decreased by $46 \%$ and $41 \%$, respectively (Figure $9 \mathrm{~A}$ and C). Furthermore, PLB induced a time-dependent reduction in the expression level of TCF-8/ZEB1 in SCC25 cells. The expression level of TCF-8/ZEB1 was decreased by $22.0 \%, 27.0 \%$, and $70.3 \%$ when SCC25 cells were treated with $5 \mu \mathrm{M}$ PLB for 6,24 , and 48 hours, respectively (Figure 9B and D).

Vimentin is a type III intermediate filament protein in mesenchymal cells. $\beta$-Catenin can act as an integral component of a protein complex in adherens junctions that helps cells maintain epithelial layers, and $\beta$-catenin participates in the Wnt signaling pathway as a downstream target. In SCC 25 cells, PLB inhibited the expression of vimentin in a concentration- and time-dependent manner. The expression level of vimentin was decreased by $19.3 \%$ and $24.7 \%$ when cells were treated with 1 and $5 \mu \mathrm{M}$ PLB for 24 hours, respectively $(P<0.01$; Figure $9 \mathrm{~A}$ and $\mathrm{C})$. Consistently, the expression level of vimentin was decreased by $21.0 \%$ and $51.3 \%$ when SCC25 cells were incubated with $5 \mu \mathrm{M}$ PLB for 24 and 48 hours, respectively $(P<0.01$ or 0.001 ; Figure $9 \mathrm{~B}$ and $\mathrm{D})$. There was also a significant reduction in the expression level of $\beta$-catenin in both the concentration and time course experiment when SCC25 cells were treated with $5 \mu \mathrm{M}$ PLB. PLB at $5 \mu \mathrm{M}$ markedly decreased the expression level of $\beta$-catenin by $24.7 \%$ with a 24 -hour incubation period $(P<0.01$; Figure $9 \mathrm{~A}$ and $\mathrm{C})$. Finally, the expression of tight junction proteins $\mathrm{ZO}-1$ and claudin-1 

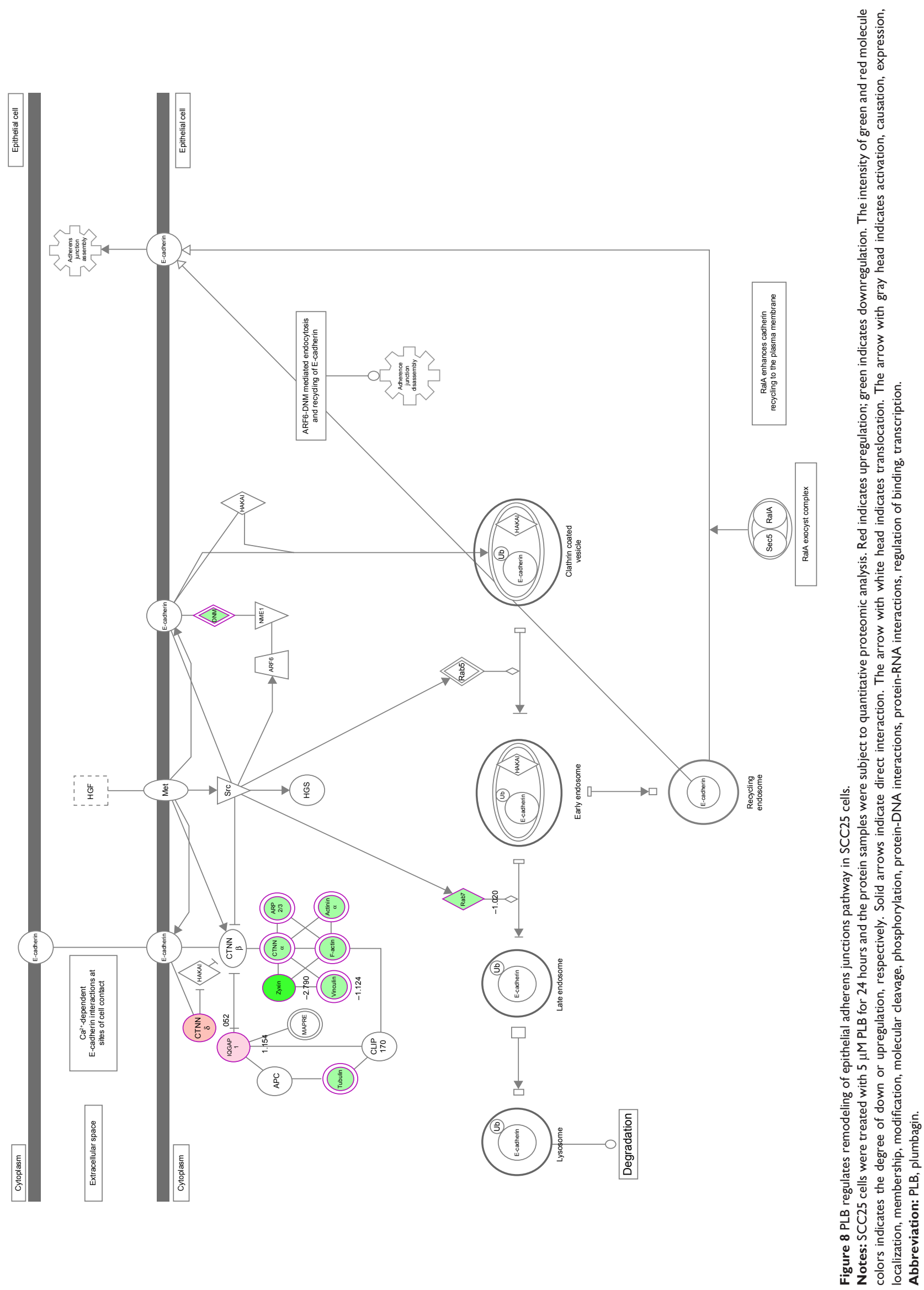
A

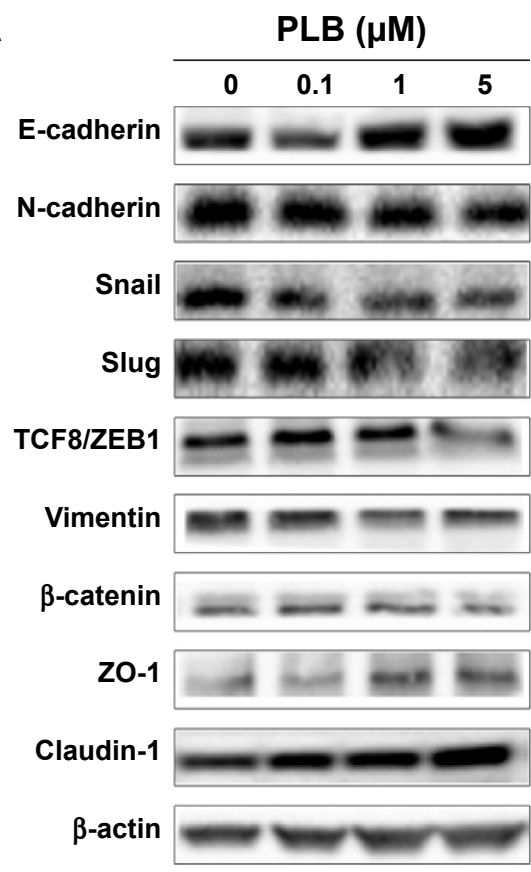

B

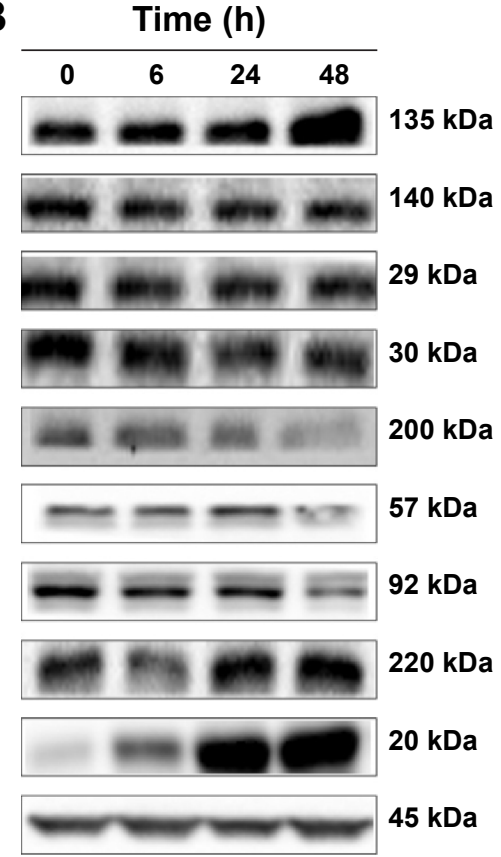

C

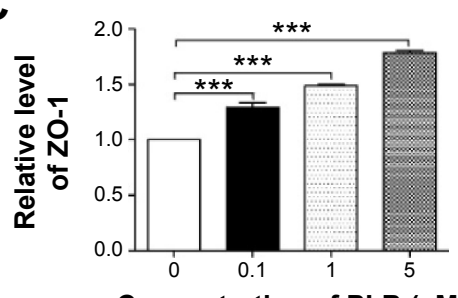

Concentration of PLB $(\mu \mathrm{M})$
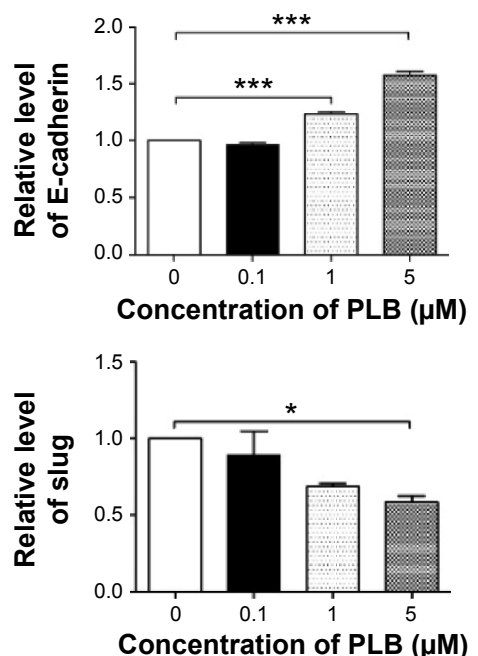

Concentration of PLB ( $\mu M)$

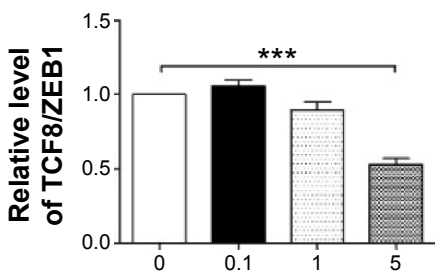

Concentration of PLB ( $\mu \mathrm{M})$
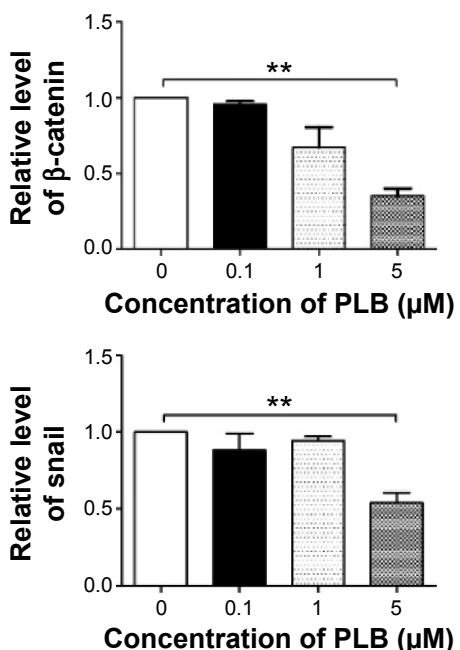

Concentration of PLB ( $\mu \mathrm{M})$

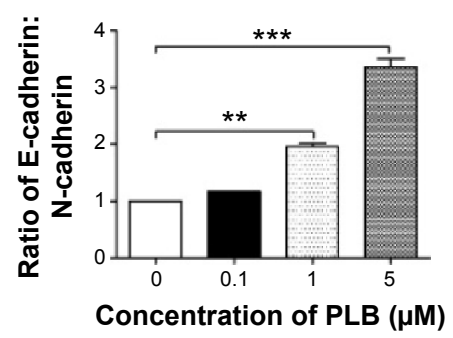

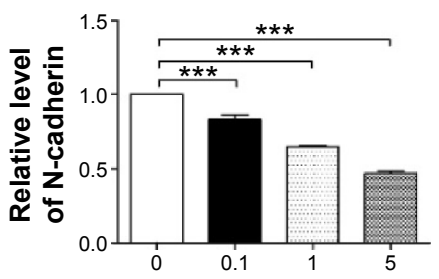

Concentration of PLB $(\mu \mathrm{M})$
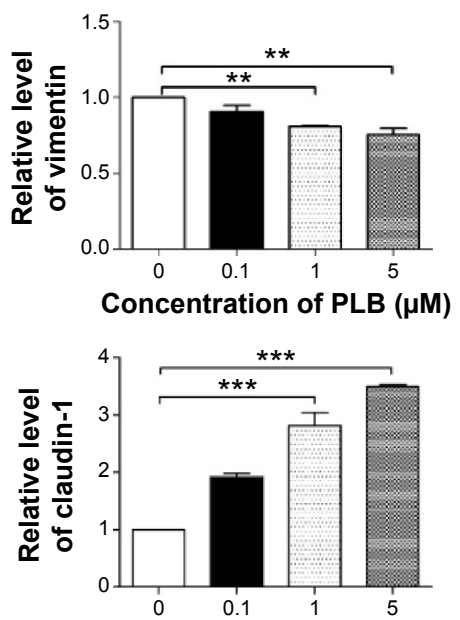

Concentration of PLB ( $\mu M)$

Figure 9 (Continued) 
D
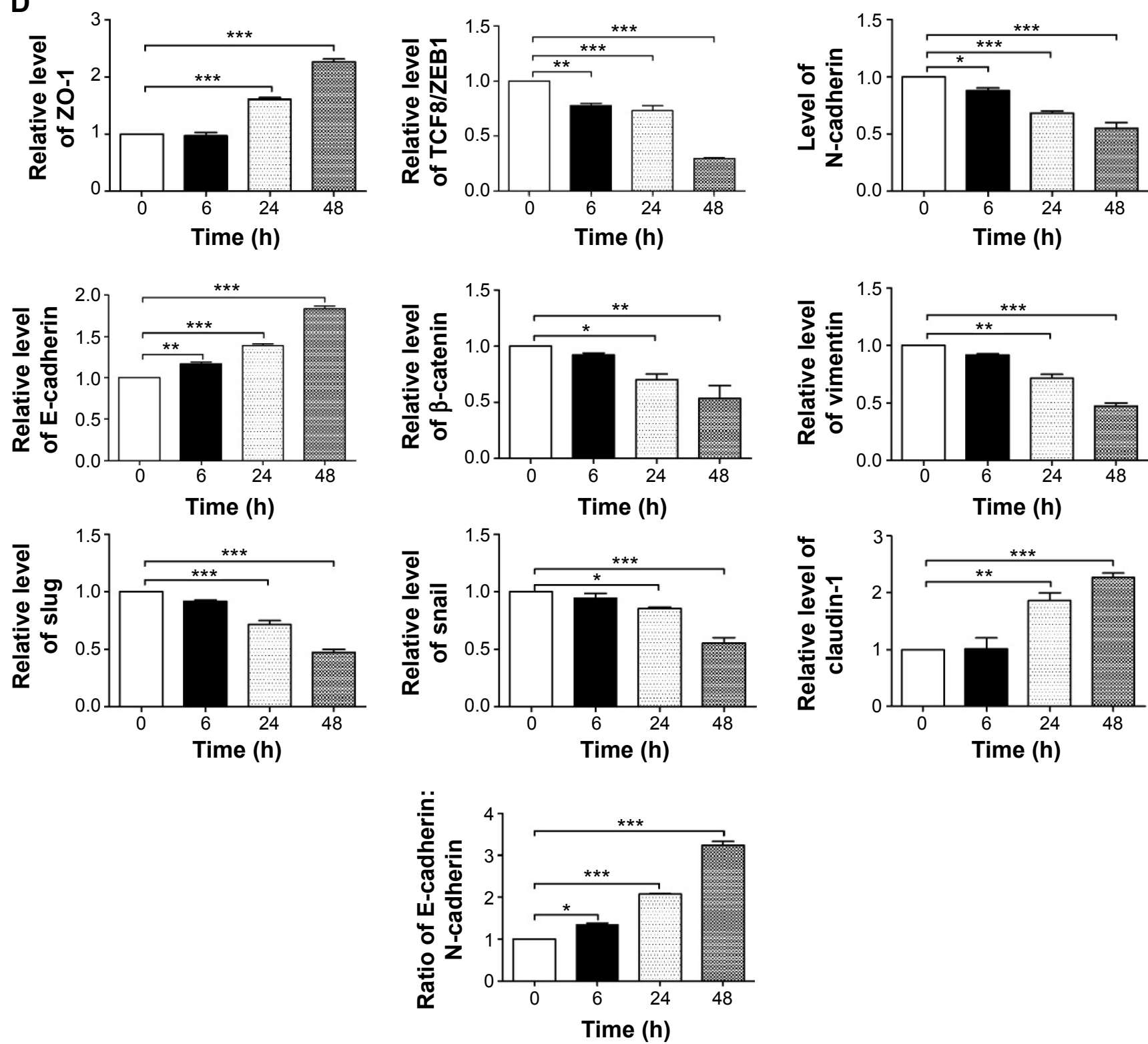

Figure 9 PLB regulates the expression of EMT-related markers in SCC25 cells.

Notes: SCC25 cells were treated with PLB in the concentration and time course experiments and protein samples were subject to Western blotting assay. (A) Representative blots of E-cadherin, N-cadherin, snail, slug, TCF8/ZEBI, vimentin, $\beta$-catenin, ZO-I, and claudin-I in SCC25 cells after the treatment of 0.1 , I, and $5 \mu$ M PLB for 24 hours; (B) representative blots of E-cadherin, N-cadherin, snail, slug, TCF8/ZEBI, vimentin, $\beta$-catenin, ZO-I, and claudin-I in SCC25 cells after the treatment of $5 \mu$ M PLB for 6, 24 , and 48 hours. (C) Bar graphs showing the relative level of E-cadherin, N-cadherin, snail, slug, TCF8/ZEBI, vimentin, $\beta$-catenin, ZO-I, and claudin-I in SCC25 cells after the treatment of $0 . I$, I, and $5 \mu$ M PLB for 24 hours, and (D) bar graphs showing the relative level of E-cadherin, N-cadherin, snail, slug, TCF8/ZEBI, vimentin, $\beta$-catenin, ZO-I, and claudin-I in SCC25 cells after the treatment of $5 \mu \mathrm{M}$ PLB for 6,24 , and 48 hours. Data are the mean \pm SD of three independent experiments. $* P<0.05$; $* * P<0.01$; and $* * * P<0.00$ I by one-way ANOVA.

Abbreviations: PLB, plumbagin; ANOVA, analysis of variance; SD, standard deviation.

were examined in SCC25 cells after the treatment of PLB. ZO-1 and -2 are required for tight junction formation and function. The effect of PLB on the expression of ZO-1 and claudin-1 in SCC25 cells increased significantly in a concentration- and time-dependent manner (Figure 9A and B). Treatment of cells with $5 \mu \mathrm{M}$ PLB for 24 hours led to a 1.8- and 3.5-fold rise in the expression level of ZO-1 and claudin-1, compared to the control cells, respectively
$(P<0.001$; Figure 9A and $\mathrm{C})$. These results from Western blotting assay verified our proteomic data.

In addition, there is increasing evidence showing that CSCs can display EMT characteristics such as loss of the adhesion protein E-cadherin. This relationship drives us to think about the stemness-attenuating effect of PLB in SCC25 cells. Therefore, we primarily conducted the Western blotting assay to examine the key stemness markers, including 
Oct-4, Bmi-1, Nanog, and Sox-2. Oct-4, also known as Oct-3, belongs to the POU (Pit-Oct-Unc) transcription factor family and plays an important role during early embryogenesis. ${ }^{47}$ Sox- 2 is a member of the Sox gene family that encodes transcription factors and plays an important role in the maintenance of stemness. ${ }^{48}$ Nanog transcription factor cooperates with Oct-4 and Sox-2 and is identified as a key CSCs marker. ${ }^{49}$ Bmi-1 is a transcriptional repressor that belongs to the polycomb-group family of proteins that determine the proliferation and senescence of normal and CSCs. ${ }^{50}$ The Western blotting results showed that PLB significantly decreased the expression level of Oct-4, Sox-2, Nanog, and Bmi-1. Incubation of SCC25 cells with $5 \mu \mathrm{M}$ PLB remarkably decreased the expression level of Oct-4, Sox-2, Nanog, and Bni- 1 by $35.7 \%, 27.0 \%, 70.7 \%$, and $38.3 \%$, respectively, compared with the control cells $(P<0.001$; Figure $10 \mathrm{~A}$ and $\mathrm{C}$ ). In a separate experiment, we evaluated the effect of different incubation times with $5 \mu \mathrm{M}$ PLB. Totally, the expression levels of Bmi-1, Nanog, and Sox-2 were decreased significantly after 6 hours of incubation, while the Oct-4 expression level was decreased significantly after 24 hours of incubation (Figure 10B and D). These results indicate that PLB suppresses the stemness of human TSCC cells.

\section{PLB induces intracellular ROS generation and regulates redox homeostasis via suppressing Nrf2-mediated oxidative signaling pathway in SCC25 cells}

As shown in the proteomic results, PLB exhibited a regulating effect on intracellular redox homeostasis in SCC25 cells, which may possibly contribute to the cell cycle arresting, apoptosis inducing, EMT inhibiting, and stemnessattenuating effects of PLB. Herein, we examined the role of Nrf2-mediated signaling pathway in PLB's beneficial action in SCC25 cells. Nrf2, also known as Nfe2I2, is a nuclear factor that controls the expression of various detoxifying enzymes, ROS elimination proteins, drug transporters, and antiapoptotic proteins. Normally, Nrf2 is suppressed in the cytoplasm by the interaction with Kelch-like ECH-associated protein 1 (Keap1) and Cullin3. Once exposed to the antioxidant response element (ARE)-mediated inducers, Nrf2 will translocate to the nucleus where it forms a heterodimer with a small Maf protein and binds to other nuclear factors and initiates the transcription of antioxidative genes. ${ }^{51,52}$ As noted earlier, the proteomic results indicated that Nrf2oxidative signaling pathway responded to the PLB treatment in SCC25 cells (Figure 11). Therefore, we analyzed this pathway using Western blotting assay. First, SCC25 cells were treated with $0.1,1$, and $5 \mu \mathrm{M}$ PLB for 24 hours and their nuclear proteins were extracted. The results showed that the expression levels of nuclear (n)-Nrf2, NQO1, GST, and HSP90 were all decreased, while the expression level of cytosolic (c)-Nrf2 was increased in SCC25 cells, compared with the control cells (Figure 12A). The ratio of n-Nrf2 to c-Nrf2 was decreased by $13.3 \%$ and $37.0 \%$ when SCC25 cells were incubated with 1 and $5 \mu \mathrm{M}$ PLB for 24 hours, respectively ( $P<0.01$ or 0.001 ; Figure $12 \mathrm{C})$. In addition, the expression levels of c-Nrf2, n-Nrf2, NQO1, GST, and HSP90 were also examined with the treatment of $5 \mu \mathrm{M}$ PLB over a 48-hour treatment period. The ratio of n-Nrf2 to c-Nrf2 was decreased by $28.3 \%$ and $39.0 \%$ when SCC25 cells were incubated with $5 \mu \mathrm{M}$ PLB for 24 and 48 hours, respectively ( $P<0.001$; Figure 12D). The expression levels of NQO1, GST, and HSP90 were all markedly decreased $(P<0.05$ or 0.001 ; Figure 12D). Taken together, the results show that Nrf2-oxidative signaling pathway is involved in the ROS-generation-inducing effect of PLB, contributing to the regulatory activities of PLB on intracellular redox homeostasis in SCC25 cells (Figure 13).

\section{Relationship between PLB-induced ROS generation and PLB-mediated cell cycle arrest, apoptosis induction, EMT inhibition, and stemness attenuation}

The relationship between PLB-induced ROS generation and PLB-mediated cell cycle arrest, apoptosis induction, EMT inhibition, and stemness attenuation was further examined in SCC25 cells with the application of ROS scavengers (NAC and GSH). SCC25 cells were treated with $5 \mu \mathrm{M}$ PLB, $100 \mu \mathrm{M}$ NAC, $1 \mathrm{mM}$ GSH, $5 \mu \mathrm{M}$ PLB plus $100 \mu \mathrm{M}$ NAC, and $5 \mu \mathrm{M}$ PLB plus $1 \mathrm{mM}$ GSH, respectively. As shown in Figures 14-16, the cell cycle arresting, apoptosis inducing, EMT inhibiting, and stemness-attenuating effects of PLB were abolished by NAC and GSH. The percentage of cells in $\mathrm{G}_{2} / \mathrm{M}$ phase was decreased by $53.2 \%$ and $61.4 \%$ in SCC25 cells when cells were coincubated with NAC and PLB or GSH and PLB, compared to PLB-treated cells, respectively $(P<0.01$ or 0.001; Figure 14B). In addition, in comparison to PLB-treated cells, NAC and GSH ablated PLB-induced apoptosis 53.3\% and 55.6\%, respectively $(P<0.001$; Figure 15B). Furthermore, the expression of EMT and stemness representative markers were measured (Figure 16). Compared to PLB-treated cells, the expression level of E-cadherin was decreased by $30.4 \%$ and $36.2 \%$ when cells were cotreated with NAC and PLB or GSH and PLB, respectively $(P<0.001$; Figure $16 \mathrm{~A}$ and $\mathrm{B})$. On the contrary, the expression level of N-cadherin, Oct-4, Bmi-1, and 
A

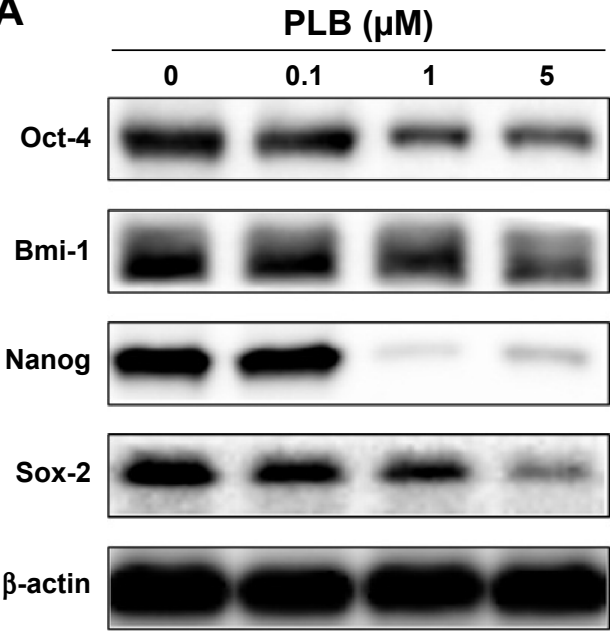

C
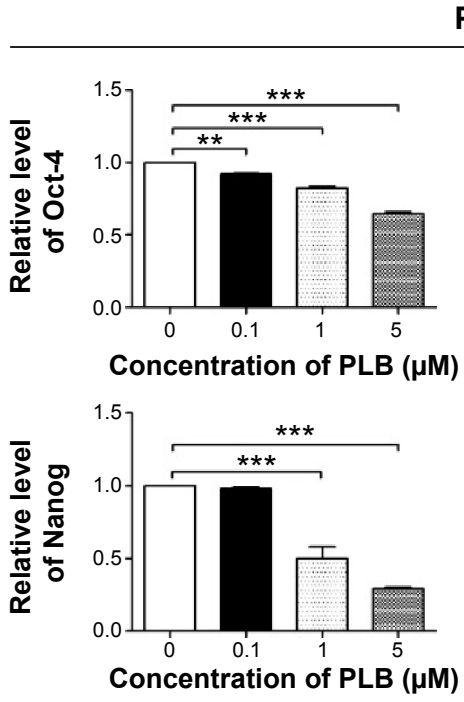

B Time (h)

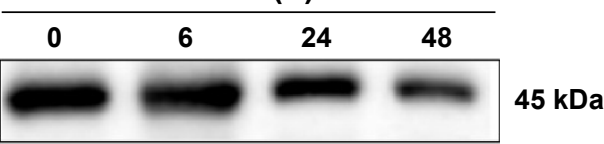

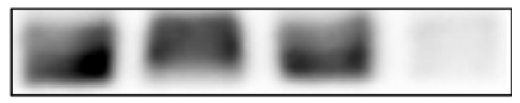

$43 \mathrm{kDa}$

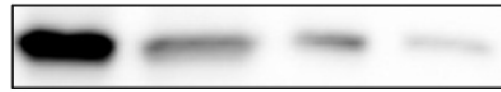

$42 \mathrm{kDa}$

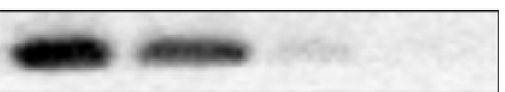

$35 \mathrm{kDa}$

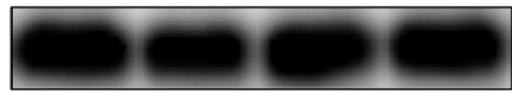

$45 \mathrm{kDa}$

D

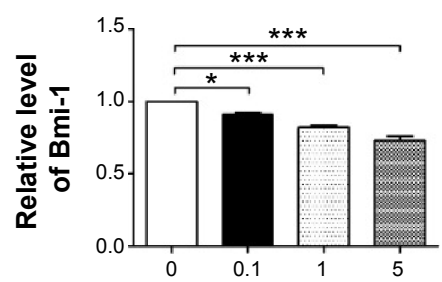

Concentration of PLB $(\mu \mathrm{M})$

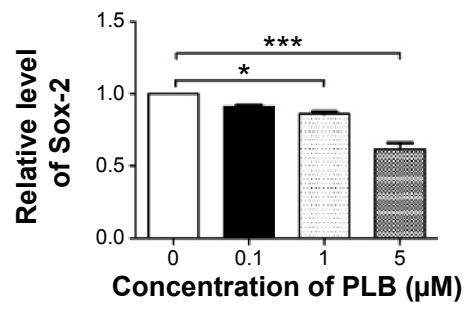

Time (h)
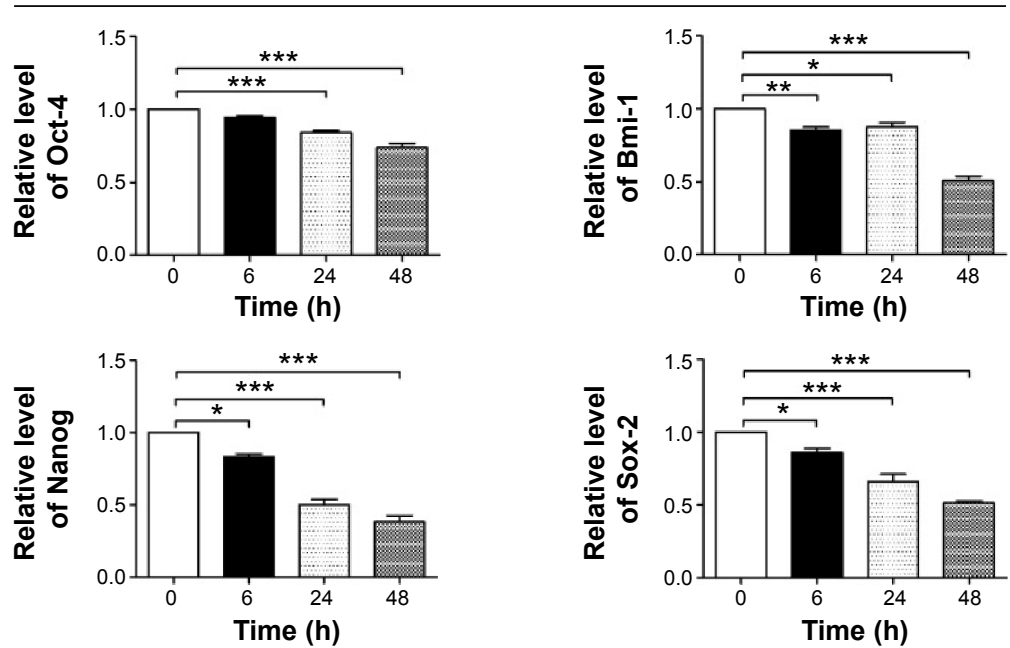

Figure 10 PLB regulates the expression of stemness markers in SCC25 cells.

Notes: SCC25 cells were treated with PLB in the concentration and time course experiments and protein samples were subject to Western blotting assay. (A) Representative blots of Oct-4, Bmi-I, Nanog, and Sox-2 in SCC25 cells after the treatment of 0.I, I, and $5 \mu$ M PLB for 24 hours, and (B) representative blots of Oct-4, Bmi-I, Nanog, and Sox-2 in SCC25 cells after the treatment of $5 \mu$ M PLB for 6, 24, and 48 hours. (C) Bar graphs showing the relative levels of Oct-4, Bmi-I, Nanog, and Sox-2 in SCC25 cells after the treatment of $0.1, I$, and $5 \mu$ M PLB for 24 hours, and (D) bar graphs showing the relative levels of Oct-4, Bmi- I, Nanog, and Sox-2 in SCC25 cells after the treatment of $5 \mu \mathrm{M}$ PLB for 6,24 , and 48 hours. Data are the mean \pm SD of three independent experiments. $* P<0.05$; $* * P<0.01$; and $* * * P<0.001$ by one-way $A N O V A$.

Abbreviations: PLB, plumbagin; ANOVA, analysis of variance; SD, standard deviation. 

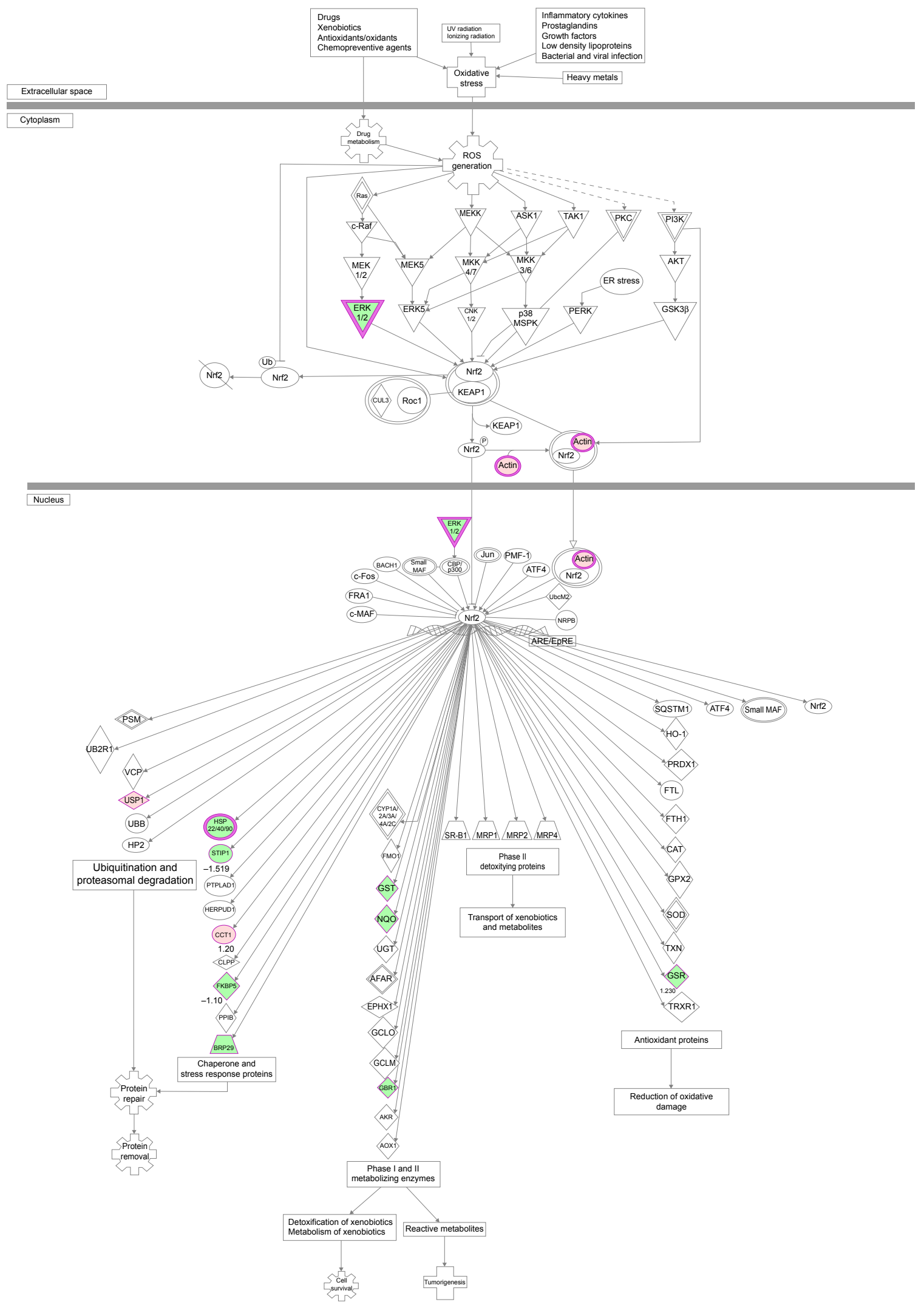

Figure II PLB regulates Nrf2 oxidative signaling pathway in SCC25 cells.

Notes: SCC25 cells were treated with $5 \mu$ M PLB for 24 hours and the protein samples were subject to quantitative proteomic analysis. Red indicates upregulation; green indicates downregulation. The intensity of green and red molecule colors indicates the degree of down or upregulation, respectively. Solid arrows indicate direct interaction and dashed arrows indicate indirect interaction.

Abbreviations: PLB, plumbagin; UV, ultraviolet. 
A

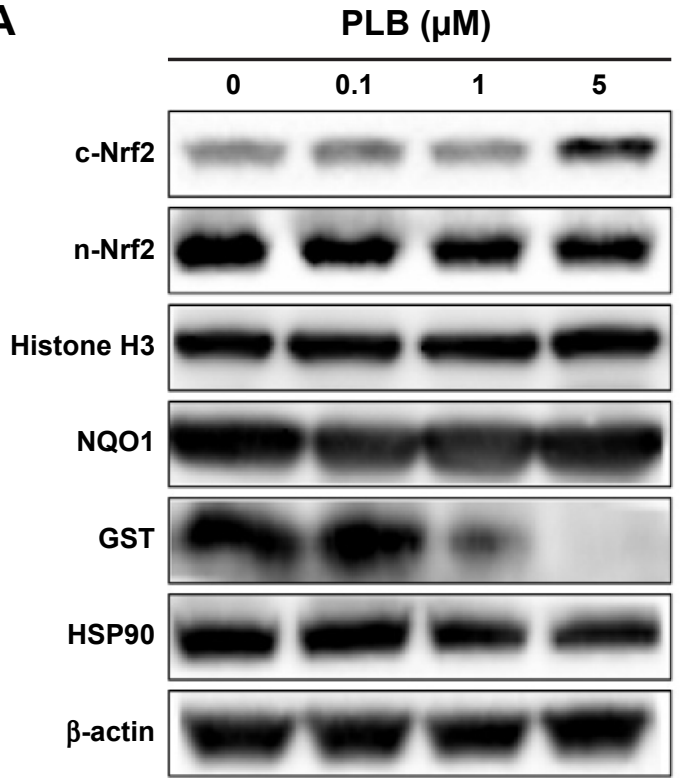

B

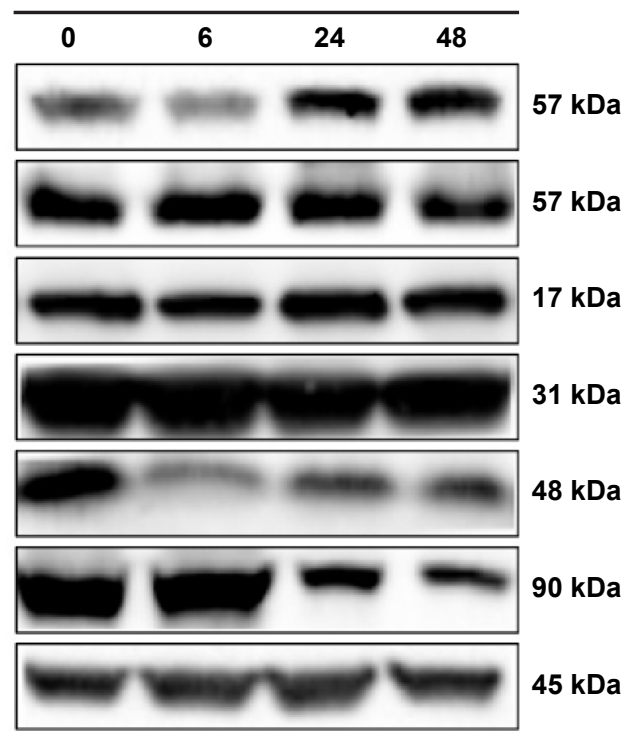

C

PLB ( $\mu$ M)

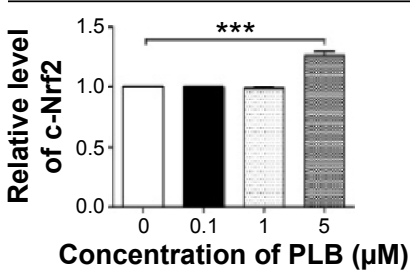

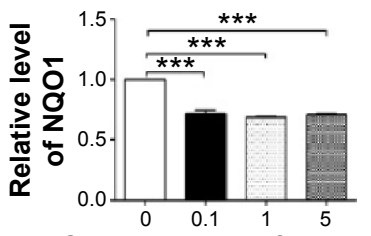

Concentration of PLB ( $\mu \mathrm{M})$

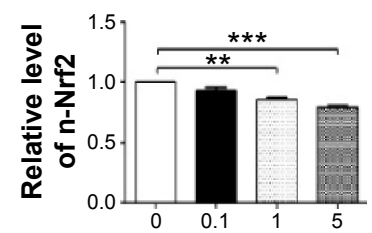

Concentration of PLB $(\mu \mathrm{M})$

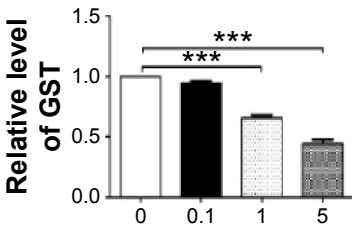

Concentration of PLB $(\mu \mathrm{M})$

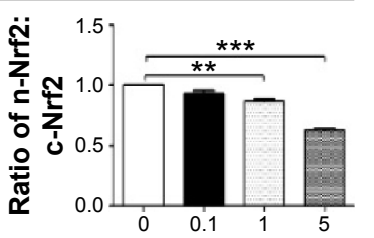

Concentration of PLB ( $\mu$ M)

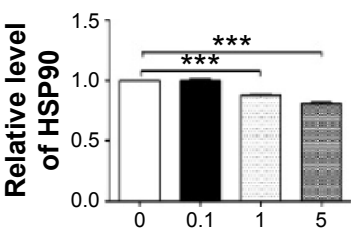

Concentration of PLB ( $\mu \mathrm{M})$

D

Time (h)
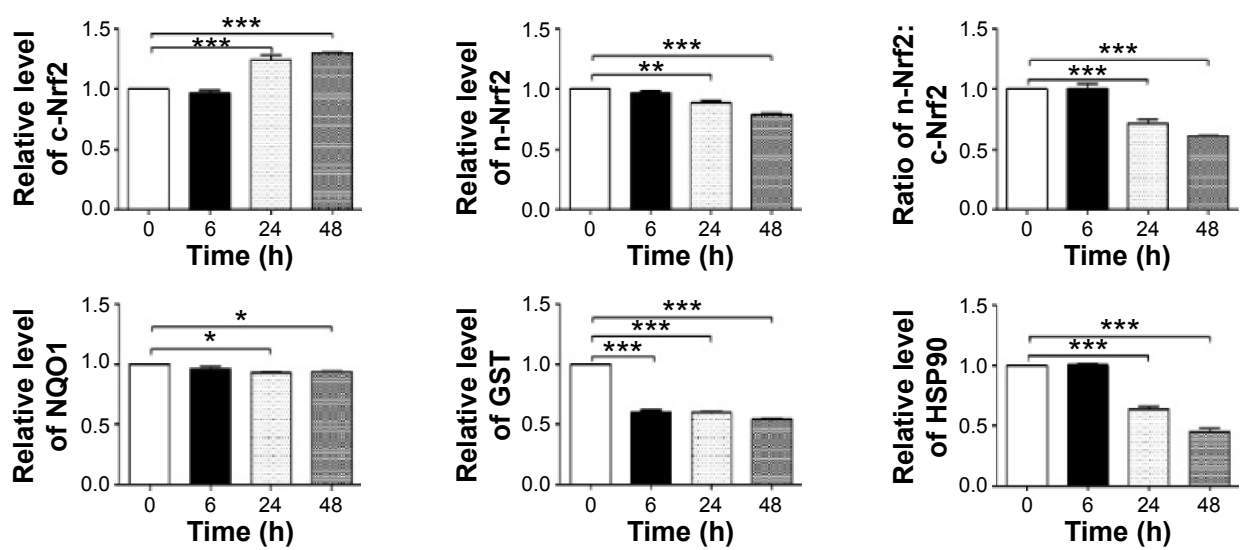

Figure 12 PLB regulates the expression of Nrf2, NQOI, GST, and HSP90 in SCC25 cells.

Notes: SCC25 cells were treated with PLB in the concentration and time course experiments and protein samples were subject to Western blotting assay. (A) Representative blots of c-Nrf2, n-Nrf2, NQOI, GST, and HSP90 in SCC25 cells after the treatment of 0.1, I, and $5 \mu$ M PLB for 24 hours, and (B) representative blots of Nrf2, NQOI, GST, and HSP90 in SCC25 cells after the treatment of $5 \mu$ M PLB for 6, 24, and 48 hours. (C) Bar graphs showing the relative level of Nrf2, NQOI, GST, and HSP90 in SCC25 cells after the treatment of $0.1, \mathrm{I}$, and $5 \mu \mathrm{M}$ PLB for 24 hours, and (D) bar graphs showing the relative levels of Nrf2, NQOI, GST, and HSP90 in SCC25 cells after the treatment of $5 \mu \mathrm{M}$ PLB for 6,24 , and 48 hours. Data are the mean \pm SD of three independent experiments. $* P<0.05$; $* * P<0.01$; and $* * * P<0.00$ I by one-way $A N O V A$. Abbreviations: PLB, plumbagin; ANOVA, analysis of variance; SD, standard deviation. 


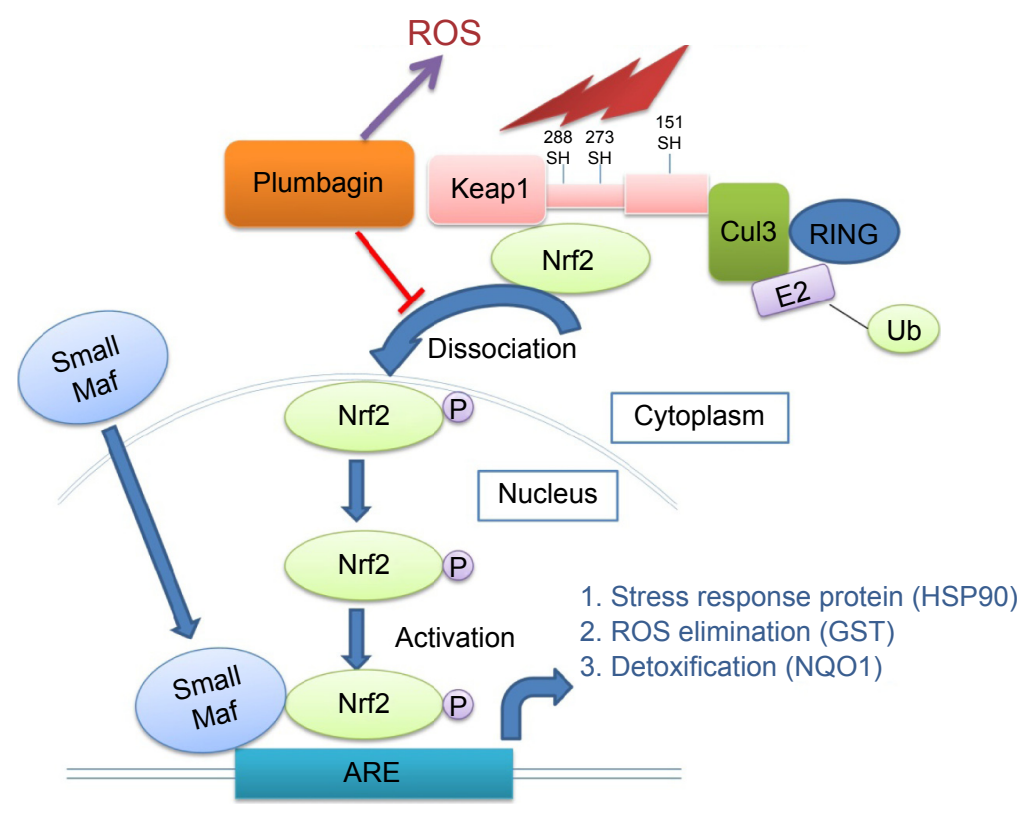

Figure 13 Schematic diagram shows that PLB regulates the Nrf2-mediated oxidative signaling pathway and its downstream proteins NQOI, GST, and HSP90 in SCC25 cells. Abbreviations: ROS, reactive oxygen species; GST, glutathione S-transferase.
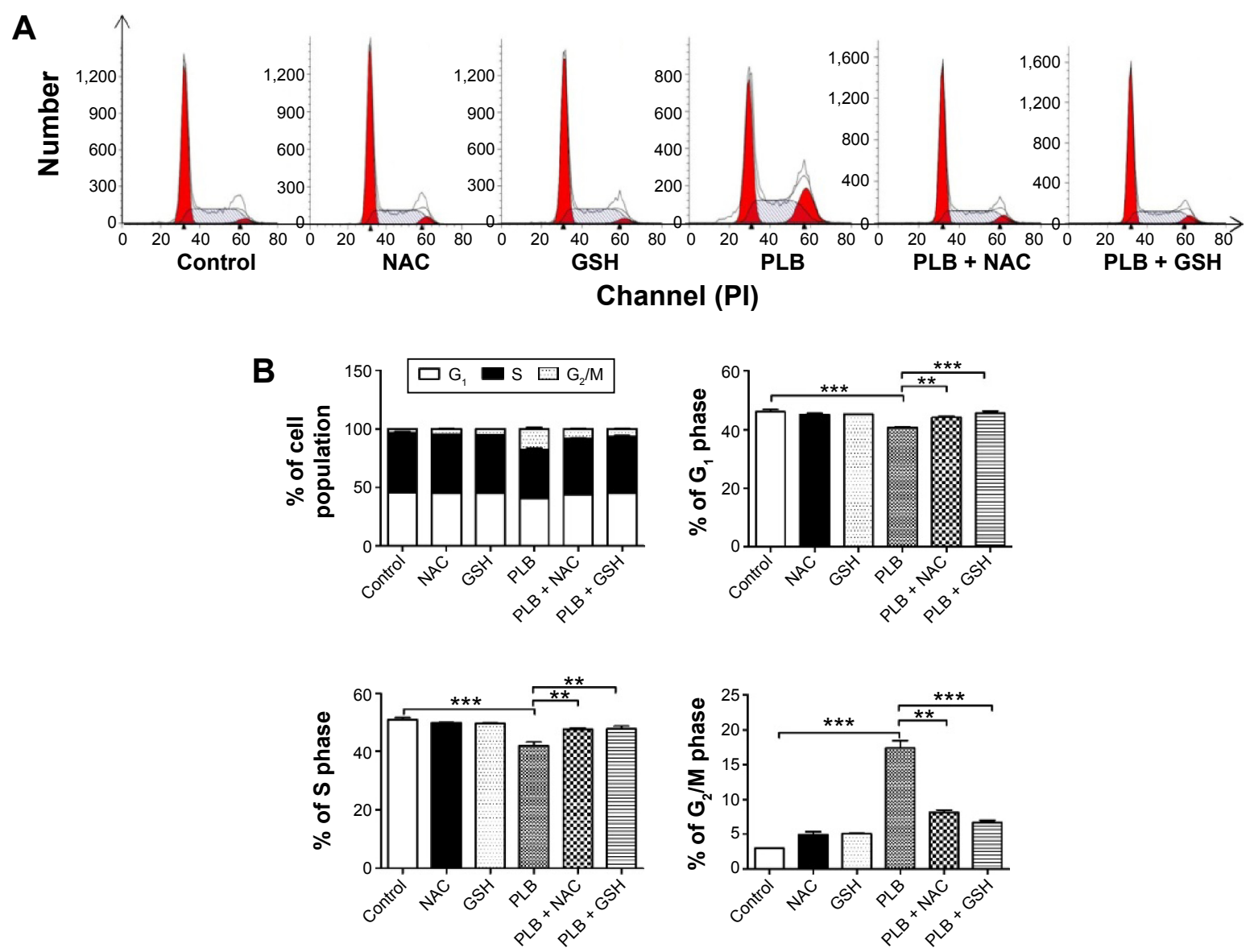

Figure 14 The effect of ROS scavengers NAC and GSH in PLB-induced $\mathrm{G}_{2} / \mathrm{M}$ arrest in SCC25 cells.

Notes: (A) Representative flow cytometric plots of cell cycle distribution of SCC25 and (B) bar graphs showing the percentage of SCC25 cells in $\mathrm{G}_{1}, \mathrm{~S}_{\text {and }} \mathrm{G}_{2} / \mathrm{M}_{\text {phases }}$ after the treatment of $5 \mu \mathrm{M}$ PLB, $100 \mu \mathrm{M}$ NAC, I mM GSH, $5 \mu$ M PLB plus $100 \mu \mathrm{M}$ NAC, and $5 \mu$ M PLB plus I mM GSH for 24 hours. Data are the mean \pm SD of three independent experiments. ${ }^{*} * P<0.0 \mathrm{I}$; and ${ }^{* * *} P<0.00 \mathrm{I}$ by one-way ANOVA.

Abbreviations: ROS, reactive oxygen species; NAC, N-acetyl-L-cysteine; GSH, L-glutathione; PLB, plumbagin; ANOVA, analysis of variance; SD, standard deviation. 

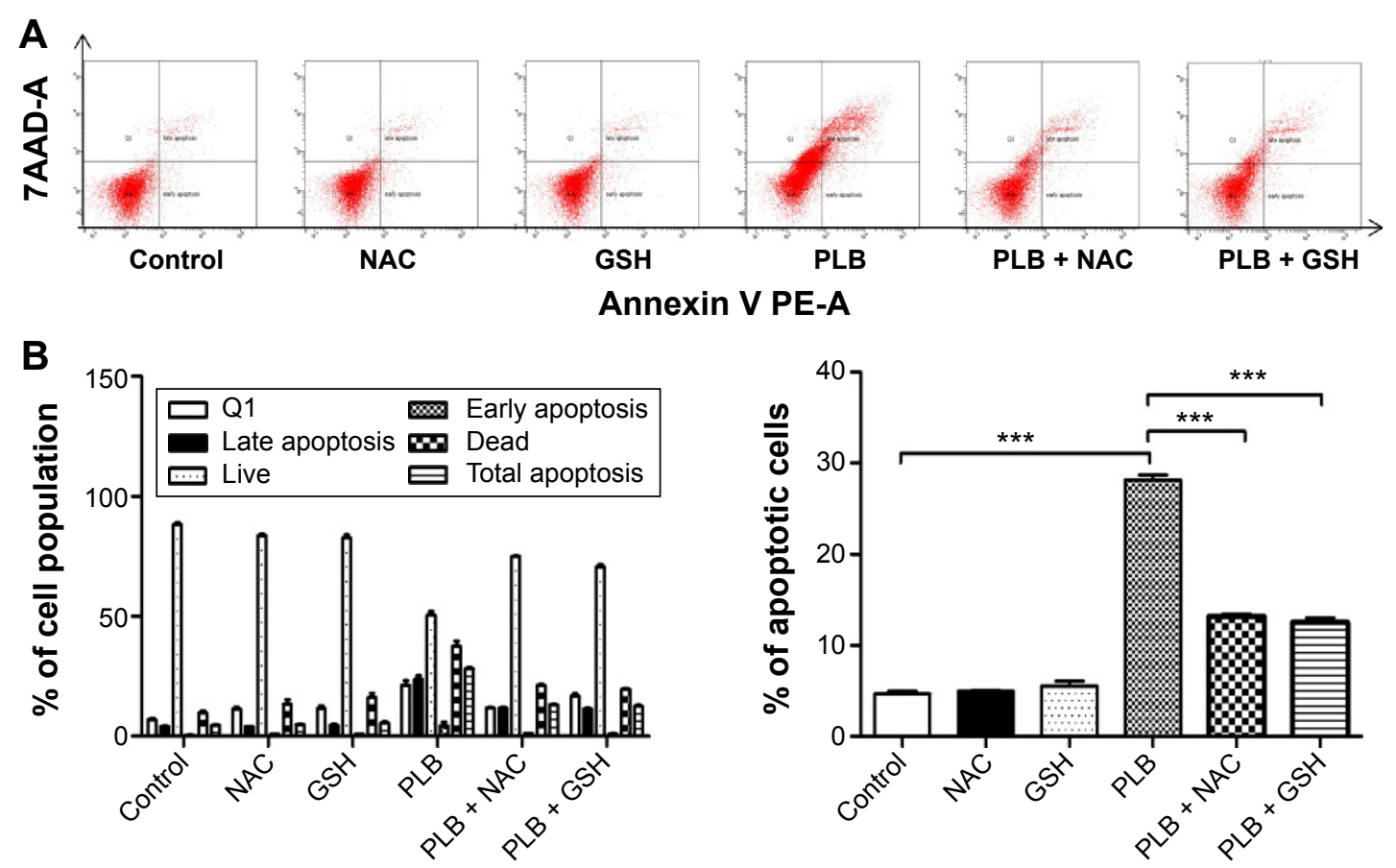

Figure 15 The effect of ROS scavengers NAC and GSH in PLB-induced apoptosis in SCC25 cells.

Notes: (A) Representative flow cytometric plots of apoptosis in SCC25 and (B) bar graphs showing the apoptotic percentage of SCC25 cells after the treatment of $5 \mu \mathrm{M}$ PLB, $100 \mu \mathrm{M}$ NAC, I mM GSH, $5 \mu$ M PLB plus $100 \mu \mathrm{M}$ NAC, and $5 \mu$ M PLB plus I mM GSH for 24 hours. Data are the mean \pm SD of three independent experiments. $* * * P<0.00$ I by one-way ANOVA.

Abbreviations: ROS, reactive oxygen species; NAC, N-acetyl-L-cysteine; GSH, L-glutathione; PLB, plumbagin; ANOVA, analysis of variance; SD, standard deviation.

Nanog was increased when cells were coincubated with NAC and PLB or GSH and PLB (Figure 16A and B). However, the expression level of Sox-2 did not show statistical significance (Figure 16A and B). This may be partially ascribed to PLBmediated other pathways that downregulate the Sox-2 level. Taken together, PLB-induced ROS generation may interact with the actions of PLB-mediated cell cycle arrest, apoptosis induction, EMT inhibition, and stemness attenuation.

\section{Discussion}

TSCC remains one of the devastating malignancies in oral and maxillofacial tumors. TSCC is notorious for its lymphatic metastasis and relapse. Although sequential treatments are available, including radiotherapy, surgery, and chemotherapy, the therapeutic efficacy is not so optimistic. ${ }^{1}$ This is partially due to hyperactive cell survival pathways and radiotherapy/ chemotherapy resistance. ${ }^{53,54}$ It is urgent to probe into the

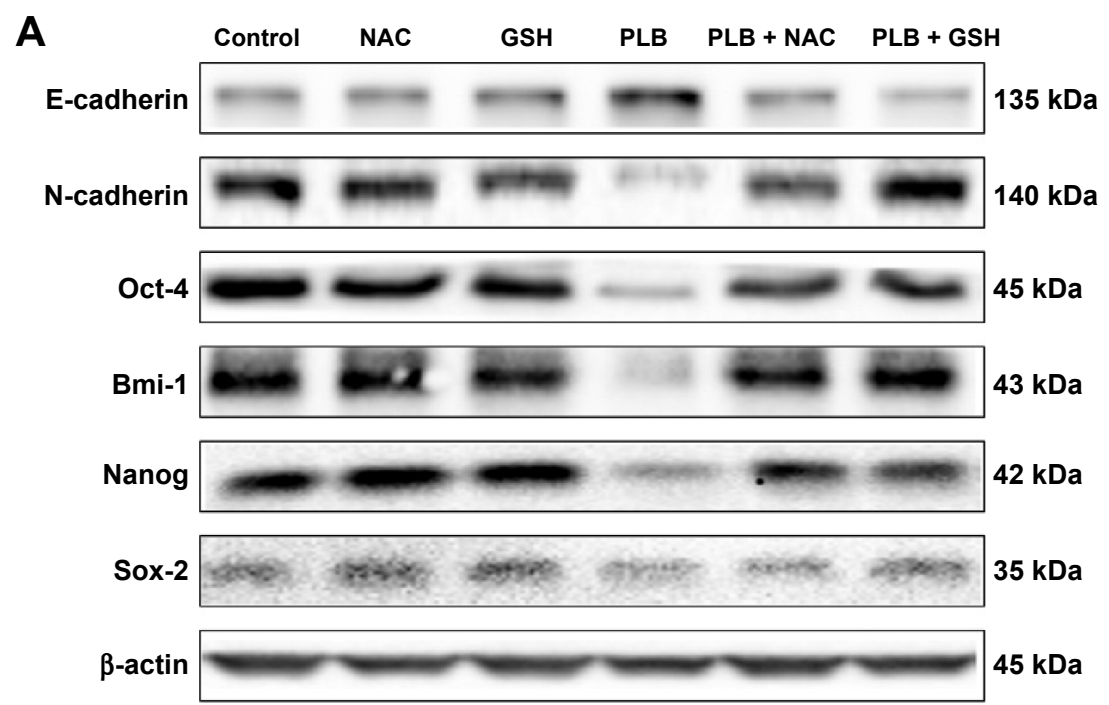

Figure 16 (Continued) 
B
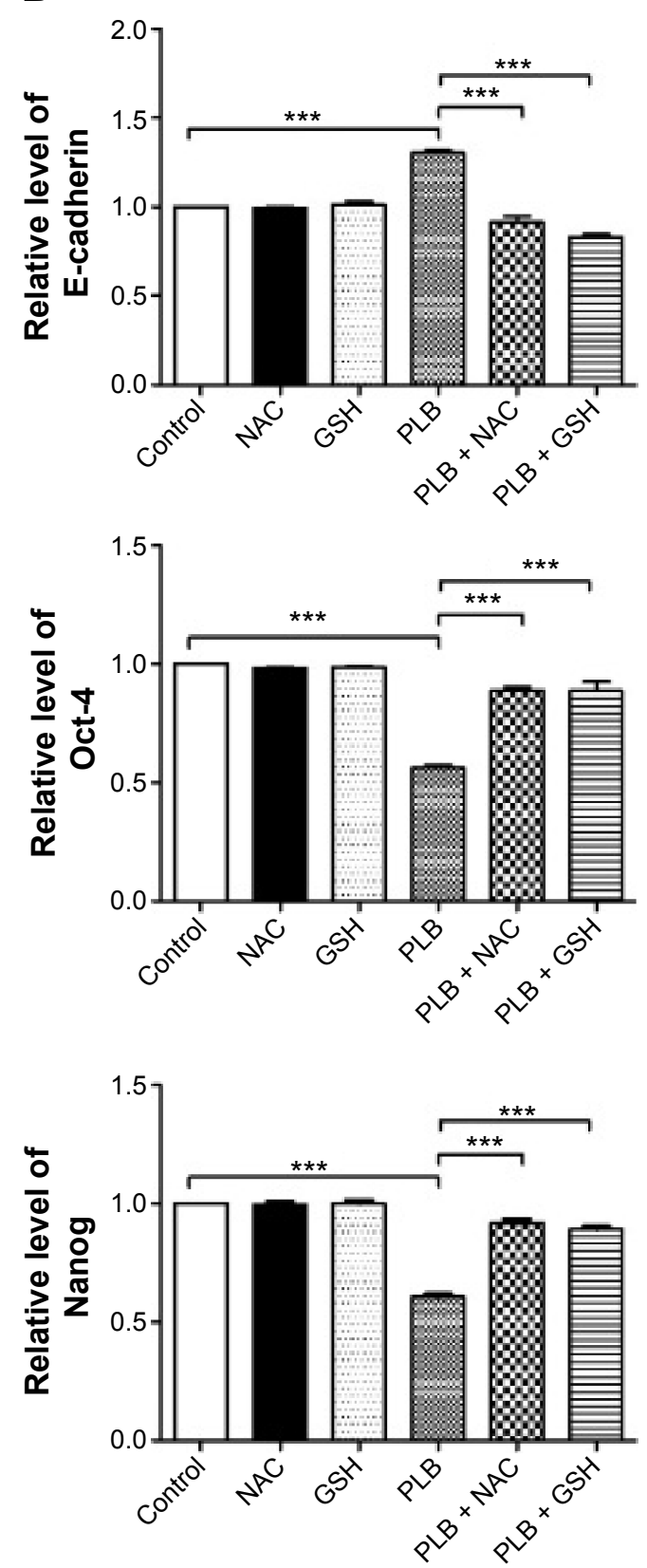
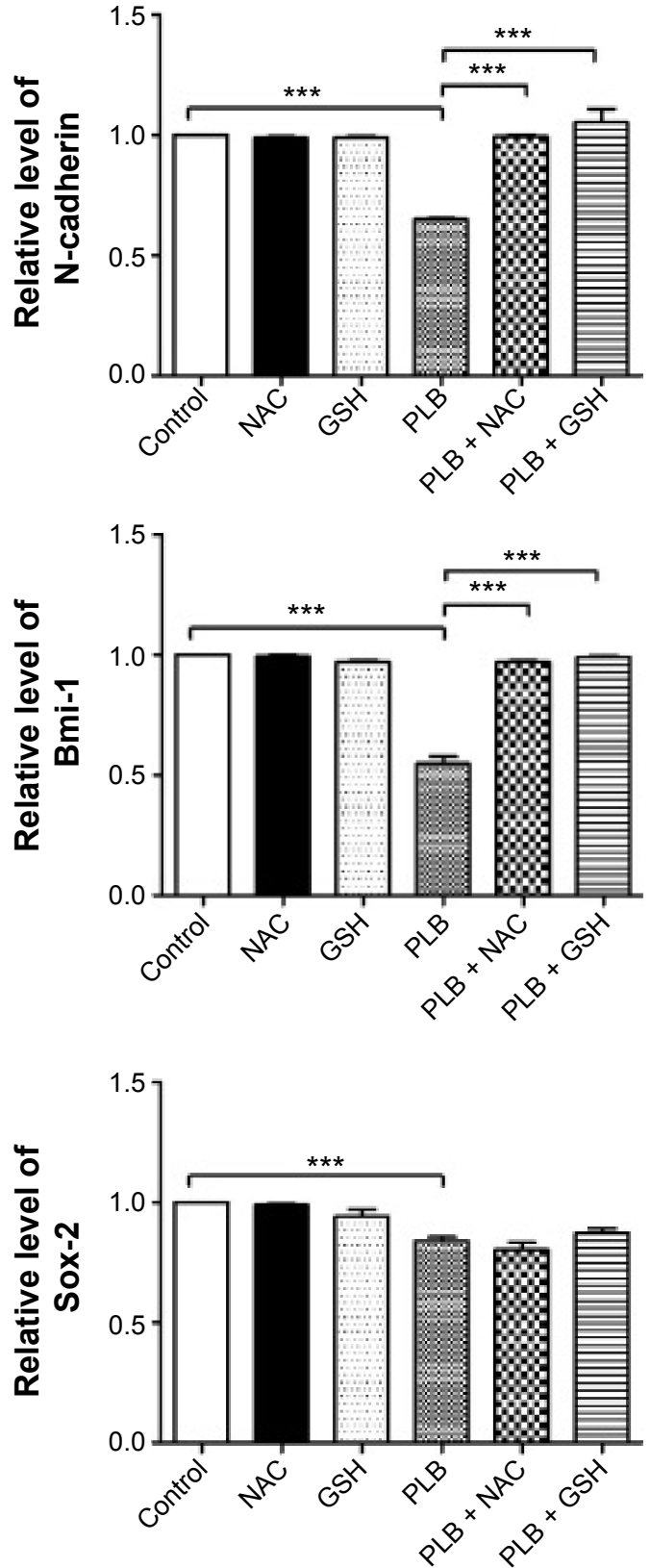

Figure 16 The effect of ROS scavengers NAC and GSH in PLB-mediated EMT inhibition and stemness attenuation in SCC25 cells.

Notes: (A) Representative blots of E-cadherin, N-cadherin, Oct-4, Bmi-I, Nanog, and Sox-2 in SCC25 cells and (B) bar graphs showing the relative level of E-cadherin, $\mathrm{N}$-cadherin, Oct-4, Bmi-I, Nanog, and Sox- 2 in SCC2 5 cells after the treatment of $5 \mu$ M PLB, $100 \mu$ M NAC, I mM GSH, $5 \mu$ M PLB plus $100 \mu M$ NAC, and $5 \mu$ M PLB plus I mM GSH for 24 hours. Data are the mean \pm SD of three independent experiments. $* * * P<0.00$ I by one-way ANOVA.

Abbreviations: ROS, reactive oxygen species; NAC, N-acetyl-L-cysteine; GSH, L-glutathione; EMT, epithelial to mesenchymal transition; PLB, plumbagin; ANOVA, analysis of variance; SD, standard deviation.

corresponding molecular alterations and seek novel effective drugs for TSCC treatment. PLB is an active naphthoquinone constituent isolated from the roots of Plumbaginaceae plants..$^{17}$ It has been reported that PLB exhibits anticancer activities with minimal side effect in vitro and in vivo, which is greatly ascribed to its effects on multiple signaling pathways related to ROS generation, apoptosis, and autophagy. ${ }^{23,55,56}$ In this study, we employed a SILAC-based quantitative proteomic study to obtain a comprehensive view of the proteomic response to PLB treatment in TSCC cell line SCC25, and the findings have shown that PLB regulates a variety of functional protein molecules and signaling pathways involved in critical cellular processes. Further validation results have shown that PLB induces $\mathrm{G}_{2} / \mathrm{M}$ arrest and extrinsic apoptosis, but inhibits EMT and stemness via ROS generation through Nrf2-mediated oxidative signaling pathway in TSCC cell line SCC25 cells. 
The SILAC-based proteomic approach can provide a system-level analysis to tackle the challenges in cancer treatment, such as chemoresistance. One study applied SILAC-based quantitative proteomic approach to analyze differences in protein expression level between parental hepatocellular carcinoma cell line $\mathrm{HuH}-7$ and sorafenibacquired resistance HuH-7 (HuH-7R) cells. Results indicated that galectin- 1 is a predictive marker of sorafenib resistance and a downstream target of the Akt/mTOR/HIF-1a signaling pathway. ${ }^{57}$ The SILAC-based proteomic approach can also quantitatively evaluate the effect of a given compound or drug and identify its potential molecular targets and related signaling pathways. ${ }^{58-60}$ For example, the SILAC-based proteomic approach was used to screen the therapeutic targets of histone deacetylases inhibitor vorinostat in human breast cancer MDA-MB-231 cell line, and the results found that 61 proteins were lysine acetylated by vironostat. ${ }^{30}$ This study demonstrated that PLB modulated a plethora of protein molecules, of which the expression levels of 143 protein molecules were increased while the levels of 255 protein molecules were decreased. Furthermore, 101 signaling pathways were potentially regulated by PLB in SCC25 cells. The following proteins are widely involved in cell survival, cell proliferation, redox homeostasis, cell metabolism, cell migration, and cell death: YWHAQ, PRKDC, YWHAG, YWHAE, YWHAH, YWHAB, YWHAZ, SFN, SKP1, CDK1, ACIN1, CAPNS1, MAPK1, RRAS, LMNA, CAPN2, SPTAN1, CYCS, PARP1, AIFM1, FADD, ACTB, ACTA1, ACTG1, ACTN1, ACTN4, ACTR3, ARPC1B, CTNNA1, CTNND1, DNM1L, EGFR, IQGAP1, JUP, MYH9, RAB7A, RHO1, TUBA1B, TUBA1C, TUBA4A, TUBB, TUBB4B, VAL, VCL, ZYX, CBR, DNAJA2, GSTP1, NQO1, HSP90AA1, PPIB, SOD1, STIP1, and VCP. The network of signaling pathways was mainly related to cell cycle distribution, cell migration, redox hemostasis, and cell death. The top ten targeted signaling pathways were EIF2 signaling pathway, regulation of eIF4 and p70S6K signaling, remodeling of epithelial adherens junctions pathway, mTOR signaling pathway, protein ubiquitination pathway, Nrf2-mediated oxidative stress response signaling pathway, epithelial adherens junction signaling pathway, caveolar-mediated endocytosis signaling pathway, RhoA signaling pathway, and oxidative phosphorylation pathway. The proteomic results indicate that PLB may target these molecules and related signaling pathways to elicit its anticancer effects in the treatment of TSCC. Notably, we have observed a differential effect of PLB on turmoral and nontumoral cells, with a higher half-maximal inhibitory concentration toward to nontumoral cells than that to the corresponding tumoral cells,${ }^{20}$ which renders PLB a promising anticancer drug candidate.

Subsequently, we further validated the proteomic responses to PLB in SCC25 cells. We found that PLB induced $\mathrm{G}_{2} / \mathrm{M}$ arrest in SCC25 cells in a concentration- and timedependent manner. Meanwhile, the expression level of key regulators of $\mathrm{G}_{2} / \mathrm{M}$ phase, such as cdc2, cyclin $\mathrm{B} 1$, and cdc25, were decreased after the treatment of PLB. It has been reported that cell cycle progression is tightly regulated by cyclins and CDKs. ${ }^{61}$ The complex formed by the association of CDK1/ cdc2 and Cyclin B1 plays a major role in the entry of cells into mitosis. Phosphorylation of CDK1/cdc2 at Thr161 by CDK-activating kinase is essential for CDK1/cdc2 kinase activity. The process of the CDK1/cdc2 phosphorylation and dephosphorylation are mediated by the nuclear kinase Wee1 and the dual-specificity phosphatase cdc25. Wee1 can stop mitosis by inhibiting the CDK1/cdc2 phosphorylation, while cdc25 can help entry into mitosis by eliminating the inhibitory phosphorylation. ${ }^{61}$ Thus, taking the proteomic, flow cytometric, and Western blotting results into consideration, PLB-induced cell cycle arrest may be mediated through the regulation of key modulators controlling the $\mathrm{G}_{2} / \mathrm{M}$ check point in SCC25 cells.

Apoptosis is a conserved physiological mechanism that is important during embryogenesis and homeostasis of tissue. Dysregulated apoptosis has been implicated in many diseases including cancer. ${ }^{62}$ The successful execution of apoptosis is crucial for many chemotherapy drugs. ${ }^{63}$ It is widely accepted that there are two types of apoptosis: intrinsic apoptosis and extrinsic apoptosis. Mitochondrial disruption and the subsequent cytochrome c release can initiate the caspase-dependent apoptosis. Bcl-2 family plays an important role during this process. ${ }^{64,65}$ Previously, our findings showed that PLB triggered the mitochondrialmediated apoptosis in SCC25 cells. ${ }^{20}$ In this study, the proteomic study showed that PLB regulated mitochondrial function and death receptor signaling pathway. We found that PLB could induce FADD-mediated extrinsic apoptosis in SCC25 cells. The proteomic results hinted that PLB regulated the death receptor signaling and that the protein molecule FADD was upregulated by PLB. FADD is a key adaptor protein for death receptor-mediated apoptosis. The death domain of FADD binds to the death domain of death receptor. Subsequently, procaspase- 8 is recruited and caspase 3, 6, and 7 are cleaved. Finally, apoptosis is induced; and both intrinsic and extrinsic apoptosis converge into the cleavage of caspase 3. TRADD is a tumor necrosis factor receptor 1 (TNFR1) associated signal transducer that enhances association of FADD with TNFR 1. ${ }^{66,67}$ DR5, also 
known as TRAIL-R2, can bind to adaptor molecules FADD and TRADD.$^{68}$ In this study, we found that PLB increased the level of FADD, TRADD, and DR5. This indicated the extrinsic apoptosis-inducing effect of PLB in SCC25. Together with the results from our previous paper, ${ }^{20}$ it seems that PLB can efficiently induce both intrinsic and extrinsic apoptosis in SCC25 cells.

TSCC is notorious for its metastasis and relapse, and acquisition of EMT and induction of CSC-like properties are inevitably responsible for the metastasis and relapse. ${ }^{69}$ EMT is a highly conserved biological process that converts epithelial cells into mesenchymal cells via the modulation of various transcription factors. ${ }^{70-73}$ EMT has been classified into three types according to specific physiological context. Type I EMT plays an important role in embryogenesis and organ development. Type II EMT functions in wound healing and tissue regeneration. Type III EMT, the one we focus on, is involved in cancer metastasis and CSC formation. ${ }^{35,74}$ The EMT process is characterized by loss of epithelial markers such as E-cadherin, claudin, and occludin, and acquisition of mesenchymal markers such as N-cadherin, vimentin, snail, slug, and ZO-1.75,76 Many signaling pathways, such as Wnt, TGF- $\beta$, and STAT3, can mediate the EMT process via activating a plethora of transcriptional regulators of mesenchymal markers. ${ }^{75,76}$ Furthermore, CSCs can display EMT characteristics such as loss of adhesion protein E-cadherin. ${ }^{11}$ Static CSCs that have moved to distant sites might be responsible for metastases and relapse, especially after curative surgical treatment of a primary tumor. ${ }^{77}$ Seminal findings demonstrate that EMT activators, such as Twist1 and Prrx1, can serve as a direct molecular link between EMT and stemness. ${ }^{78,79}$ Our proteomic study showed that PLB could regulate the epithelial adherens junctions pathway in SCC25 cells. The Western blotting assay validated that PLB could increase the expression level of E-cadherin and decrease the level of $\mathrm{N}$-cadherin in SCC25 cells. Furthermore, we examined other key regulators of EMT. We found that PLB significantly reduced the expression level of snail, slug, TCF-8/ZEB1, $\beta$-catenin, and vimentin, while increasing the expression level of claudin-1 and ZO-1. All these implied the EMT-inhibiting role of PLB in SCC25 cells. Subsequently, CSCs markers were also measured, and the expression levels of Oct-4, Bmi-1, Nanog, and Sox-2 were all found to be decreased by PLB in a concentration- and time-dependent manner in SCC25 cells. Taken together, PLB can inhibit EMT and attenuate stemness in SCC25 cells. We can speculate that there are interconnections between EMT and stemness, such as the loss of E-cadherin. Given that PLB can regulate the key factors in EMT, the stemness property may more or less be affected. However, the exact network between EMT and stemness needs further investigation. Importantly, it has been reported that ROS may link the EMT and stemness via glucose metabolism. ${ }^{80}$ In our previous paper, ${ }^{20}$ we found that PLB can efficiently induce ROS generation, which can be abolished by ROS scavengers NAC and GSH. On the basis of the results of the present proteomic analysis, PLB can efficiently regulate the Nrf2-mediated oxidative stress response signaling pathway. Nrf2, also known as Nfe2I2, is a nuclear factor that controls the expression of various detoxifying enzymes, ROS elimination proteins, drug transporters, and antiapoptotic proteins. Normally, Nrf2 is suppressed in the cytoplasm by combination with Keap1 and Cullin3. Once exposed to the ARE-mediated inducers, Nrf2 will translocate to the nucleus where it forms a heterodimer with a small Maf protein and binds to other nuclear factors and initiates the transcription of antioxidative genes. ${ }^{51,52}$ The Western blotting results showed that the ratio of $n-N r f 2$ to c-Nrf2 was significantly decreased. Furthermore, the downstream effectors NQO1, GST, and HSP90 were examined. These effectors are involved in ROS elimination and detoxification. ${ }^{81-83}$ Results showed that PLB can decrease the expression level of NQO1, GST, and HSP90 in SCC25 cells. We can carefully draw a conclusion that PLB can kill TSCC cells via ROS generation and attenuation of ROS elimination factors. Finally, we employed the ROS scavengers NAC and GSH to further examine the effect of PLB in cell cycle arrest, apoptosis induction, EMT inhibition, and stemness attenuation. Interestingly, results showed that the cell cycle arresting, apoptosis inducing, EMT inhibiting, and stemness-attenuating effect of PLB can be efficiently abolished by NAC and GSH. This highlights the ROS-generation-inducing effect of PLB as an upstream effector to regulate other downstream biological activities such as cell cycle arrest and apoptosis.

In summary, the quantitative SILAC-based proteomic approach showed that PLB inhibited cell proliferation, activated death receptor-mediated apoptotic pathway, remodeled epithelial adherens junctions pathway, and increased intracellular level of ROS via Nrf2-mediated oxidative stress response signaling pathway in human SCC25 cells involving a number of key functional proteins. This study may provide a clue to fully identify the molecular targets and elucidate the underlying mechanisms of PLB in the treatment of TSCC.

\section{Acknowledgments}

The authors appreciate the financial support by the National Natural Science Foundation of China (grant number: 81560440) 
and the Key Project of Chinese Medicine Research Plan of Jiangxi province (grant number: 2013Z010).

\section{Disclosure}

The authors report no conflicts of interest in the work.

\section{References}

1. Siegel RL, Miller KD, Jemal A. Cancer statistics, 2015. CA Cancer J Clin. 2015;65(1):5-29.

2. Li R, Koch WM, Fakhry C, Gourin CG. Distinct epidemiologic characteristics of oral tongue cancer patients. Otolaryngol Head Neck Surg. 2013;148(5):792-796.

3. Joseph LJ, Goodman M, Higgins K, et al. Racial disparities in squamous cell carcinoma of the oral tongue among women: a SEER data analysis. Oral Oncol. 2015;51(6):586-592.

4. Markopoulos AK. Current aspects on oral squamous cell carcinoma. Open Dent J. 2012;6:126-130.

5. Dogan E, Cetinayak HO, Sarioglu S, Erdag TK, Ikiz AO. Patterns of cervical lymph node metastases in oral tongue squamous cell carcinoma: implications for elective and therapeutic neck dissection. J Laryngol Otol. 2014;128(3):268-273.

6. Liu F, Kong X, Lv L, Gao J. TGF-beta1 acts through miR-155 to down-regulate TP53INP1 in promoting epithelial-mesenchymal transition and cancer stem cell phenotypes. Cancer Lett. 2015;359(2): 288-298.

7. Donnenberg VS, Donnenberg AD. Stem cell state and the epithelialto-mesenchymal transition: implications for cancer therapy. J Clin Pharmacol. 2015;55(6):603-619.

8. Perdigao-Henriques R, Petrocca F, Altschuler G, et al. miR-200 promotes the mesenchymal to epithelial transition by suppressing multiple members of the Zeb2 and Snail1 transcriptional repressor complexes. Oncogene. Epub 2015.

9. Brabletz T. EMT and MET in metastasis: where are the cancer stem cells? Cancer Cell. 2012;22(6):699-701.

10. Morrison SJ, Kimble J. Asymmetric and symmetric stem-cell divisions in development and cancer. Nature. 2006;441(7097):1068-1074.

11. Martin-Belmonte F, Perez-Moreno M. Epithelial cell polarity, stem cells and cancer. Nat Rev Cancer. 2012;12(1):23-38.

12. Boumahdi S, Driessens G, Lapouge G, et al. SOX2 controls tumour initiation and cancer stem-cell functions in squamous-cell carcinoma. Nature. 2014;511(7508):246-250.

13. Chiou SH, Yu CC, Huang CY, et al. Positive correlations of Oct-4 and Nanog in oral cancer stem-like cells and high-grade oral squamous cell carcinoma. Clin Cancer Res. 2008;14(13):4085-4095.

14. Molofsky AV, Pardal R, Iwashita T, et al. Bmi-1 dependence distinguishes neural stem cell self-renewal from progenitor proliferation. Nature. 2003;425(6961):962-967.

15. Kagias K, Ahier A, Fischer N, Jarriault S. Members of the NODE (Nanog and Oct4-associated deacetylase) complex and SOX-2 promote the initiation of a natural cellular reprogramming event in vivo. Proc Natl Acad Sci U S A. 2012;109(17):6596-6601.

16. Stuckey DW, Shah K. Stem cell-based therapies for cancer treatment: separating hope from hype. Nat Rev Cancer. 2014;14(10): 683-691.

17. Padhye S, Dandawate P, Yusufi M, Ahmad A, Sarkar FH. Perspectives on medicinal properties of plumbagin and its analogs. Med Res Rev. 2012;32(6):1131-1158.

18. Sung B, Oyajobi B, Aggarwal BB. Plumbagin inhibits osteoclastogenesis and reduces human breast cancer-induced osteolytic bone metastasis in mice through suppression of RANKL signaling. Mol Cancer Ther. 2012;11(2):350-359.

19. Sinha S, Pal K, Elkhanany A, et al. Plumbagin inhibits tumorigenesis and angiogenesis of ovarian cancer cells in vivo. Int J Cancer. 2013; 132(5):1201-1212.
20. Pan ST, Qin Y, Zhou ZW, et al. Plumbagin induces G2/M arrest, apoptosis, and autophagy via p38 MAPK- and PI3K/Akt/mTOR-mediated pathways in human tongue squamous cell carcinoma cells. Drug Des Devel Ther. 2015;9:1601-1626.

21. Li YC, He SM, He ZX, et al. Plumbagin induces apoptotic and autophagic cell death through inhibition of the PI3K/Akt/mTOR pathway in human non-small cell lung cancer cells. Cancer Lett. 2014; 344(2):239-259.

22. Sandur SK, Ichikawa H, Sethi G, Ahn KS, Aggarwal BB. Plumbagin (5-hydroxy-2-methyl-1,4-naphthoquinone) suppresses NF-kappaB activation and NF-kappaB-regulated gene products through modulation of p65 and IkappaBalpha kinase activation, leading to potentiation of apoptosis induced by cytokine and chemotherapeutic agents. $J$ Biol Chem. 2006;281(25):17023-17033.

23. Kuo PL, Hsu YL, Cho CY. Plumbagin induces G2-M arrest and autophagy by inhibiting the AKT/mammalian target of rapamycin pathway in breast cancer cells. Mol Cancer Ther. 2006;5(12):3209-3221.

24. Wang F, Wang Q, Zhou ZW, et al. Plumbagin induces cell cycle arrest and autophagy and suppresses epithelial to mesenchymal transition involving PI3K/Akt/mTOR-mediated pathway in human pancreatic cancer cells. Drug Des Devel Ther. 2015;9:537-560.

25. Zhou ZW, Li XX, He ZX, et al. Induction of apoptosis and autophagy via sirtuin 1- and PI3K/Akt/mTOR-mediated pathways by plumbagin in human prostate cancer cells. Drug Des Devel Ther. 2015;9: 1511-1554.

26. Sun J, McKallip RJ. Plumbagin treatment leads to apoptosis in human K562 leukemia cells through increased ROS and elevated TRAIL receptor expression. Leuk Res. 2011;35(10):1402-1408.

27. $\mathrm{Xu} \mathrm{KH,} \mathrm{Lu} \mathrm{DP.} \mathrm{Plumbagin} \mathrm{induces} \mathrm{ROS-mediated} \mathrm{apoptosis} \mathrm{in}$ human promyelocytic leukemia cells in vivo. Leuk Res. 2010;34(5): 658-665.

28. Lee JH, Yeon $\mathrm{JH}, \mathrm{Kim} \mathrm{H}$, et al. The natural anticancer agent plumbagin induces potent cytotoxicity in MCF-7 human breast cancer cells by inhibiting a PI-5 kinase for ROS generation. PLoS One. 2012;7(9): e45023.

29. Edelmann MJ, Shack LA, Naske CD, Walters KB, Nanduri B. SILACbased quantitative proteomic analysis of human lung cell response to copper oxide nanoparticles. PLoS One. 2014;9(12):e114390.

30. Zhou Q, Chaerkady R, Shaw PG, et al. Screening for therapeutic targets of vorinostat by SILAC-based proteomic analysis in human breast cancer cells. Proteomics. 2010;10(5):1029-1039.

31. Ong SE, Mann M. A practical recipe for stable isotope labeling by amino acids in cell culture (SILAC). Nat Protoc. 2006;1(6):2650-2660.

32. Pan ST, Zhou ZW, He ZX, et al. Proteomic response to 5,6-dimethylxanthenone 4-acetic acid (DMXAA, vadimezan) in human non-small cell lung cancer A549 cells determined by the stable-isotope labeling by amino acids in cell culture (SILAC) approach. Drug Des Devel Ther. 2015;9:937-968.

33. Qiu JX, Zhou ZW, He ZX, et al. Plumbagin elicits differential proteomic responses mainly involving cell cycle, apoptosis, autophagy, and epithelial-to-mesenchymal transition pathways in human prostate cancer PC-3 and DU145 cells. Drug Des Devel Ther. 2015;9:349-417.

34. Qin Y, Zhou ZW, Pan ST, et al. Graphene quantum dots induce apoptosis, autophagy, and inflammatory response via p38 mitogenactivated protein kinase and nuclear factor-kappaB mediated signaling pathways in activated THP-1 macrophages. Toxicology. 2015; 327:62-76.

35. Thiery JP, Lim CT. Tumor dissemination: an EMT affair. Cancer Cell. 2013;23(3):272-273.

36. Stebbing J, Filipovic A, Giamas G. Claudin-1 as a promoter of EMT in hepatocellular carcinoma. Oncogene. 2013;32(41):4871-4872.

37. Furuse M, Hirase T, Itoh M, et al. Occludin: a novel integral membrane protein localizing at tight junctions. J Cell Biol. 1993;123(6 Pt 2): 1777-1788.

38. Furuse M, Itoh M, Hirase T, et al. Direct association of occludin with ZO-1 and its possible involvement in the localization of occludin at tight junctions. J Cell Biol. 1994;127(6 Pt 1):1617-1626. 
39. Haskins J, Gu L, Wittchen ES, Hibbard J, Stevenson BR. ZO-3, a novel member of the MAGUK protein family found at the tight junction, interacts with ZO-1 and occludin. J Cell Biol. 1998;141(1):199-208.

40. Umeda K, Ikenouchi J, Katahira-Tayama S, et al. ZO-1 and ZO-2 independently determine where claudins are polymerized in tight-junction strand formation. Cell. 2006;126(4):741-754.

41. Gheldof A, Berx G. Cadherins and epithelial-to-mesenchymal transition. Prog Mol Biol Transl Sci. 2013;116:317-336.

42. Janda E, Nevolo M, Lehmann K, et al. Raf plus TGFbeta-dependent EMT is initiated by endocytosis and lysosomal degradation of E-cadherin. Oncogene. 2006;25(54):7117-7130.

43. Zhang X, Liu G, Kang Y, et al. N-cadherin expression is associated with acquisition of EMT phenotype and with enhanced invasion in erlotinibresistant lung cancer cell lines. PLoS One. 2013;8(3):e57692.

44. Polakis P. More than one way to skin a catenin. Cell. 2001;105(5): 563-566.

45. Eger A, Stockinger A, Park J, et al. Beta-Catenin and TGFbeta signalling cooperate to maintain a mesenchymal phenotype after FosERinduced epithelial to mesenchymal transition. Oncogene. 2004;23(15): 2672-2680.

46. Stemmer V, de Craene B, Berx G, Behrens J. Snail promotes Wnt target gene expression and interacts with beta-catenin. Oncogene. 2008; 27(37):5075-5080.

47. Koo BS, Lee SH, Kim JM, et al. Oct4 is a critical regulator of stemness in head and neck squamous carcinoma cells. Oncogene. 2015;34(18): 2317-2324.

48. Sarkar A, Hochedlinger K. The sox family of transcription factors: versatile regulators of stem and progenitor cell fate. Cell Stem Cell. 2013;12(1):15-30.

49. Hayashi Y, Caboni L, Das D, et al. Structure-based discovery of NANOG variant with enhanced properties to promote self-renewal and reprogramming of pluripotent stem cells. Proc Natl Acad Sci U S A. 2015;112(15):4666-4671.

50. Lessard J, Sauvageau G. Bmi-1 determines the proliferative capacity of normal and leukaemic stem cells. Nature. 2003;423(6937):255-260.

51. DeNicola GM, Karreth FA, Humpton TJ, et al. Oncogene-induced Nrf2 transcription promotes ROS detoxification and tumorigenesis. Nature. 2011;475(7354):106-109.

52. Zhang Y, Gordon GB. A strategy for cancer prevention: stimulation of the Nrf2-ARE signaling pathway. Mol Cancer Ther. 2004;3(7):885-893.

53. Tsurutani J, West KA, Sayyah J, Gills JJ, Dennis PA. Inhibition of the phosphatidylinositol 3-kinase/Akt/mammalian target of rapamycin pathway but not the MEK/ERK pathway attenuates laminin-mediated small cell lung cancer cellular survival and resistance to imatinib mesylate or chemotherapy. Cancer Res. 2005;65(18):8423-8432.

54. Zhao G, Cai C, Yang T, et al. MicroRNA-221 induces cell survival and cisplatin resistance through PI3K/Akt pathway in human osteosarcoma. PLoS One. 2013;8(1):e53906.

55. Aziz MH, Dreckschmidt NE, Verma AK. Plumbagin, a medicinal plantderived naphthoquinone, is a novel inhibitor of the growth and invasion of hormone-refractory prostate cancer. Cancer Res. 2008;68(21): 9024-9032.

56. Wang CC, Chiang YM, Sung SC, et al. Plumbagin induces cell cycle arrest and apoptosis through reactive oxygen species/c-Jun N-terminal kinase pathways in human melanoma A375.S2 cells. Cancer Lett. 2008; 259(1):82-98

57. Yeh CC, Hsu CH, Shao YY, et al. Integrated SILAC and iTRAQ quantitative proteomic analysis identifies galectin-1 as a potential biomarker for predicting sorafenib resistance in liver cancer. Mol Cell Proteomics. 2015;14(6):1527-1545.

58. Dolai S, Xu Q, Liu F, Molloy MP. Quantitative chemical proteomics in small-scale culture of phorbol ester stimulated basal breast cancer cells. Proteomics. 2011;11(13):2683-2692.

59. Geiger T, Cox J, Ostasiewicz P, Wisniewski JR, Mann M. Super-SILAC mix for quantitative proteomics of human tumor tissue. Nat Methods. 2010;7(5):383-385.
60. Everley PA, Krijgsveld J, Zetter BR, Gygi SP. Quantitative cancer proteomics: stable isotope labeling with amino acids in cell culture (SILAC) as a tool for prostate cancer research. Mol Cell Proteomics. 2004;3(7):729-735.

61. Hunter T. Protein kinases and phosphatases: the yin and yang of protein phosphorylation and signaling. Cell. 1995;80(2):225-236.

62. Evan GI, Vousden KH. Proliferation, cell cycle and apoptosis in cancer. Nature. 2001;411(6835):342-348.

63. Reed JC. Apoptosis-based therapies. Nat Rev Drug Discov. 2002;1(2): 111-121.

64. Boehning D, Patterson RL, Sedaghat L, et al. Cytochrome $\mathrm{c}$ binds to inositol $(1,4,5)$ trisphosphate receptors, amplifying calcium-dependent apoptosis. Nat Cell Biol. 2003;5(12):1051-1061.

65. Yang J, Liu X, Bhalla K, et al. Prevention of apoptosis by Bcl-2: release of cytochrome c from mitochondria blocked. Science. 1997; 275(5303):1129-1132.

66. Pobezinskaya YL, Liu Z. The role of TRADD in death receptor signaling. Cell Cycle. 2012;11(5):871-876.

67. Park YC, Ye H, Hsia C, et al. A novel mechanism of TRAF signaling revealed by structural and functional analyses of the TRADD-TRAF2 interaction. Cell. 2000;101(7):777-787.

68. Zlotorynski E. Apoptosis. DR5 unfolds ER stress. Nat Rev Mol Cell Biol. 2014;15(8):498-499.

69. Biddle A, Mackenzie IC. Cancer stem cells and EMT in carcinoma. Cancer Metastasis Rev. 2012;31(1-2):285-293.

70. Okada T, Sinha S, Esposito I, et al. The Rho GTPase Rnd1 suppresses mammary tumorigenesis and EMT by restraining Ras-MAPK signalling. Nat Cell Biol. 2015;17(1):81-94.

71. Kudo-Saito C, Shirako H, Takeuchi T, Kawakami Y. Cancer metastasis is accelerated through immunosuppression during Snail-induced EMT of cancer cells. Cancer Cell. 2009;15(3):195-206.

72. Ansieau S, Bastid J, Doreau A, et al. Induction of EMT by twist proteins as a collateral effect of tumor-promoting inactivation of premature senescence. Cancer Cell. 2008;14(1):79-89.

73. Waerner T, Alacakaptan M, Tamir I, et al. ILEI: a cytokine essential for EMT, tumor formation, and late events in metastasis in epithelial cells. Cancer Cell. 2006;10(3):227-239.

74. Qureshi R, Arora H, Rizvi MA. EMT in cervical cancer: its role in tumour progression and response to therapy. Cancer Lett. 2015;356 (2 Pt B):321-331.

75. De Craene B, Berx G. Regulatory networks defining EMT during cancer initiation and progression. Nat Rev Cancer. 2013;13(2):97-110.

76. Rhim AD, Mirek ET, Aiello NM, et al. EMT and dissemination precede pancreatic tumor formation. Cell. 2012;148(1-2):349-361.

77. Clevers $H$. The cancer stem cell: premises, promises and challenges. Nat Med. 2011;17(3):313-319.

78. Mani SA, Guo W, Liao MJ, et al. The epithelial-mesenchymal transition generates cells with properties of stem cells. Cell. 2008;133(4): 704-715.

79. Ocana OH, Corcoles R, Fabra A, et al. Metastatic colonization requires the repression of the epithelial-mesenchymal transition inducer Prrx1. Cancer Cell. 2012;22(6):709-724.

80. Schieber MS, Chandel NS. ROS links glucose metabolism to breast cancer stem cell and EMT phenotype. Cancer Cell. 2013;23(3):265-267.

81. Matsui A, Ikeda T, Enomoto K, et al. Increased formation of oxidative DNA damage, 8-hydroxy-2'-deoxyguanosine, in human breast cancer tissue and its relationship to GSTP1 and COMT genotypes. Cancer Lett. 2000;151(1):87-95.

82. Beck R, Dejeans N, Glorieux C, et al. Hsp90 is cleaved by reactive oxygen species at a highly conserved N-terminal amino acid motif. PLoS One. 2012;7(7):e40795.

83. Li L, Dong H, Song E, et al. Nrf2/ARE pathway activation, HO-1 and NQO1 induction by polychlorinated biphenyl quinone is associated with reactive oxygen species and PI3K/AKT signaling. Chem Biol Interact. 2014;209:56-67. 


\section{Publish your work in this journal}

Drug Design, Development and Therapy is an international, peerreviewed open-access journal that spans the spectrum of drug design and development through to clinical applications. Clinical outcomes, patient safety, and programs for the development and effective, safe, and sustained use of medicines are a feature of the journal, which has also been accepted for indexing on PubMed Central. The manuscript management system is completely online and includes a very quick and fair peer-review system, which is all easy to use. Visit http://www.dovepress.com/testimonials.php to read real quotes from published authors.

Submit your manuscript here: http://www.dovepress.com/drug-design-development-and-therapy-journal 